

Digitized by the Internet Archive in 2011 with funding from

LYRASIS members and Sloan Foundation 




\title{
THE CONNECTICUT
}

\section{AGRICULTURAL EXPERIMENT STATION}

\author{
NEW HAVEN, CONN.
}

BULLETIN 167, APRIL, 1911.

\section{INHERITANCE IN MAIZE.}

By E. M. East and H. K. Hayes.

The Bulletins of this Station are mailed free to citizens of Connecticut who apply for them, and to others as far as the limited edition permit. 


\title{
Connecticut Agricultural Experiment Station.
}

\author{
OFFICERS AND STAFF
}

BOARD OF CONTROL.

His Excellency, Smeon E. Baldwin, Ex Officio, President.

Prof. H. W. Conn, Vice President . . . . . . . Middletown. George A. Hopson, Secretary. . . . . . . . . . Wallingford. E. H. Jenkins, Director and Treasurer. . . . . . . New Haven. J. W. Alsop ... . . . . . . . . . Avon. Charles M. Jarvis . . . . . . . . . . . . Berlin. Frank H. Stadtmueller . . . . . . . . Elmwood.

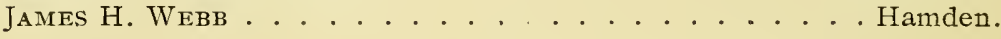

Administration

Chemistry.

Analytical Laboratory, John Philips Street, M. S., Chemist in Charge.

Proteid ReseARCH,

BOTANY.

Entomology.

Forestry.

Plant Breeding.

BuILDINGS AND GRounds. E. Monroe Bailey, Ph. D., C. B. Morrison, B. S., R. B. Roe, A. B., C. E. Shepard, Assistants. Hugo Lange, Laboratory Helper.

V. L. Churchill, Sampling Agent.

STATION STAFF.

E. H. Jenkins, $\mathrm{PH} . \mathrm{D}$, Director and Treasurer. Miss V. E. Cole, Librarian and Stenographer. Miss L. M. Brautlecht, Bookkeeper and Stenographer.

T. B. Osborne, PH. D., Chemist in Charge. Miss E. L. Ferry, A. B., Assistant. Miss Luva Francis, Stenographer.

G. P. Clinton, S. D., Botanist.

E. M. Stoddard, B. Agr., Assistant. Miss M. H. JAgger, Seed Analyst.

Miss E. B. Whittlesey, Herbarnu Assistant.

W. E. Britton, PH. D., Entomologist; also State Entomologist

B. H. Walden, B. Agr., D. J. Caffrey, B. Agr., A. B. Champlain, Assistants.

Miss E. B. Whittleser, Stenographer.

Samuel N. Spring, M. F., Forester; also State Forester and State Forest Fire Warden W. O. Filley, Assistant.

Miss E. L. Avery, Stenographer.

H. K. Hayes, B. S., Plant Breeder.

C. D. Hubbell, Assistant.

William Veitch, In Charge. 


\section{TABLE OF CONTENTS.}

Page.

Introduction,

Part I. - The Material and the Problem.

The Plant and its Origin, . . . . . 10

The Varieties of Maize, . . . . . . . . 14

The Problem and its Treatment, . . . . 18

Previous Work on Inheritance in Maize, . . . . 21

The Material used, . . . . . . 25

Methods used, . . . . . . . 28

Experimental Error, . . . . . . . 31

PART II. - ENDOSPERII CHARACTERS.

Inheritance of Starchiness, . . . . $\quad 32$

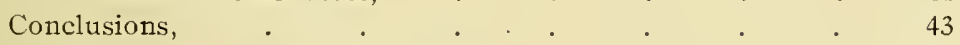

Inheritance of Yellow Endosperm, . . . . . . 46

Conclusions, . . . . . . . . . . 56

Inheritance of Aleurone Color, . $\quad$. $\quad$. $\quad$. 57

Family $(24 \times 54)$, . $\quad . \quad$. $\quad . \quad$. 59

Family $(8 \times 54)$, . . . . . $\quad .67$

Family $(15 \times 54)$, . $\quad . \quad$. $\quad . \quad$. 74

Family $(18 \times 54)$, $\quad . \quad$. $\quad . \quad$. $\quad . \quad$. $\quad . \quad 76$

Family $(7 \times 54)$, $\quad$. $\quad$. $\quad . \quad$. $\quad 80$

Family $(17 \times 54)$, . $\quad . \quad$. $\quad . \quad$. $\quad 80$

Family $(19 \times 54)$, $\quad . \quad$ : $\quad . \quad$. $\quad . \quad$. $\quad$. 81

Family $(60 \times 54)$, . $\quad . \quad$. $\quad . \quad . \quad . \quad 61$

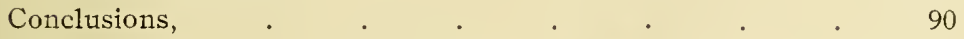

PAR'T III, - XENIA.

General Discussion of Zenia, . . . . . . 101 
PART IV.-Plant Characters.

Page.

Podded and Podless Maize, . . . . . 105

Pericarp Color, . $\quad$. $\quad . \quad$. $\quad . \quad$. 105

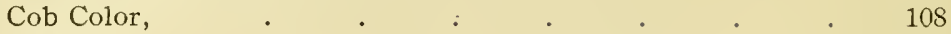

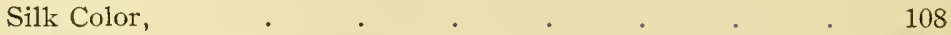

Glume Color, . $\quad$. $\quad$. $\quad$. 109

General Discussion of Red Sap Color, . . . . 109

Physical Transformations of Starchiness, . . . 110

Size Characters, . . . . . . . . 117

Number of Rows of Seeds, . . . . . 120

Heights of Plants, . . . . . . 123

Length of Ears, . . . . . . . 124

Weight of Seeds, . . . . . . 124

PART V.-Plant Abnormalities.

Dwarf Forms, . . . . . . . 129

Regularity of Rows of Seeds, . . . . . 131

Bifurcated Ears, . . . . . . . . ${ }_{.132}$

Ears with Lateral Branches, . . . . . 133

Plants with Striped Leaves, . . . . . 134

Hermaphrodite Flowers, . . . . . 134

General Conclusions, _ . . . . . $\quad$. 136

Literature Cited, . . . . . $\quad 138$ 


\title{
INHERITANCE IN MAIZE.
}

BY

\author{
E. M. East and H. K. Hayes.
}

\section{INTRODUCTION.}

The investigations reported in this paper were begun in the spring of the year 1906. During the first four years the work was conducted at the Connecticut Agricultural Experiment Station. Since the fall of 1909, it has been carried on both there and at the Bussey Institution of Harvard University. Strictly speaking the researches comprise more than five years' work, for several of the pure varieties used as parent stocks had been selfed for the two previous years, so that a number of crosses were made in 1905 with full assurance that as far as most of the visible characters were concerned, the parent strains were pure. There was some further advantage gained in that the writers have been interested in experimental maize breeding since 1900, for without this experience the probable error of the results would be greatly increased.

Genetic research during the past decade has been very fruitful of results; nevertheless one could scarcely say that the field has been thoroughly surveyed, much less that any part of it has been completely investigated. The rediscovery of Mendel's law in 1900 opened up a new era in the search for the principles

* "Contribution from the Laboratory of Genetics, Bussey Institution of Harvard University, No. 9." 
of heredity. Mendel's chief discovery - segregation of potential characters in the germ-cells of hybrids and their fortuitous recombination - was one of the really great achievements in biology, but even so, it may be questioned whether his chief legacy is not his method of work. As has already been stated by Bateson, previous investigators even including the biometricians dealt with facts en masse, and the seeming order of the mathematical formulas deduced served rather to conceal than to reveal the individual facts. Mendel's method of individual analysis by the study of simple characters in carefully controlled pedigree cultures, however, has yielded and will continue to yield results of great value to science. Still, since we are dealing, as yet, with the simplest elements of the science of genetics, the subject matter of an investigation may be expected to yield results (other things being equal) somewhat in the proportion in which it fulfills the following technical requirements.

1. The genus or species under investigation should be variable. There should be a goodly list of types which are differentiated by definite characters easy of determination. That is, the differences should be largely qualitative and not quantitative.

2. The different types should be freely fertile inter se, unless an investigation of the causes of sterility is contemplated.

3. The flower structure should be such that the technique of crossing and selfing is simple and accurate.

4. Since the accuracy of an analysis of the manner in which characters are inherited increases - generally speaking - as the square root of the number involved, the subjects should return a large number of seed per operation (selfing or crossing).

5. The flowering branches should be numerous. This is necessary for three reasons. If one is dealing with flower characters he must be able to determine the character of the plant from a mature flower while immature blossoms still remain for the production of the controlled seed. Obviously, it is also an advantage when dealing with plant characters, 
to have more than one opportunity to secure a desired union. Further, it is advantageous to be able to make several different crosses upon one plant.

6. Seed should be viable for several years in order that different generations may be compared at the same time. This enables one to reduce to a minimum the physiological fluctuation due to varying environment which many characters undergo in a marked degree.

7. The subject material should be "workable" cytologically in order that it may be attacked from both standpoints.

It might be remarked here that some botanists consider that genetic research can throw no new light upon evolution and upon the meaning of species, unless the subject material is an uncultivated genus or species. This criticism is apparently no more pertinent than the one the chemists had to meet years ago when they were told that synthetic compounds could not possibly be the same as those produced by nature. The fact of physiological fluctuation due to varying environment is admitted, but it is not admitted that the mechanism of hereditary transmission of the character in question is affected by these fluctuations.

Some idea as to the effectiveness of an inquiry concerning inheritance in maize from the standpoint of science may be gained then by examining the degree in which the plant fulfils the above requirements.

Although the forms of maize are regarded by botanists as belonging to the one species Zea mays L., there is probably no species of the flowering plants - if horticultural color varieties are excepted - that appears under such varied forms. These forms are perfectly fertile inter se, moreover, so that the first and second of our requirements are fulfilled perfectly. The third requirement, that of an easy technique and accurate control of desired matings, is met very imperfectly. The plant is monœcious. Ordinarily, this type of flowering habit is desirable in pedigree culture work because accidental selfing is usually much more easy to prevent than it is in hermaphroditic plants. In the case of maize, however, there is such an enor- 
mous production of pollen that it is continually present in the air of the maize field. In spite of all precautions, therefore, seeds of unknown paternal ancestry do creep into the cultures. The general error due to this source has been determined in cases which are described later, but the determination of a probable error in a mass of data is not sufficient in genetic work. An actual error in which a single seed of unknown paternity becomes the ancestor of a pedigreed line, is sufficient to upset all inductions drawn from the data. For this reason the cultures have had to be larger than would otherwise have been necessary.

The requirement of a large number of seeds from one union to reduce the probable error of chance fertilization among gametes differing in character is quite satisfactory in maize as from two hundred and fifty to twelve hundred seeds are produced on the cobs of the various races. The small number of flowering branches, however, is a serious objection. In some cases there are two or even three and four ears upon each plant; but in most cases, especially in the large races, there is but one ear. And even where there is an extra ear one gains but little advantage. The ears mature about the same time and it is impossible to find out what seed characters the plant possesses before pollinating the ear which is to have its place in the controlled culture. The disadvantage of this fact to the investigator is apparent if one remembers that when studying ear abnormalities sometimes twenty to twenty-five cobs must be selfed by hand to be reasonably certain that one selfed ear with the desired characters is obtained.

Maize seed is rather delicate and must be carefully dried in a place where there is a good circulation of air. When dried until the moisture content is only about ten per cent, it remains in fairly good condition for three seasons. Seed older than this is almost worthless. In fact, there is a possibility of obtaining distorted results even in the second year. Ninetyeight to one hundred per cent of properly dried seed should germinate the next spring after harvesting, but this percentage falls to about ninety the year following. If, therefore, seeds of any particular gametic structure should lose their vitality first, incorrect results would be obtained.

The chromosomes of maize are small and difficult to study 
and scarcely anything is known of their behavior during the maturation divisions.

This discussion should give some idea of the advantages and disadvantages that maize presents as subject material for a genetic investigation from the standpoint of pure science. The plant, however, even if not as perfect as some others from this point of view, has a nother claim which ought not to be disregarded. The fact that maize is the basis of the agricultural wealth of the country makes it eminently desirable that every fact about the inheritance of its characters, should be learned as soon as possible. It is only through the application of such knowledge that the present arbitrary, and, in a way, unscientific methods of its improvement as an economic crop will be placed upon a definite and orderly basis. 


\section{PART I. \\ THE MATERIAL AND THE PROBLEM. \\ The Plant and its Origin.}

Although there is no absolute information as to the origin of maize, most botanists agree that its original home is Mexico (Harshberger '93) or the region to the south of there. As to how it originated there has been much speculation, and various views are held by different writers. We think it not out of place to give here a synopsis of the most important theories, because in our opinion, the results from the pedigree culture work on the inheritance of plant characters described in Parts IV and $\mathrm{V}$ throw considerable light on the subject.

The Tribe Maydeæ of the order Gramineæ comprises but seven genera and only sixteen or seventeen species. The two genera which interest the maize student are Zea and Euchlæna both of which are monotypic. The especial distinctions between the two are given by Lamson-Scribner $(: 00)$ in his key to the genera of Maydeæ as follows:

"Euchlæna, pistillate spikes axillary fasciculate, distinct, axis of each articulate."

"Zea, pistillate spikes axillary, grown together, forming a compound spike with a much thickened, continuous axis."

His complete descriptions are:

"Euchlana Schrad. Ind. Sem. Hort. Gœett. 1832. Spikelets unisexual, monœeious; the staminate 2-flowered, in pairs, one sessile the other pedicellate, arranged in terminal paniculate racemes; the pistillate 1-flowered, sessile and solitary at each joint of an obliquely articulate rhacis of a simple spike; the spikes fasciculate in the leaf axils and each more or less enveloped by a foliaceous bract. Glumes in the staminate spikelets 4 , acute, the first two membranaceous, empty; flowering glumes smaller and like their paleas, hyaline. Stamens 3. Glumes of the pistillate spikelets 4 , the outer one broad and boat-shaped, smooth, soon becoming hard, surrounding the inner glumes and 
narrow rhacis, second glume empty coriaceous, third glume hyaline with a palea but no flower; fourth or flowering glume with its palea hyaline. Styles very long, filiform, shortly bifid at the apex.

Tall annuals with long and broad leaves, closely resembling Indian corn in habit. Species one with several varieties in Mexico and Central America."

"Zea Linn. Sp. P1. 971. 1753. Spikelets unisexual, monoecious; the staminate 2 -flowered in pairs, one sessile the other pedicellate, along the numerous branches of a terminal panicle; the pistillate 1-flowered, sessile, crowded in several rows, along a much thickened continuous axis arising from the lower leafaxils and closely enveloped by numerous large foliaceous bracts. Glumes four, awnless; those of the staminate spikelet acute; those of the pistillate very broad and obtuse or emarginate. Grain hard, only partially inclosed by the fruiting glumes. A well-known tall and striking annual grass with erect stems and broad leaves. The terminal staminate inflorescence forms the "spindle" [tassel], and the long projecting styles of the pistillate flowers constitute the "silk." The cob is formed by the union of the axes of several female spikes into a much thickened body. Species one or two, of American origin, presenting many varieties in cultivation known as corn, Indian corn or maize."

From these descriptions of the two monotypic genera, it is seen that Euchlana mexicana Schrad., the common teosinte, is not greatly different from Zea mays L., our ordinary maize. Indeed to one who has grown and followed the extraordinary variability of both, it does not seem a greater step from teosinte to the maize most similar to it - the short many branched pop or flint types - than it does from the small dwarf pop maize to the giant dent forms. Teosinte is perfectly fertile with maize, which fact has led to some confusion, for Watson ('91) thinking that hybrids between the two constituted a pure wild species, named it Zea canina Watson. Segura (Harshberger, '96), however, by remaking the crosses and growing them near the region where the "Zea canina" was found, clearly proved the true nature of the latter. Harshberger ('93) first fell into the same error as Watson but later (Harshberger '96) 
discovering the true state of affairs suggested that maize originated either from (1) a cross between teosinte and some extinct but closely related plant, which by variation under a better environment finally produced a plant with larger maize-like ears; or that it came from (2) a cross between teosinte and a race of the latter that had varied under long continued cultivation. The basis of Harshberger's argument that teo inte must have been crossed by another form is his idea that only in the progeny from a cross would sufficient variability have appeared to have produced the more vigorous plant - the aboriginal maize.

More recently Montgomery [ :06] has advanced the theory that teosinte and maize are both descended from an unknown many-branched grass whose branches terminated in a panicle of spikelets bearing hermaphrodite flowers. He says: "As evolution progressed, the central tassel came to produce only staminate flowers, these being higher and in a better position to fertilize the flowers on the lower branches. At the same time, the lateral branches came to produce only pistillate flowers, their position not being favorable as pollen producers, while, on the contrary, they were favorably placed to receive pollen. This differentiation in the flowers was accompanied by a shortening of the internodes of the lateral branches until they were entirely enclosed in the leaf sheaths [the husks]." The especial difference between the evolution of teosinte and of maize was thought to have been in the development of the ear of the first from the lateral branches of the tassel-like panicle and the ear of the second from its central spike. This argument of Montgomery is directly opposed to the old theory that the cob of modern maize is the result of a fusion of a number of two-rowed pistillate spikelets such as are found upon teosinte. His theory then, emphasizes the nature of the changes that took place; Harshberger's theory, the way they were transmitted.

In addition to these views it seems only necessary to mention that since maize is the only grass with a naked seed, the podded variety $Z$. mays tunicata Sturt. is by many considered to be an earlier stage in maize development.

Our own views on the subject have resulted from a consideration of the behavior of the characters of the various races of 
PLATE I.

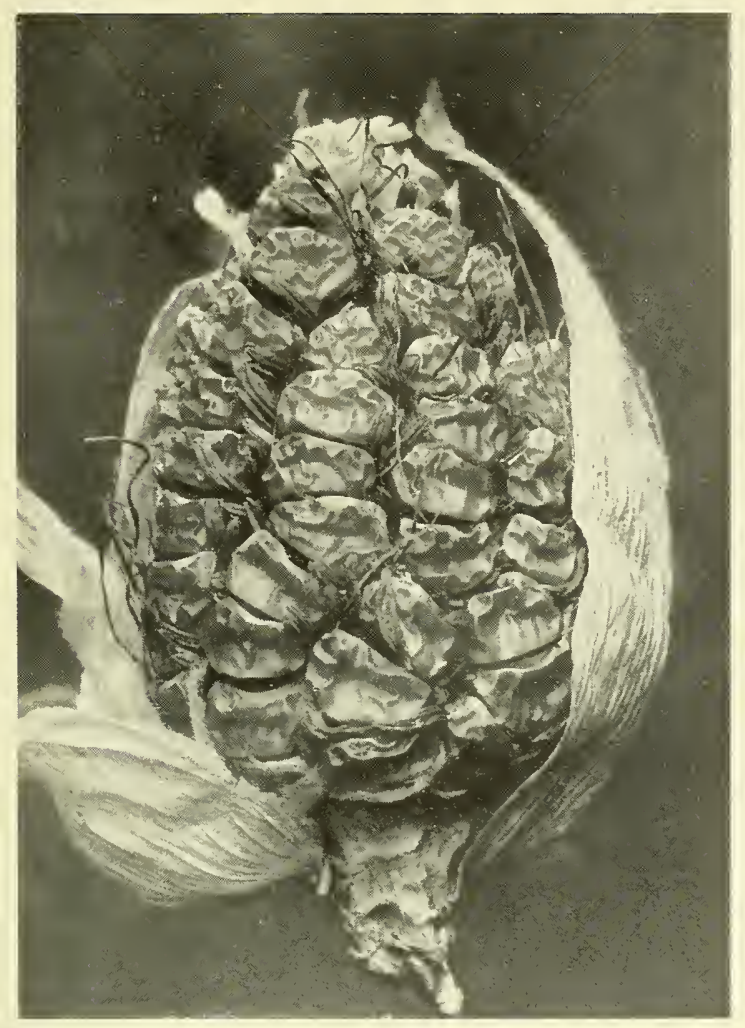

a Ear with hermaphrodite flowers from the dwarf plant which appeared in Stowell's Evergreen sugar maize.

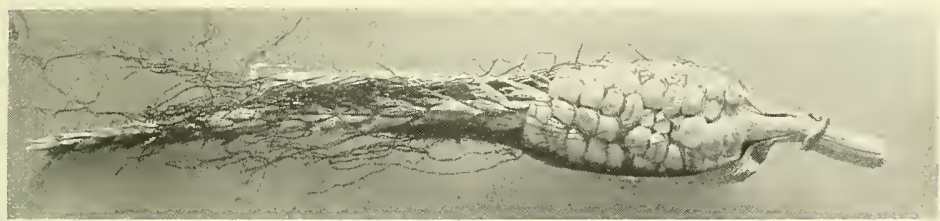

b. Mature seeds on male spike of plant heterozygous for starchiness, showing segregation. A common physiological fluctuation. 

maize when crossed, the data on which they are based being given later. The matter is largely speculation and should be considered as such. It is merely the simplest manner of interpreting the known facts, by connecting maize with the other Maydeæ by a short series of changes that involve characters that mendelize. On the whole it does not differ greatly from Montgomery's theory.

Since we now believe that the essential rôle of hybridization is to recombine the characters possessed by the parent plants in definite ratios without actually producing anything new, [new combinations may produce characters formerly unknown], there is no necessity of postulating hybridization of teosinte with a more maize-like variety. It is known that when teosinte is cultivated in rich soil it sometimes produces ears having an irregular development of four rows. This is only an expression of one of the commonest modes of variation, repetition of parts or meristic variation. This variation in the ear has taken place again and again in maize and is inherited although sometimes obscured by physiological fluctuation. The ear of maize then is a meristic variation produced from the central spike of the tassel of the lateral branches of teosinte or of a teosinte-like plant, and not a fusion of the lateral spikelets. Lateral spikelets still appear in maize, apparently as if variation ran in grooves or paths of least resistance. This character has been found to segregate in a manner essentially Mendelian. The podded character also mendelizes and is allelomorphic to its absence. If then progressive meristic variations occurred in the central spikes of the side branches of the teosinte-like ancestor, followed by retrogressive variations affecting both the lateral spikes of the lateral branches and the pod character, a plant would have originated bearing naked hermophroditic ears. Further change might easily have come about, as Montgomery suggests, by a shortening of the side branches producing the modern husk, and finally the origination of the monœcious character. The latter occurrence is not at all hard to picture for the change of the staminate inflorescence to an hermaphroditic or even a pistillate one, is something which is exceedingly common in all or almost all strains of maize. It is a physiological fluctuation produced by excessive rainfall and fertile soil. The appearance of stamens 
on the modern maize ear is much more rare but that it does occur is shown by the ear pictured in Plate I. In fact one of our sterile dwarf mutations had nothing but hermaphroditic flowers.

\section{The Varieties of Maize.}

Although all of the varied forms of maize are regarded by modern taxonomists as sub-divisions of the species Zea mays L., many varieties have at various times been given specific rank. The Index Kewensis gives the six following types as species. The original sources have been consulted but the descriptions have been shortened to include only essential facts.

Z. Curagua, Molina, J. I. Saggio sulla storia naturale del Chili. pp. 306, Bologna, 1810. = Z. mays.

This variety is distinguished by its serrate leaf-edge. It has never been cultivated in the United States, but appears to be a flint type, Z. mays indurata. Syn. Z. Caragua, Stend. Nom. ed II, ii. 797.

Z. erythrolepsis, Bonafous, M. Histoire naturelle, agricole et économique du Maïs. Folio, pp. 181, Plates 19, Paris, 1836, $=$ Z. mays.

"Glumis rubris, seminibus compressis." "Le Maïs à rafle rouge cultivé sur les rives du Missouri, se distinque par l'aplatissement de ses grains, et surtout par le coleur rouge des écailles et corallines de l'epi femelle. La constance de ce caractère tend à lui mériter le titre d'espèce."

This form could hardly be considered a variety as it is a common variation in all of the commonly recognized varieties.

$Z$. hirta, Bonafous, M. Note sur une nouvelle espèce de Maïs. Ann, Sci. Nat. Ser. I v.17; 156-158. 1829. = Z. mays. "Foliis hirtis et dependentibus; spiculis masculis sessilibus, diandris triandrisve; antheris subaureis."

A good variety, originally sent to Bonafous from Balbis of the Jardin des Plantes de Lyon. It varies into a series of flint, pop and dent types.

Z. japonica, Van Houtte, Fl. des Serres, XVI (1865-67), 121. t. 1673-74. 1867.=Z. mays. Syn. Z. vittata, Hort. and $Z$. variegata, Hort.

A small variety with leaves variously striped with white. A small flint type is the one chiefly cultivated for ornament, 
but the variety occurs again and again in fields of all of our common maize strains. It could undoubtedly be isolated pure by careful selection of these individuals.

Zea macrosperma Klotzsch. Bot. Zeitung 9; 718. 1851. In der Sitzung des Ges. naturf. Freunde zu Berlin.=Z. mays. Seed received by Humboldt from Cuzco. It is simply a large seeded dented starchy type.

Zea rostrata, Bonafous, M. Ann. Soc. Agr. Lyon. v. (1842), 197.=Z. mays. Simply a hook-seeded form of pop maize, somewhat similar to our common rice pop.

Of these types $Z$. mays Curagua Molina and $Z$. mays hirta Bonafous might be considered as good varieties. The four remaining names and also the varieties of $Z$. mays listed in the Index Kewensis might well be placed under the classification porposed by Sturtevant ('99), leaving out his Zea mays amyleasaccharata because the latter is a type which is probably identical with the "flinty" sweet corns with which canners have so much trouble. The three ears from the San Padro Indian collection sent to Sturtevant by Palmer, and upon which he based the variety, failed to yield a mature crop in Geneva, New York. It is therefore unknown whether this type would really prove true. Sturtevant's classification follows although I have added the word mays and have listed them as varieties instead of species. It is not strictly correct to give him as the authority for the names, as he used them specifically, but since they have come into general use in the United States it seems more convenient to keep them. Sturtevant himself based his claim for separate species principally upon the fact that intermediates were either absent or rare. This fact comes about, as will be shown later, from the alternative manner in which the distinguishing characters are inherited. In reality many other characters are inherited in the same manner, and it is only because the chief characters of these five varieties are striking to the eye that it is advantageous to keep them in use.

Zea mays tunicata, the pod corns. Sturtevant, Bul. Torr. Bot. Club 1894, p. 355 (Also St. Hil., Ann. Sci. Nat. 16; p. 143 , fide De Candolle). A form in which each kernel is enclosed in husks (usually four) besides the foliaceous bracts that enclose the ear. 
This form was first described by C. Bauhin in 1623, and has been the basis of a long list of synonyms since that time. It is probable that the prototype of the species possessed this character for it would thus be linked closer to the other Maydex. The strains now obtainable under this name have been hybridized until ears can be found whose kernels run the whole gamut of the other four kinds. The tendency of plants to form anew characters once possessed that have been lost, is well illustrated here. We have come across several ears of our ordinary varieties in which a few of the kernels at the base have been podded. Sturtevant gives two authentic cases where fully podded ears have appeared in other varieties under such conditions that it is very improbable that it was the result of hybridization.

Zea mays everta, the pop corns. Sturtevant, Bul. Torr. Bot. Club, 1894, p. 324 .

"This [species] group is characterized by the excessive proportion of the corneous [starch in the] endosperm and the small size of the kernels and ear. The best varieties have a corneous endosperm throughout. This gives the property of popping, which is the complete eversion or turning inside out of the kernel through the explosion of the contained moisture on the application of heat."

Strains of the pop maizes are the smallest of our cultivated corns, and although there are varieties that reach a height of nine feet when cultivated on fertile soil, plants comparable in size to the average dent or starchy maize are never found. There appears to be a distinct correlation between size of seed and size of plant; therefore, since one never obtains large size seeds without a development of soft starchy matter, pop kernels much larger than those now grown are not likely to be produced through selection or hybridization.

Two forms of seed are known in the pop corns; one is simply a small seed with rounded crown similar in shape to the small flints; the other, characteristic only of pop corns, is peaked at the point where the style or "silk" was attached.

Other variations such as purple colored aleurone cells, yellow endosperm, red silks, and red and variegated pericarps characterize the pop maizes in common with the flint, sweet, dent and starchy corns. The modal number of rows also varies 
in different varieties from eight to sixteen. In this, pop maize is similar to dent, sweet and starchy, but different from flint maize. It is doubtful whether any true flint maize exists with a mode for number of rows higher than twelve.

Zea mays indurata, the flint corns. Sturtevant, Bul. Torr. Bot. Club, 1894, p. 327.

This group is characterized by the seeds having a corneous starchy endosperm, surrounding a soft starchy center immediately behind or partially surrounding the embryo. The strains in common cultivation are considerably larger than the pop corns, but varieties do exist which form a definite series from pop to dent differing only by the amount and extent to which soft starch replaces corneous starch in the endosperm. The same color varieties that were described for pop corns occur.

Zea' mays indentata, the dent corns. Sturtevant, Bul. Torr. Bot. Club, 1894, p. 329.

A group characterized by the extension of the soft starch until it completely covers the summit of the seed. Corneous starch, however remains at the sides of the kernel and acts as a frame work to support the drying seed. The soft starchy portion shrinking in drying to a much greater extent than the other forms a characteristic indentation. Dent varieties occur averaging from five feet to twenty feet (reported) in height, with from eight to twenty-four rows as the modes (extremes to thirty-six rows). The usual color varieties occur.

Zea mays amylacea, the soft or flour corns. Sturtevant, Bul. Torr. Bot. Club, 1894, p. 331.

A group characterized by entire absence of corneous starch in the endosperm. Uniform shrinkage in drying usually gives a seed with no indentation. The mummy corns of Peru, Mexico and the southern United States appear to belong to this group, but this is not absolutely certain. The specimens that we have examined belonging to the New York Botanical Garden might have been flint corns which owe their floury appearance to partial decomposition.

This group marks the final disappearance of corneous starch in the endosperm. It is the end of a series beginning with the pop corns and coming up through the flints and dents. For this reason one might expect them to possess the largest seeds, as the length of time necessary for maturing the seed undoubtedly 
has something to do with the amount of soft starch formed. The plants are indeed large, but seeds occur varying from the size of the smaller flints to that of the larger dents. The origin of the starchy corns is not due simply to their correlation with the general plant structure and therefore a simultaneous origin with large varieties, but is dependent upon a separate character or group of characters. The usual color varieties occur.

Zea mays saccharata, the sweet corns. Sturtevant, Bu1. Torr. Bot. Club, 1894, p. 333.

"A well defined group characterized by the translucent horny appearance of the kernels and their more or less crinkled, wrinkled or shriveled condition." The sweet corns are simply pop, flint and dent varieties (East : 09) that have lost their ability to mature starch normally. Some few starch grains are produced but they are generally small, angular and abortive. The reserve material of the endosperm seems to undergo a decomposition to cane sugar and the various hexoses. There is apparently something more than a simple non-development of starch, for the sweet corns in the "milk" state contain greater percentages of sugar than do the starchy varieties in a similar stage of ripeness. The same color varieties occur.

\section{The Problem and its Treatment.}

It is apparent that maize furnishes an admirable series of types which are perfectly fertile among themselves. The primary object of our work is to obtain pure forms of these diverse types by inbreeding, then to test the mechanism of inheritance of each separate character by controlled matings and an analysis of the resulting progeny. In doing this we simply follow Mendel's method of the individual analysis of pedigree cultures.

The specific questions attacked are numerous. Our principal object is to find whether the different characters under observation all obey the same law of heredity or whether separate principles are involved, and whether characters apparently inherited independently are not sometimes correlated with each other. The question of dominance of a character in the first generation of a cross has also interested us. Some characters are perfectly dominant, other characters imperfectly dominant, while still others form heterozygous combinations differing from 
either of the parents. There are even cases in which dominance appears to be reversible. If such a thing is possible, an explanation is desirable. The study of the phenomenon of Xenia, which has already formed the basal object of Correns' (:01) fine monograph, throws some light on these questions.

Another object we have kept in mind is the problem of the purity of extracted homozygotes. It is a matter of common knowledge that characters that have been lost through retrogressive variations - characters that behave as mono-hybrids in inheritance - often reappear. The reverse of this phenomenon is also true. Is it because there is a phylogenetic "path" in which these changes run, so that the same variation appears again and again, or is there no absolute purity of the germ-cells but only a comparative purity as indicated by Morgan ( $: 10)$ ?

The idea of prepotency has been held with great tenacity up to the present time. We hope these researches will throw some light upon this subject of so much importance to practical breeders. If there are individuals whose constitution is such that chance production of zygotes is interfered with, the fact brings many complications into the study of inheritance; but such complications must not interfere with the facts. Various other questions will be discussed in the proper places and for this reason will not be considered further here.

It may be well to mention that although these questions smack of the technical, it is maintained that in just so far as one contributes toward their solution, that far is the broad practical problem of better methods for the production of new economic maize types solved. The questions of purity of homozygotes, inheritance of size and number of ear-rows in the different sub-species are easily seen to be of practical agricultural importance. Other questions may seem of less importance or even of no importance from this point of view, but this is fallacious as is easily shown by illustrations from the science of chemistry where abstruse theoretical researches have continually proved to be the most practical in the end.

In certain quarters there has been a marked reaction against the continued Mendelian interpretation which has been given to every paper published since the year nineteen hundred in which actual experimental studies concerning the mechanism of inheritance have been reported. This reaction has taken 
the form of a philosophical query as to whether the characters of the organic complex of which living organisms are composed can in any sense be dissected and analyzed into the "units" of heredity which are the basis of Mendelian inheritance. Further it has been questioned whether there is any justification for the increasing complexity with which Mendelian formulæ are involved. It has been argued that with a multiplicity of "factors" any particular case can be interpreted as segregating according to the Mendelian hypothesis. For these reasons the writers wish to have their position in reporting the following investigations distinctly understood at the beginning.

It is fully understood that there is danger in improper analysis of complex ratios from pedigree cultures. This is inevitable. Yet it is not a more pertinent criticism to condemn complexity in biological facts than it is to frown upon the intricacies of modern organic chemistry because it is so different from the simple chemistry of Liebig. The answer is that the facts of heredity are complex.

In regard to the question of the ultimate nature of unit characters or the possibility of absolute segregation of characters in the germ-cells so that in the recessive there is actual absence of the character (gene) in question, we must await more results from the different points of view of the breeder, the cytologist, the physiologist and the physiological chemist. The facts reported in genetic investigations remain indelible. The interpretation of these facts may or may not be correct; they simply arbitrarily represent the facts in a convenient system of notation much as the facts of chemistry are represented by structural formulæ. This is the idea in the minds of the authors in the following report. It is thought moreover to represent the attitude of most genetic investigators and the excuse for making the above statements lies in the fact that unfortunately one often finds no appreciation of this attitude by biologists not actually engaged in genetic research.

We have, then, used the ordinary Mendelian notation, with allelomorphic pairs interpreted as presence and absence of characters not because we know that there is actual absence but because this interpretation fits our present knowledge. We have interpreted complex characters such as height which 
we are not able to analyze completely, as segregating characters. The conclusion that there is a segregation in the second hybrid generation very much in excess of the sum of the non-inherited fluctuation and of other variation due to the heterozygous condition of the pure (?) forms used and also of their combination in the first hybrid generation, is justified by the data. This is the essence of Mendelian theory; and, whether absolutely correct or not, it is an interpretation that cannot fail to be valuable to the commercial plant breeder. It gives him some knowledge of what may be expected in his endeavors to produce new types of maize by hybridization.

It might also be mentioned that following Johannsen, the word "gene" has been used to signify that substance present in the germ-cell which represents potentially the "unit character" or whatever it may be called that acts as an entity in heredity.

\section{Previous Work on Inheritance in Maize.}

Before describing in detail the material used in these experiments it may be well to give a short summation of the previous work in the field.

The early hybridists, Camerarius, Logan, Pontedera and Henschel, each made a desultory study of maize crosses, but obtained no results of present interest. Hardly more satisfactory are the papers of Dudley (1724), Sageret ('26), Puvis ('37), Gärtner ('49), Naudin ('63), Hildebrand ('67, '68), Vilmorin ('67) and Focke ('81), although these researches representing work of the principal students of hybridization of the period - each gives several observations concerning the immediate effect of pollen upon the endosperm, - that phenomenon called Xenia by Focke ('81). These observations, however, can hardly be compared with those made since the cause of Xenia was discovered for the obvious reason that the facts concerning the changes in the endosperm were almost lost to sight in the search for effect of cross-pollination on the tissues of the maternal parent.

In the work of a slightly later period particularly in the United States (Kellerman and Swingle '89, '90; McCluer '92; Morrow and Gardner '92) a great improvement was made in 
the methods of investigation employed. The parental stock was often inbred to establish its purity, crosses were made by hand upon protected flowers, and the resulting progeny were studied with great care. Many facts of inheritance are unconsciously reported in their papers which are confirmed in the post-Mendelian work which gives them a meaning For example one finds these data in Kellerman and Swingle ('91). A *chance hybrid evidently produced by the pollination of a white maize with pollen from a variety with purple aleurone cells was inbred. A hand-pollinated ear contained 370 seeds, of which 206 were blue, 71 pink, 71 orange-yellow and 22 pure white. One wonders how the essential facts of dominance and segregation remained unnoticed in the face of such ratios as this. But even if it is interesting to reread these papers and consider them from a more modern viewpoint, it is hardly profitable to discuss them further here. The work previous to 1900 was in the wrong epoch, and since that time three valuable contributions to the subject in hand have been made. (De Vries 1899 and 1900, Correns 1899, 1900 and 1901, and Lock 1906.)

It is interesting at least, to note that in the cases of both De Vries and of Correns the studies of maize hybrids in which presence and absence of yellow and presence and absence of starch in the endosperm were concerned, contributed largely to their independent discoveries of dominance and segregation in hybrids, which they both unselfishly credited entirely to Mendel after their discovery of his previous paper. Thus Zea mays shares with Pisum sativum the honor of being the subject material in the establishment of Mendel's laws.

Correns' (:01) beautiful monograph was written with the especial idea of furnishing an explanation of the phenomenon of Xenia, but it naturally contributed a large amount of data upon the mechanism of inheritance of the characters with which he worked.

Correns' technique was as follows. The seeds were planted first in pots, allowed to attain a healthy start, and finally transplanted to the field. In the first year (1894) the plants to be used as "mothers" were planted together in his experiment field, castrated at the right time and the silks protected between

* The immediate parents were thought to have been white, but this was probably an error. 
pollinations with paper bags. The individuals that furnished the pollen were planted together in places apart from the proposed mother plants and from them pieces of the male panicles (tassels) were carried in glass bottles to the mother plants. Slight changes in the plan of planting were made in 1895 and 1896 , but I cannot find in any case that either the male flowers were protected from foreign pollen during their maturation or that special care was taken to have pollen for a cross furnished by an individual plant. Furthermore in handling the hybrids individuals were not selfed but bred inter se. Some of the families were given to gardeners who were growing no other maize, while others were detasseled and naturally pollinated en masse with the pollen of a pure race. The first method predominated. We can see then that the methods in use furnished correct results only when the characters in question were simple and of such nature that the races could be kept pure by inspection. Complex ratios such as are furnished when maize with purple aleurone cells is crossed with various white maizes differing in gametic structure, could not possibly be analyzed correctly.

Correns reached conclusions regarding the mode of inheritance of the following characters but it must be borne in mind that these results came from the study of data more or less massed, and not the study of individual crosses in as precise a manner as that outlined by Mendel.

Yellow endosperm was found to be dominant to its absence, and starchiness dominant to absence of starchiness (sweet). Both of these characters behaved as Mendelian mono-hybrids. It cannot be definitely stated, however, that crosses between all races of maize where presence and absence of these characters are concerned would give the same results. Long aleurone cells also proved dominant to short aleurone cells, and red pericarp to absence of red, but Correns was not entirely satisfied that these characters behaved as simple Mendelian monohybrids although he supposed this to be the case.

Purple aleurone cells appeared to form an allellomorphic pair with absence of purple, but he found that the heterozygotes when bred inter se did not give the normal number of whites. What he took to be heterozygotes of the same character were either pure purple, partial purple, or pure white 
when the purple was used as the male parent. In the reverse cross the purple appeared to be fully dominant. Correns (:01) endeavors to explain this phenomenon by the fact that in the formation of the hybrid endosperm two nuclei come from the female and but one from the male parent. He supposes that in some cases this may cause a dominance of the female characters. This purple character seemed to interfere with normal inheritance in still another case (Correns :02), where a blue sweet corn was crossed with a non blue pop. Here the second generation yielded only about $15 \frac{1}{2} \%$ of sweet kernels out of a total of over 8,000. Pollinated with the recessive parent there appeared nearly $50 \%$ of sweet kernels so that the female germ-cells seemed to have segregated normally. Correns suggested that in this case the four possible combinations of characters in the germ-cells did not take place with equal facility.

Our own data shows the error in the first case to be due to the fact that white races differ in their gametic structure in characters which affect the purple color. The observations in the second case have not been confirmed, but were probably due to improper classification of the heterozygous dominants and the recessives. (See starchy and non-starchy crosses.)

The shape and size of seed and relative weight of embryo and endosperm Correns thought behaved in a non-Mendelian manner, although he was not prepared to say in exactly what manner these characters were inherited.

Lock (:06) carried out a much more extended series of maize crosses at Peradeniya, Ceylon, from 1902 to 1906 . His technique in certain cases was a considerable improvement on that of Correns in that both the male and female inflorescences were enclosed in bags and thus crosses were made between single individuals. Unfortunately his method was later changed and cross pollination was accomplished by planting the two races in alternate rows on an isolated plot of ground, and detasseling all plants of the race which it was proposed to use as the female parent. This method of course gave no chance to make a proper analysis of complex characters for could not be known just what gametic composition was possessed by the male parent. This criticism was anticipated by Lock himself but the method was used because he desired 
to have a large amount of data from which to establish the mathematical accuracy of Mendel's hypothesis of definite segregation and chance mating. In the cases of starchy and non-starchy, and yellow and non-yellow endosperm Lock's results were in accord with those of Correns. Furthermore he showed definitely that red pericarp behaved as a Mendelian character, allelomorphic to absence of red. Lock also crossed indented and non-indented races and remarks that in the $F_{2}$ generation a high degree of variability appeared, but without making crosses between individual plants and studying the progeny he could not decide whether or not Mendel's Law was followed. No data is reported on inheritance of height of plants but a number of crosses were made between $F_{1}$ plants and the shorter of the parental races, and he states that no segregation into short and intermediate plants took place. The plants on the contrary were remarkably uniform in height and he believed blended inheritance to be the rule for this character.

Lock's results in crossing races with purple aleurone cells with races with non-purple aleurone cells is so seriously complicated from the fact that he followed out no individual crosses that it is impossible to criticize his data. From the fact that individual ears showed such different ratios as $3: 1,9: 7$ and $1: 3$ we may suspect that he was dealing with white races of varying composition such as are described in our work on this character.

These short abstracts from the work of Correns and of Lock do not give an adequate idea of the large amount of painstaking investigation for which each should be credited however, and anyone interested in the subject should therefore consult the original papers.

\section{The Material Used.}

The types of maize which furnished the parental stock with which crosses were made for this series of studies were in most cases inbred by hand for at least two generations before any hybrids were actually made. When this procedure was impossible the parental ears were obtained from various commercial growers who made a specialty of the types which they furnished. From the maize obtained from them single ears were selected and planted. The plants forming the immediate 
progeny of these ears were used in part as the parents of crosses and in part to inbreed. When any of the seeds from the original ear were found to be heterozygous in any characters the fact is noted when the crosses are described. In this manner we were able to determine the purity of the parental stock used, for all of the grosser characters. Of course new variations were continually isolated and these were given numbers which show their origin. For example, the original stock of Longfellow corn is No. 15; if, however, new variations appeared in the Longfellow progeny they were numbered 15-1, 15-2, etc.

The following descriptions, then, comprise only original material; that is, single ears of various commercial varieties.

Zea mays tunicata. The podded corns.

21. Podded maize.

A fourteen-rowed ear with four husks around each kernel in addition to the usual paleas. The seeds looked like rice pop; they were small but showed a considerable amount of white starchy matter.

Zea mays everta. The pop corns.

20. A flint-like 8-row purple pop.

A pop with purple aleurone cells, showing a small amount of white starchy matter immediately behind the embryo, sufficient to keep the seeds from popping well. Ear $15 \mathrm{~cm}$. long, $11 \mathrm{~cm}$. in cir. Seeds .9 x.9 $\mathrm{cm}$., white endosperm. Cob white.

60. Tom Thumb pop.

A dwarf true pop. Ear $7.5 \mathrm{~cm}$. long, $8 \mathrm{~cm}$. in cir., 12-rowed; pericarp colorless. Seeds rounded, true pop, $.5 \times .4 \mathrm{~cm}$., endosperm yellow. Cob white.

23. White rice pop.

A white true pop. Ear $15.5 \mathrm{~cm}$. long, $10 \mathrm{~cm}$. in cir., 16-rowed. Seeds white, $.9 \times .5 \mathrm{~cm}$., hooked. Cob white.

26. A white, flint-like pop.

A white true pop with rounded flint-like seeds. Ear $17 \mathrm{~cm}$. long, $9 \mathrm{~cm}$. in cir., 8-rowed. Seeds $.8 \times .9 \mathrm{~cm}$. rounded. Cob white.

27. Red rice pop.

A true rice pop with red pericarp. Used only for inheritance of pericarp color.

28. White rice pop.

A true rice pop with white or colorless pericarp. Used only in cross with No. 27.

Zea mays indurata. The flint corns.

4. Benton maize.

An eight-rowed race intermediate between the flint and the dent corns. Ear $34 \mathrm{~cm}$. long, $14 \mathrm{~cm}$, in cir., 8-rowed, pericarp red becoming colorless at summit. Seeds $1.1 \times 1.4 \mathrm{~cm}$., some very slightly dented; endosperm yellow, slightly more starchy than a true flint. Cob white. 
5. Watson flint.

A true flint with a pericarp rose red when developing in full sunlight, the seeds at the tip usually showing simply red striations beginning at point of attachment of the silk. Ear $27 \mathrm{~cm}$. long, $13 \mathrm{~cm}$. in cir., 8 rowed. Seeds $1.0 \times 1.2 \mathrm{~cm}$., endosperm colorless. Cob white.

11. Sturges' flint.

A twelve-rowed yellow flint race. Ear $20 \mathrm{~cm}$. long, $14 \mathrm{~cm}$. in cir., 12-rowed, pericarp colorless. Seeds $1.0 \times 1.0 \mathrm{~cm}$., endosperm yellow. Cob white.

13. Sanford flint.

An eight-rowed race. Ear $30 \mathrm{~cm}$. long, $13 \mathrm{~cm}$. in cir., 8-rowed; pericarp colorless. Seeds $1.0 \times 1.3 \mathrm{~cm}$.; endosperm colorless. Cob white.

15. Longfellow yellow flint.

An eight-rowed yellow race. Ear $27 \mathrm{~cm}$. long, $11.5 \mathrm{~cm}$. in cir.; 8rowed; pericarp colorless. Seeds $.9 \times 1.2 \mathrm{~cm}$.; endosperm bright yellow. Cob white.

17. Palmer's red-nosed yellow flint.

An eight-rowed yellow race. Ear $22 \mathrm{~cm}$. long, $12 \mathrm{~cm}$. in cir.; 8-rowed; pericarp a dirty red at the sides of seed becoming almost colorless at summit. Color not deep as in common red maize. Seeds $1.0 \times 1.4$ cm.; endosperm yellow. Cob white.

24. Rhode Island white cap.

An eight-rowed flint race. Ear $29 \mathrm{~cm}$. long, $12 \mathrm{~cm}$. in cir.; 8-rowed; pericarp colorless except for a slight pink tinge of rose similar to No. 5 but less in amount. Seeds $.9 \times 1.2 \mathrm{~cm}$; endosperm colorless. Cob white.

25. Brindle flint.

A common flint race not breeding true to the character from which it derives its name, - a mosaic pericarp formed by slashes of dark red extending irregularly from the point of the attachment of the silk. Eightrowed true flint.

Zea mays indentata. The dent corns.

2. Illinois low protein dent.

A white dent selected for low proteid content at the Illinois Agricultural Experiment Station for eight generations. Protein content 8.30 per cent. Ear $19 \mathrm{~cm}$. long, $18 \mathrm{~cm}$. in cir.; 16-rowed; pericarp colorless. Seeds $1.5 \times .8 \mathrm{~cm}$; endosperm colorless; white starchy matter largely increased in summit over usual dent type. Cob white.

8. Illinois high protein dent.

A white dent selected for high proteid content at the Illinois Agricultural Experiment Station for eight generations. Proteid content 15.46 per cent. Ear $20 \mathrm{~cm}$. long, $14 \mathrm{~cm}$. in cir.; 14-rowed; pericarp colorless. Seed $1.1 \times .9 \mathrm{~cm}$; ; endosperm colorless; white starchy matter decreased from amount usual in dent types but summit still well dented. Cob white.

3. Leaming dent.

A yellow dent race. Ear $21 \mathrm{~cm}$. 1ong, $16 \mathrm{~cm}$. in cir.; 20-rowed; pericarp colorless but sometimes very slightly tinted with dirty brick red at sides of seeds. Seeds $1.3 \times .7 \mathrm{~cm}$; endosperm dark yellow; considerable soft starch at summit; well dented. Cob dark red. 
6. Leaming dent.

Same race as No. 3 but of different ancestry. Ear, $19.5 \mathrm{~cm}$. long, $18.5 \mathrm{~cm}$. in cir.; 18 -rowed.

7. Leaming dent.

Same race as No. 3 but of different ancestry. Ear $18 \mathrm{~cm}$. long, 17 $\mathrm{cm}$. in cir.; 20-rowed.

9. Leaming dent.

Same race as No. 3 but of different ancestry. Ear $18.5 \mathrm{~cm}$. long, $16.5 \mathrm{~cm}$. in cir.; 16 -rowed.

\section{Leaming dent.}

Same race as No. 3 but of different ancestry. Ear $19 \mathrm{~cm}$. long, 17 cm. in cir.; 18 -rowed.

16. Leaming dent.

Same race as No. 3 but of different ancestry. This ear was 18-rowed and perfectly formed. It was surrounded by five lateral branches each having either four or eight rows of seeds.

1. Missouri cob pipe dent.

A very large dent race characterized by large cob. Ear $28 \mathrm{~cm}$. long' $22.5 \mathrm{~cm}$. in cir.; cob $14 \mathrm{~cm}$. in cir.; 20 -rowed; pericarp colorless. Seeds $1.5 \times .9 \mathrm{~cm}$; endosperm white. Red cob.

22. Mosaic red dent.

A dent characterized by dark intense red pericarp. Used only for study of that character.

Zea mays amylacea. The flour corns.

10. White floury.

A thoroughly floury race, showing absolutely no corneous starch. Ear $22 \mathrm{~cm}$. long, 14.5 in cir.; 14-rowed; pericarp colorless. Seeds $1.2 \mathrm{x}$ $1.0 \mathrm{~cm}$. ; endosperm colorless. Cob white.

Zea mays saccharata. The sweet corns.

19. Stowell's evergreen.

A large-eared extremely wrinkled-seeded late sugar corn. Ear 16 $\mathrm{cm}$. long, $15.5 \mathrm{~cm}$. in cir.; 14 -rowed; pericarp colorless. Seeds $1.4 \mathrm{x} .7$ cm.; endosperm colorless. Cob white.

18. Early Crosby.

A twelve-rowed sugar corn. Ear $14.5 \mathrm{~cm}$. long, $14 \mathrm{~cm}$. in cir.; 12 rowed; pericarp colorless. Seeds $.9 \times .9 \mathrm{~cm}$; d decidedly wrinkled but thick full seeds; endosperm colorless. Cob white.

54. Black Mexican.

An eight-rowed sugar corn characterized by purple aleurone cells. Ear $13.5 \mathrm{~cm}$. long, $12 \mathrm{~cm}$. in cir.; 8-rowed; pericarp colorless. Seeds $.9 \times 1.1 \mathrm{~cm}$.; aleurone cells purple; endosperm colorless.

\section{Methods Used.}

In carrying out the large amount of tedious routine work necessary in the collection of data from the crosses of the above types, a great effort was made to reduce experimental errors 
to a minimum. No part of the work was left to farm workmen except the preparation of the breeding plots and their cultivation. The planting, labeling of families, crossing, selfing, harvesting, filing of seed and collection and reduction of data were done by the authors. The senior author alone is responsible for the details of the work until 1909. In 1909 and 1910 the senior and junior authors both shared in the labor. Since 1907 efficient aid in harvesting, filing seed, etc., has been given by Mr. C. D. Hubbell of the Conn. Agr. Exp. Station. In 1910 Mr. D. W. Davis and Mr. O. E. White, graduate students at Harvard University, aided in selfing ears of various selections.

The ears have always been shelled and seeds classified and filed in seed envelopes. Where there has been the least question aboul classification the work has been duplicated by two observers. If then there has been a doubt concerning the characters borne by particular seeds, those in question have been grown for another generation. The planting has been done from the seed envelopes directly to the field. There they were planted in hills three and one-half feet apart each way, four seeds to the hill. It was not considered necessary to start the seeds in the greenhouse in sterilized soil as is done with smaller seeds. Maize seed very seldom germinates after remaining in the ground over the winter in this climate. Furthermore the corn which was not hand pollinated was not husked directly on the field so that there was but little chance that any seeds should remain upon the ground. Great care was taken not to drop seeds at planting time in other than the hills marked out. These were covered carefully and after the young plants appeared above the surface, any individuals not exactly in the hill were removed. No plants have ever given evidence that they were misplaced and there is every reason to believe that the work is accurate in this regard.

The different families were marked in the field by heavy stakes to which wired tree labels were attached. As an additional precaution against mis-labeling or misplacement of labels, however, a planting plan was always kept on file showing the exact location of every plant in the field. With this safeguard every field stake might have been removed without making the least confusion.

A11 crossing and selfing were done by hand. Individual 
plants were used as the male parent in nearly every case. If possible the male parent of a cross was also selfed with its own pollen so that selfed seed of that individual was accessible if necessary. If for any reason it was particularly desirable to have the progeny of a plant where through an accident none of its own pollen was available, it was pollinated from a sister plant. This fact was always noted, however, and the male parent selfed if possible.

Heavy manila paper bags were used to protect both male and female inflorescences from foreign pollen. These were found much more desirable than paraffined bags as the latter were likely to become inverted and filled with water during a rain storm. The manila bags stood up well in the rain, dried out quickly, and seldom failed to furnish dry viable pollen. The tassels were bagged about three days before any pollen was ripe. Of course here there was a slight chance of enclosing foreign pollen. This pollen, however, would have been three or more days older than the pollen coming from the bagged flowers, and therefore much less viable. Even disregarding this fact, however, the immense amount of pollen furnished by the bagged infloresence would so dilute any foreign pollen that the ratio would be at least 10,000 to. 1 in favor of the former.

The female flowers were always bagged of course before any of the silks were showing, and any bracts or leaves showing foreign pollen were carefully removed. Here again, however, is a slight chance of enclosing foreign pollen. This error has been determined by bagging 53 ears and allowing them to remain in the bags. Forty-four ears formed no seeds, six ears formed one seed each, two ears formed two seeds each and one ear formed four seeds. There are over five chances to one then that no viable foreign pollen enters in this way.

The pollination is accomplished by removing the bag from the tassel, shaking out the empty anthers and dusting the pollen over the silks of the proposed mother plant. The bag covering the silks is not entirely removed but is held so that its opening is horizontal with the silks resting inside. The pollen is then shaken in at the opening as quickly as possible, taking care not to let the silks touch the hands or clothing of the operator or the leaves or stem of the plant. It is sometimes impossible to keep from touching the silks with the fingers, as it may be 
necessary to rearrange them in the bag. To guard against contamination from this source the hands are carefully cleaned with 95 per cent. alcohol after each pollination.

The silks at the base of the ear mature first; those at the tip of the ear last. For this reason, if one is to be absolutely certain of a well filled ear, it is necessary to pollinate two or three times with fresh pollen. This procedure has the disadvantages of increasing the error, however, not to speak of the difficulty of obtaining pollen, so that in this work but one pollination was made in each case. When pollinated about five days after bagging, fairly well filled ears were generally obtained, particularly with the small races.

Immediately after pollination the ear is rebagged and tagged. From this time until the ears are mature they are inspected every little while to see that the bags are not too tight for the maturing seeds. The bags remain on until the ears are harvested. They are then picked, husked, tagged with wired tree labels and dried. Boards through which wire nails have been driven are hung from the ceiling of the drying room to prevent the depredations of mice. The ears are impaled upon these nails and thus dry surrounded by a current of air.

\section{Experimental Error.}

The manipulation during pollination is undoubtedly productive of an experimental error which even the most careful work cannot entirely prevent. This error was determined as follows. Twenty-five ears were bagged and allowed to remain in this condition for five days. The bags were then opened and given the manipulation that was necessary for handpollination, except that no pollen was applied. The ears were then rebagged and remained so until harvest time. No seed were formed on sixteen ears; three ears produced one seed each; four ears produced two seeds each; while one ear produced four seeds and one ear produced five seeds.

There is a possibility then of an experimental error of five or six seeds out of the two hundred to eight hundred produced per ear. This is to be considered as a maximum error and not the probable error, the latter being less than one seed per ear. 


\section{PART II.}

\section{ENDOSPERM CHARACTERS.}

These hybridization studies are all reported under the headings of the different characters investigated, as this seems to be the method calculated to show the data with the least confusion. The female parent is written first, using the variety number given under the description of the material under investigation. For example $7 \times 54$ represents a cross of Leaming yellow dent female with Black Mexican sweet male. When this cross is grown and hand-pollinated selfed ears are obtained, they are numbered (7 x 54)-1, (7 x 54)-2, (7 x 54)-3, etc. Should ear number 2 be grown for still another generation, the crop obtained is numbered ( $7 \times 54)-2-1$, ( $7 \times 54)-2-2$, etc., thus the exact generation of a particular ear is always shown. The characters under consideration are known by letters; 'S', for example means presence of starchy character and ' $s$ ', absence of starchy character: ' $P$ ', represents presence of purple aleurone cells; ' $p$ ', its absence. An ear numbered ( $7 \times 54)-2-1$ P S represents an ear of the third or $F_{3}$ generation from which purple starchy seeds have been selected for planting.

\section{Starchiness and Non-starchiness.}

Starchiness is the condition of the endosperm of all of Sturtevant's maize varieties except Zea mays saccharata, regardless of the physical condition - corneous starch or soft starch in which it appears. The starch grains are fully developed and possess a shape characteristic of the species Zea mays. The sugar maize does not have the ability to develop these starch grains to maturity. Some starch is formed but it remains small, angular and abortive, hence the seeds ripen from the stage of maturity called the "milk" without much change, giving the seed a wrinkled translucent appearance. The difference in size of the starch grains in the two races is shown in Table 10. This difference in the size of starch grains however, 
PLATE II.

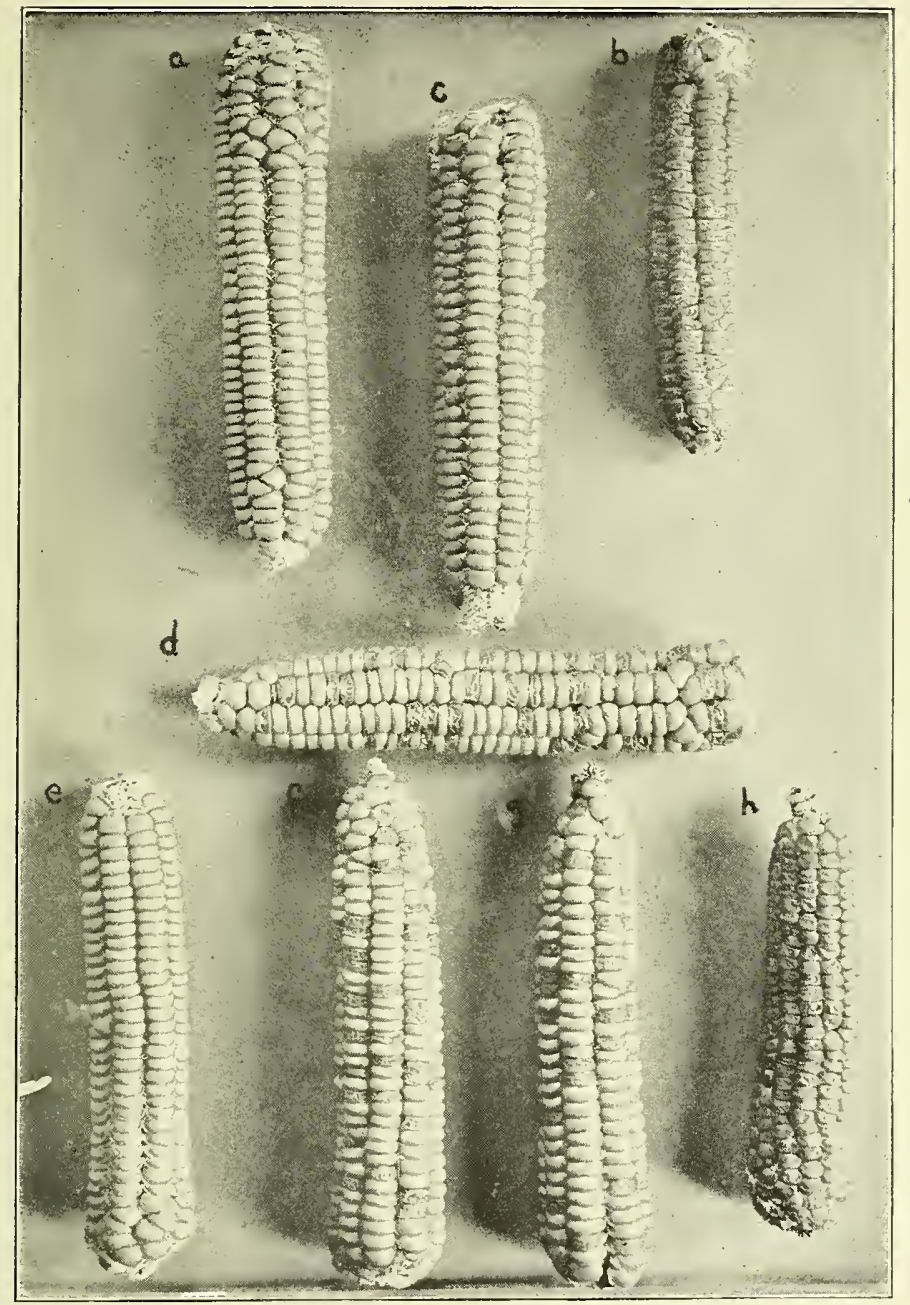

a. No. 24 Rhode Island white cap (starchy parent); b. No. 53 Crosby non-starchy parent); $c$. result of cross $24 \times 53$ showing heterozygous seeds in which starchiness is completely dominant. $d$, an ear with $\mathrm{F}_{2}$ seeds showing mono-hybrid segregation. Lower row daughters of $d$. $E, f$ and $g$, results from planting starchy seeds. One ear out of three is pure starchy. $h$, result from planting non-starchy seeds.

Segregation of Starchiness and Non-starchiness. 

is not the whole difference between starchy and non-starchy races. As the starchy races ripen, starch formation goes on at a steady rate, while in the non-starchy races there is an actual breaking down of endosperm materials into cane sugar and various hexoses. This is shown by determinations we have made of reducing sugars in both starchy and non-starchy races when both were at the "milk" stage of maturity. The non-starchy races contained from one and one-fourth to two and one-half as much reducing sugar as the starchy races.

Correns (:01) has already shown that starchiness behaves as a Mendelian dominant allelomorphic to its absence. Dominance was complete, and segregation generally * exact and inheritance discontinuous. It is not to confirm his work that the matter is taken up here, but to consider other questions to which the data are relevant. These questions relate chiefly to the mathematical hypothesis of Mendelism, to prepotency of individuals, and to gametic purity. The data from which the problems are discussed are not selected, but the figures

* The one exception was the pop and sugar cross mentioned later.

TABLE 1 .

NO. 15 FLINT STARCHY $\mathrm{x}$ No. 54 NON-STARCHY.

\begin{tabular}{|c|c|c|c|c|c|c|}
\hline Ear No. & S & $s$ & Total & Ratio per 4 & Dev. & P. E. \\
\hline 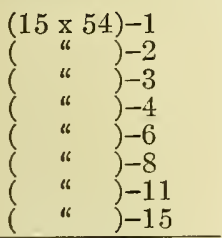 & $\begin{array}{l}135 \\
253 \\
150 \\
238 \\
190 \\
302 \\
242 \\
236 \\
\end{array}$ & $\begin{array}{r}48 \\
85 \\
42 \\
96 \\
72 \\
96 \\
105 \\
79\end{array}$ & $\begin{array}{l}183 \\
338 \\
192 \\
334 \\
262 \\
398 \\
347 \\
315\end{array}$ & $\begin{array}{l}2.9508: 1.0492 \\
2.9944: 1.0056 \\
3.1248: 0.8752 \\
2.8504: 1.1496 \\
2.9008: 1.0992 \\
3.0352: 0.9648 \\
2.7896: 1.2104 \\
2.9968: 1.0032\end{array}$ & $\begin{array}{l}0.0492 \\
0.0056 \\
0.1248 \\
0.1496 \\
0.0992 \\
0.0352 \\
0.2104 \\
0.0032\end{array}$ & $\begin{array}{l}0.0864 \\
0.0635 \\
0.0843 \\
0.0639 \\
0.0722 \\
0.0586 \\
0.0627 \\
0.0658\end{array}$ \\
\hline 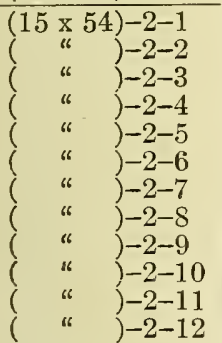 & $\begin{array}{l}235 \\
242 \\
24 S \\
227 \\
200 \\
182 \\
238 \\
195 \\
162 \\
131 \\
132 \\
101\end{array}$ & $\begin{array}{l}70 \\
79 \\
66 \\
68 \\
59 \\
74 \\
91 \\
58 \\
38 \\
53 \\
40 \\
32\end{array}$ & $\begin{array}{l}305 \\
321 \\
314 \\
295 \\
259 \\
256 \\
329 \\
253 \\
200 \\
184 \\
172 \\
133\end{array}$ & $\begin{array}{l}3.0820: 0.9180 \\
3.0156: 0.9844 \\
3.1592: 0.8408 \\
3.0780: 0.9220 \\
3.0888: 0.9112 \\
2.8436: 1.1564 \\
2.8936: 1.1064 \\
3.0832: 0.9168 \\
3.2400: 0.7600 \\
2.8476: 1.1524 \\
3.0696: 0.9304 \\
3.0376: 0.9624\end{array}$ & $\begin{array}{l}0.0820 \\
0.0156 \\
0.1592 \\
0.0780 \\
0.0888 \\
0.1564 \\
0.1064 \\
0.0832 \\
0.2400 \\
0.1524 \\
0.0696 \\
0.0376\end{array}$ & $\begin{array}{l}0.0669 \\
0.0652 \\
0.0659 \\
0.0680 \\
0.0726 \\
0.0730 \\
0.0644 \\
0.0734 \\
0.0826 \\
0.0861 \\
0.0891 \\
0.1013\end{array}$ \\
\hline
\end{tabular}


include only about one-fourth of the hand-pollinated ears at our disposal, belonging to the starchy and non-starchy cross. This number seemed sufficient for our purpose, and the segregating kernels were not counted on the remaining ears. It should be mentioned however, that any wide departures from the normal on any of the four hundred selfed heterozygous ears of this cross would have been noted and reported if such had occurred.

Dominance was found to be complete. In no case was there the slightest difference between the homozygous and the heterozygous seeds in either outward appearance or in the character of the starch cells when examined microscopically. Whatever it is that is brought in by the starchy parent to cause starch formation is sufficiently active to bring about complete change when present in one "dose" (that is from one parent). As in all endosperm characters, when $\mathrm{S}$ is the male parent the starchiness appears in the current generation so called, giving the most perfect illustration of Xenia there is known. As a matter of fact, one is not dealing with the current generation but with the $F_{1}$ generation, the endosperm being a younger generation than the plant which bears the ear. In no case, in an experience with several thousand seeds, did an $\mathrm{F}_{1}$ seed showing Xenia fail to show a heterozygous condition; nor did extracted recessives (sugar seeds) of the $\mathrm{F}_{2}$ generation ever show a heterzoygous condition. From this, one may conclude that the second male nucleus that fertilizes the endosperm nucleus always bears the same characters as the first male nucleus that fertilizes the embryo nucleus or egg. Several heterozygous seeds have been found, however, that were not completely starchy, but had developed bilaterally into half starchy and half nonstarchy. There was not a gradual change from the one condition to the other, but a distinct line of demarkation, with one side as absolutely distinct from the other as are the pure races of each kind. None of these seeds were homozygous starchy, and Correns' interpretation of similar phenomena as cases in which the second male nucleus did not fuse with the endosperm nucleus but each developed separately, seems well founded. Attention is called to the matter for this reason. It is an hypothesis generally received with quiescence if not with acquiescence, that starchiness (and other "presence" characters) 
is due to presence of an enzyme not possessed by the allelomorph. Now if this is true, the enzyme must be a colloid with such large molecules that there is absolutely no dialysis, otherwise it seems as if it would diffuse through the unripe seed sufficiently to act as a catalyser throughout the entire endosperm. No matter what is the correct interpretation, there is certainly a definite chain of hereditary transmission of characters from cell to cell during development, and each original cell follows an inertia of its own with little influence on others.

TABLE 2.

No. 24, FLINT STARCHY X NO. 54, NON-STARCHY.

\begin{tabular}{|c|c|c|c|c|c|c|}
\hline Ear No. & S & $s$ & Total & Ratio per 4 & Dev. & P. E. \\
\hline 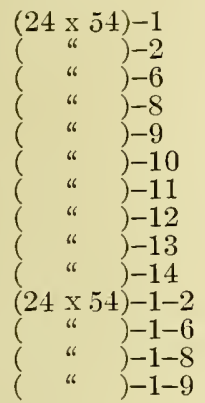 & $\begin{array}{l}274 \\
219 \\
256 \\
200 \\
155 \\
212 \\
213 \\
268 \\
264 \\
227 \\
207 \\
223 \\
235 \\
106\end{array}$ & $\begin{array}{r}94 \\
73 \\
89 \\
64 \\
69 \\
59 \\
77 \\
80 \\
106 \\
90 \\
68 \\
75 \\
90 \\
36\end{array}$ & $\begin{array}{l}368 \\
292 \\
345 \\
264 \\
224 \\
271 \\
290 \\
348 \\
370 \\
317 \\
275 \\
298 \\
325 \\
142\end{array}$ & $\begin{array}{l}2.9784: 1.0216 \\
3.0000: 1.0000 \\
2.9680: 1.0320 \\
3.0304: 0.9696 \\
2.7680: 1.2320 \\
3.1292: 0.8708 \\
2.9380: 1.0620 \\
3.0804: 0.9196 \\
2.8540: 1.1460 \\
2.8644: 1.1356 \\
3.0108: 0.9892 \\
2.9932: 1.0068 \\
2.8924: 1.1076 \\
2.9860: 1.0140\end{array}$ & $\begin{array}{l}0.0216 \\
0.0000 \\
0.0320 \\
0.0304 \\
0.2320 \\
0.1292 \\
0.0620 \\
0.0804 \\
0.1460 \\
0.1356 \\
0.0108 \\
0.0068 \\
0.1076 \\
0.0140\end{array}$ & $\begin{array}{l}0.0609 \\
0.0684 \\
0.0629 \\
0.0719 \\
0.0781 \\
0.0710 \\
0.0686 \\
0.0626 \\
0.0607 \\
0.0656 \\
0.0704 \\
0.0677 \\
0.0648 \\
0.0980\end{array}$ \\
\hline
\end{tabular}

We have said that dominance appears to be complete; segregation also appears to be complete. It is seldom necessary to subject extracted recessives to proof by growing them a further generation. Some strains of non-starchy maize, No. 18 for example, are much less wrinkled than others; and when such a strain is crossed with a flint type there is less difference between dominants and recessives in appearance than when certain other types are crossed. But in no case is there the least difficulty in separating the segregates correctly. Whether this apparent segregation is as complete as it appears we shall discuss presently. It should further be mentioned that the seeds can also be classified with absolute exactness by microscopical examination. 
Tables 1-9 contain the proportion of the starchy and nonstarchy seeds obtained as progeny when heterozygous seeds were planted; although, as was stated before, only a few ears from each family were counted. One object in view is to show the behavior of starchy and non-starchy in several races.

TABLE 3 .

NO. 5, FLINT STARCHY $\mathrm{x}$ NO. 18 , NON-STARCHY.

\begin{tabular}{|c|c|c|c|c|c|c|}
\hline Ear No. & S & $s$ & Total & Ratio per 4 & Dev. & P. E. \\
\hline$(5 \times 18)-4$ & 181 & 68 & 249 & $2.9176: 1.0924$ & 0.0924 & 0.0740 \\
\hline & 17 & 66 & 238 & $2.9908: 1.1092$ & 0.1092 & 0.0757 \\
\hline-10 & 21 & 68 & 283 & $3.0388: 0.9612$ & 0.0388 & 0.0694 \\
\hline S & 22 & 69 & 29 & $3.0612: 0.9388$ & 0.06 & 0.0681 \\
\hline-1 & 186 & 61 & 247 & $3.0120: 0.9880$ & 0.0120 & 0.0743 \\
\hline-21 & 136 & 42 & 178 & $3.0560: 0.9440$ & 0.05 & 0.0876 \\
\hline-25 & 176 & 50 & 226 & $3.1152: 0.8848$ & 0.1152 & 0.0777 \\
\hline-30 & 218 & 68 & 286 & $3.0488: 0.9512$ & 0.0488 & 0.0691 \\
\hline
\end{tabular}

There is reason to believe that different races can be identical in appearance, but may have such different gametic composition that they may affect a character possessed by a race with which they may be crossed, in very different manners. (See purple aleurone cells and non-purple.) Examination of the tables shows this not to be the case with starchy and non-starchy. All of the starchy and non-starchy races with which crosses have been made behave in exactly the same manner. There is no difference in appearance in heterozygotes from different races that is not accounted for by the different shaped seeds possessed by the parents, and wide variations in shape occur only in generations later than $F_{1}$. In the $F_{1}$ generation the shape is intermediate between that of the two parents.

TABLE 4.

No. 11 , FLINT STARCHY $\mathrm{x}$ No. 18 , NON-STARCHY.

\begin{tabular}{|c|c|c|c|c|c|c|}
\hline Ear No. & S & $s$ & Total & Ratio per 4 & Dev. & P. E. \\
\hline 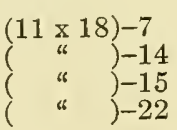 & $\begin{array}{l}220 \\
218 \\
200 \\
235\end{array}$ & $\begin{array}{l}74 \\
81 \\
77 \\
87\end{array}$ & $\begin{array}{l}294 \\
299 \\
277 \\
322\end{array}$ & $\begin{array}{l}2.9932: 1.0068 \\
2.9164: 1.0836 \\
2.8880: 1.1120 \\
2.9192: 1.0808\end{array}$ & $\begin{array}{l}0.0068 \\
0.0836 \\
0.1120 \\
0.0808\end{array}$ & $\begin{array}{l}0.0681 \\
0.0676 \\
0.0702 \\
0.0651\end{array}$ \\
\hline
\end{tabular}


If one examines the tables carefully however, he sees at once that there is quite a difference in the ratios obtained. They vary from a ratio of $2.7896: 1.2104$ in ear ( $15 \times 54)-11$, Table 1 to a ratio of $3.2020: 0.7980$ in ear $(19 \times 7)-2$, Table 7 . This brings up an important question. Does this discrepancy represent an expected probable error in chance matings; or, is there a prepotency in certain families through which excessive numbers of dominants or of recessives tend constantly to reappear? Correns did indeed find in one family such an excess of starchy seeds, but it is not known whether this apparent prepotency was transmitted in further generations.

Tables 1-9 show several cases where ears with a ratio deviating from the expected $3: 1$ of Mendelian hypothesis have been grown for another generation. For example, ear ( $8 \times 54)-1$ of Table 6 has a ratio of $2.9420: 1.0580$ while ear $(8 \times 54)-5$ of the same table has a ratio of $3.0780: 0.9220$; yet the progeny of these ears average just about the $3: 1$ ratio of theory. There are even more ears with an excess of recessives from the ear that had the excess of dominants and vice versa. Other deviants have been grown for several generations, and while the exact ratios have not been recorded it may be stated with confidence that wide deviations occurring in considerable numbers would have been noticed while making other records. It may be concluded then that no prepotency or tendency to aberrant ratios is a constant characteristic of any of our families. How then can the discrepancies from theoretical ratios be explained?

To study this question the probable errors of all of the ratios have been calculated. The method used has been that of Johannsen (:09, p. 405), except that the mean error has been reduced to the probable error by multiplying by the factor 0.6745 . The standard deviation of a Mendelian proportion is $\pm \frac{\sqrt{p \times q}}{p+q}$ where $p$ and $q$ are the Mendelian terms, in this case case 3 and 1 . Then S. D. $= \pm \frac{\sqrt{3 \times 1}}{4}= \pm \frac{1.7321}{4}= \pm 0.4330$. The S. D. probable error, $\mathrm{E}= \pm 0.6745 \frac{\mathrm{S}}{\sqrt{\mathrm{n}}}$ where $n$ is the total number of variates. 
To find out whether the different ratios given in Tables 1-9 are what should reasonably be expected if the Mendelian theory of chance matings of equal numbers of gametes $S$ and $s$ in both male and female germ-cells is correct, it should be understood just what is meant by probable error in the law of error. Plus errors and minus errors should occur with equal frequency, small errors should occur more frequently than large errors, and very large errors should not occur. Determined as above the probable error means that the chances are:

1 to 1 that the true value lies within $\pm \mathrm{E}$

4.5 to 1 that the true value lies within $\pm 2 \mathrm{E}$

21 to 1 that the true value lies within $\pm 3 \mathrm{E}$

142 to 1 that the true value lies within $\pm 4 \mathrm{E}$

The theory of error also provides for errors of any size in their proper frequency or rather infrequency, but as a matter of fact in practice if errors greater than $\pm 4 \mathrm{E}$ occur they are probably due to experimental errors or avoidable mistakes.

We may consider each ear given in Tables 1-9 as a determination and its probable error as the probable error of a single determination. With this in mind we find that in the 94 ears tabled there are 49 plus errors and 45 minus errors. Further we find that the theoretical mode or 0 error is almost $3: 1$. being in fact very slightly greater. The errors are distributed as follows:

$$
\begin{aligned}
& \text { Within } \pm \text { E } 47.8 \% \text { - Theory } 50.0 \% \\
& \text { Within } \pm 2 \text { E } 83.0 \% \text { - Theory } 82.3 \% \\
& \text { Within } \pm 3 \text { E } 96.8 \% \text { - Theory } 95.7 \% \\
& \text { Within } \pm 4 \text { E } 100.0 \% \text { - Theory } 99.3 \%
\end{aligned}
$$

The sum total of these segregates is 23529 to 7811 , a ratio of $3.0031: 0.9969 \pm .0066$.

It should be mentioned simply in order to suppress no data that one ear was found with a probable error somewhat in excess of $\pm 4 \mathrm{E}$. It was found by growing this ear for another generation however that this was due to an experimental error. There was a great excess of sugar seeds, but in the starchy seeds there proved to be about 4 heterozygotes to 1 homozygote. Since no other ear like this has ever been obtained, and since it is known that during the progress of this experiment 
several ears were first selfed with pollen killed by rain and afterward pollinated with pollen from a sugar plant to get material for another purpose, it seems highly probable that this ear was of a similar mixed parentage and that its explanatory label had been lost.

As to whether these data support the Mendelian hypothesis or not there may be slight grounds for a difference in opinion. Our own opinion is that when we take into consideration the chance for experimental error, the ratios are well within the limits of probable error. One thing at least is brought out clearly, the behavior of segregates in more than one generation and a variety of matings are necessary, if one is to draw conclusions as to the exact mode of inheritance of character pairs from small numbers.

One further point remains for discussion. Do the extracted homozygotes breed true? In other words, is segregation an absolute separation of a gene from its absence? or, is there only a relative segregation? Morgan (:10) has suggested that relative segregation may explain Mendelian facts, if one presupposes that when the amount of the gene falls below a certain limit the dominant fails to develop. This idea while interpreting the facts in the $\mathrm{F}_{2}$ generation is inadequate to explain the apparent purity of further generations of extracted recessives, for if this hypothesis were true many recessives would show the dominant character when crossed.

In Table 9 is shown the segregation of extracted dominant starchy seeds. The ratio is as nearly the expected 2 heterozygotes to 1 homozygote as could well be expected. Several

TABLE 5 .

No. 17 , FLINT STARCHY $\mathrm{X}$ No. 54 , NON-STARCHY; No. 18 , NON-STARCHY $\mathrm{x}$ No. 58, Flint STARChy; AND No. 7 , DENT STARChy $\mathrm{x}$ No. 54 , NON-STARCHY.

\begin{tabular}{|c|c|c|c|c|c|c|}
\hline Ear No. & $\mathrm{S}$ & $s$ & Total & Ratio per 4 & Dev. & P. E. \\
\hline 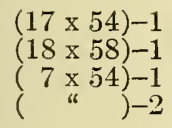 & $\begin{array}{l}328 \\
332 \\
379 \\
493\end{array}$ & $\begin{array}{l}102 \\
102 \\
137 \\
131\end{array}$ & $\begin{array}{l}430 \\
434 \\
516 \\
624\end{array}$ & $\begin{array}{l}3.0512: 0.9488 \\
3.0600: 0.9400 \\
2.9380: 1.0620 \\
3.1604: 0.8396\end{array}$ & $\begin{array}{l}0.0512 \\
0.0600 \\
0.0620 \\
0.1604\end{array}$ & $\begin{array}{l}0.0563 \\
0.0561 \\
0.0514 \\
0.0467\end{array}$ \\
\hline
\end{tabular}


thousand dominant homozygotes have been bred for further generations and these have all bred true to the starchy character. This is, in general, the case with the extracted non-starchy seeds. Furthermore, there are in commercial use many sugar corns that are extracted recessives. Golden Bantam, Late Egyptian and many others are examples of races that have originated from crosses with starchy varieties. The wrinkled seeds have been selected and have bred true. Out of the many million seeds that are annually grown for the canning factories, however, there does appear an occasional ear with semi-starchy seeds. These ears transmit the character and give the canners no end of trouble. There is no way to find out whether these ears appear only on varieties which somewhere in their ancestry had a starchy parent. One can only say that they do appear in ratios not exceeding one ear in ten thousand. By some lucky chance some of these ears made their appearance in our controlled cultures. All of our extracted recessives have proved true to non-starchiness (*) except from the progeny of ear $(8 \times 54)-1-6$. The majority of the progeny of this ear were also non-starchy, but three ears appeared which were decidedly semi-starchy, one of which is shown in Plate III, fig. b. There was no possibility that these ears could have grown from a normal heterozygous seed. They were not plump seeds like a true heterozygote nor did they segregate into starchy and non-starchy in the next generation. The entire ear was rather uniformly semi-starchy and quite different from the true starchy ears. Microscopical examination showed definitely that starch grains had been developed normally to a size intermediate between the true starchy and the true sweet seeds of the same family. This fact is shown in Table 10 .

* There are other cases where some apparent starchiness is always developed, namely when pop races are crossed with non-starchy races. We interpret this as being due to the small size of the resulting $\mathrm{F}_{2}$ seeds borne on intermediate $F_{1}$ ears. When the seeds are small the endosperm material more nearly fills the pericarp than when they are large. The wrinkled condition is therefore less apparent. If one has had considerable experience in classifying starchy and non-starchy seeds, such crosses are seen to show normal segregation. If, however, careful classification is not made and the seeds are not tested in further generations pop and non-starchy crosses always appear to show an excess of starchy seeds. It is suggested that this is the explanation of Corren's failure to obtain normal ratios in a similar cross. These cases are not real exceptions to the statement made above, however, for recessives extracted from pop crosses are never grown commercially as sugar corns. 

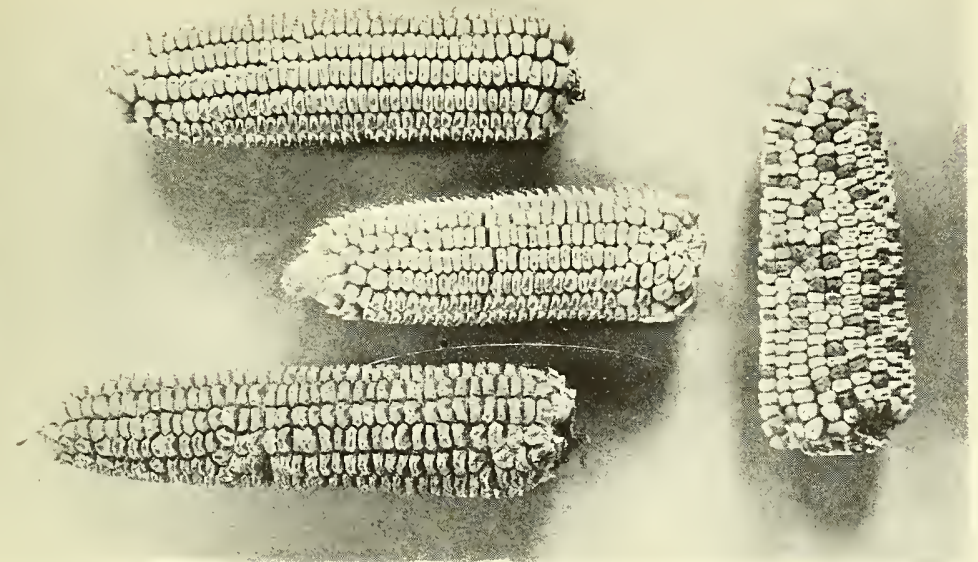

a. P2, Fi, and F2 seeds from cross between No. I9 Stowell's Evergreen sugar and No. 2 Illinois low protein dent maize.

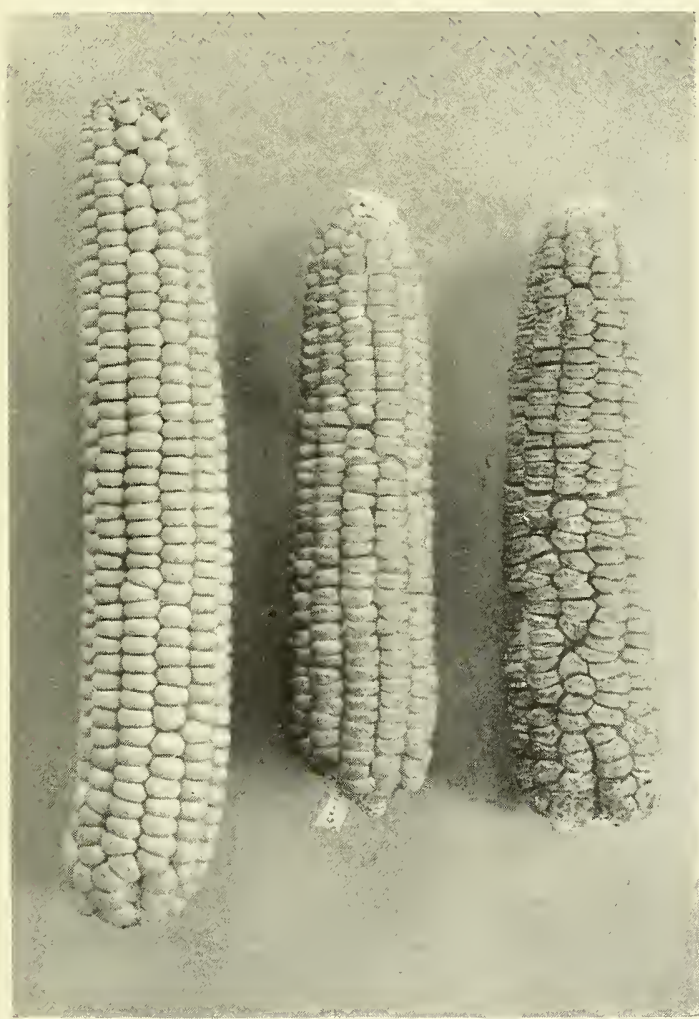

b. Middle ear is a semi-starchy ear No. $(8 \times 54)-1-6$, progeny of an extracted recessive (wrinkled) seed. On the left is an extracted dominant (starchy) ear of the same cross. On the right is a well wrinkled ear, sister of No. $(8 \times 54)-I-6$.

Segregation of Starchiness and Non-Starchiness. 



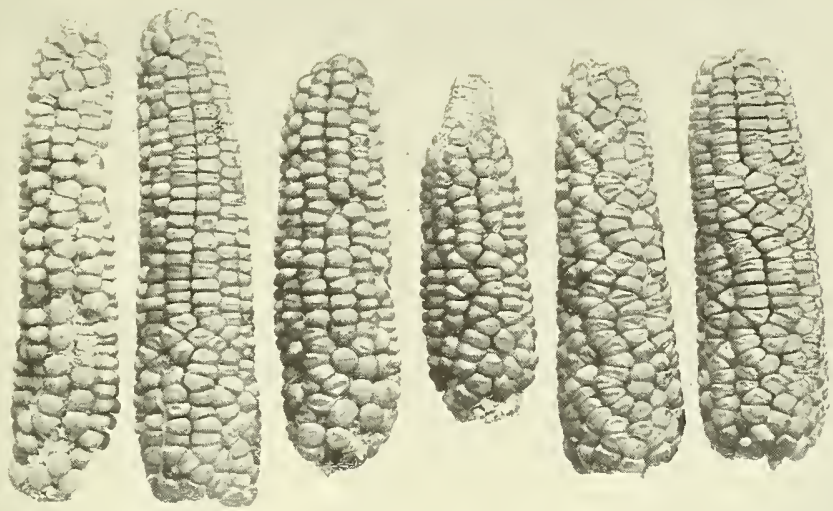

a Random sample of progeny of starchiest seeds of semi-starchy ear shown in Plate III.
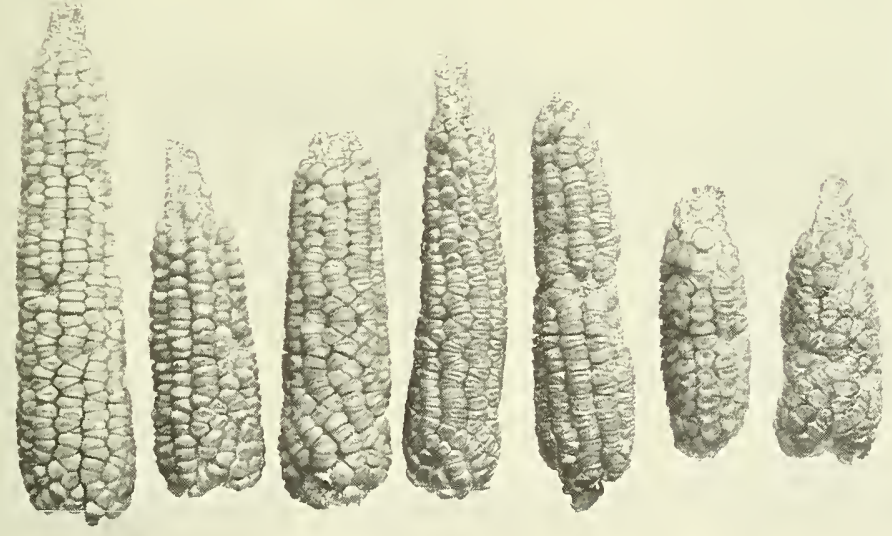

b. Random sample of progeny of most wrinkled seeds of semi-starchy ear shown in Plate III.

Gametic Purity. 

INHERITANCE OF STARCHINESS.

TABLE 6.

NO. 8, DENT STARCHY $\mathrm{X}$ NO. 54, NON-STARCHY.

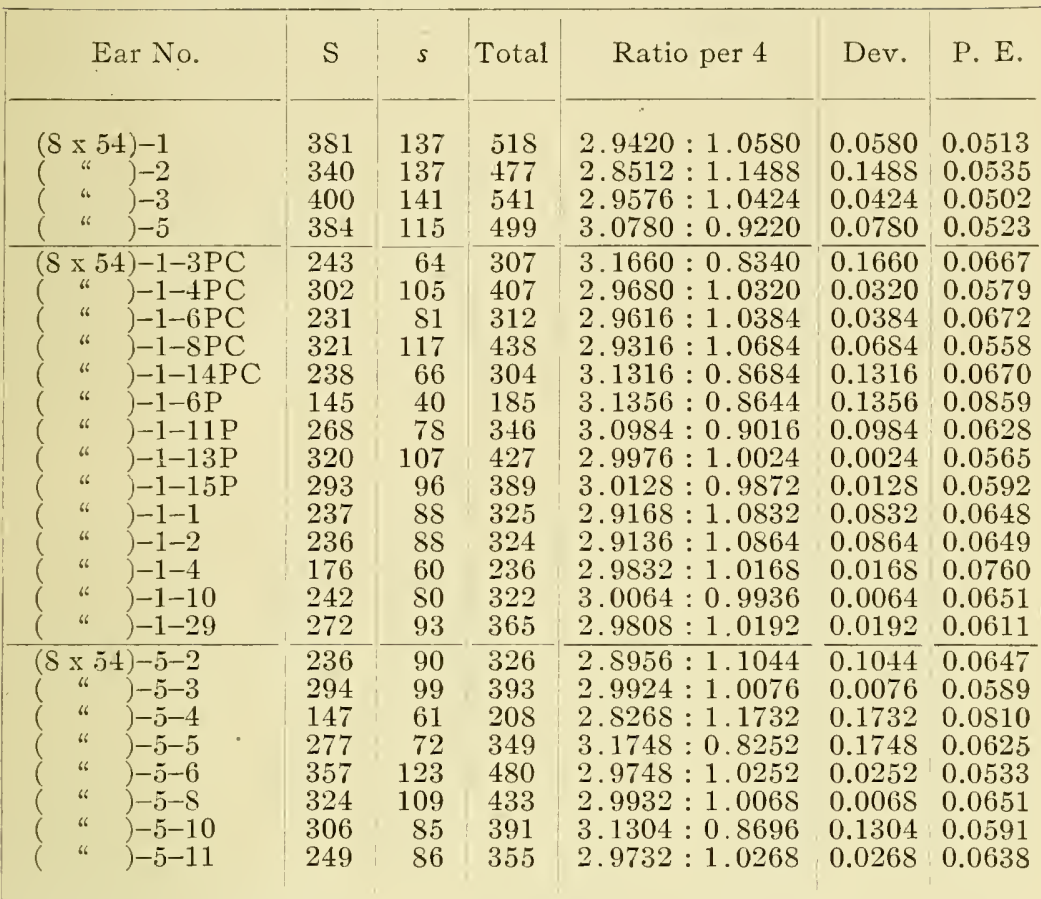

Seeds from the ear shown in Plate III, fig. b, were divided into two classes, those most nearly starchy and those most nearly non-starchy, and planted. A number of selfed ears were obtained from each class. Those resulting from the seeds most nearly non-starchy were in part what would immediately be classified as non-starchy and in part as starchy in appearance as the parent ear. The ears resulting from the seeds most nearly starchy were all as starchy as the parents and certain of them even more so. This fact is shown in Plate IV. Microscopical examination of the most starchy seeds of this generation showed that the starch grains were most of them developed to normal size. The ears were not uniform nor was there uniform starchiness among the seeds of a single ear. Seeds could be selected which formed a series running from true sweet to true starchy, yet those most nearly starchy had a rough appear- 
TABLE 7.

No. 19 , NON-STARCHY $\mathrm{x}$ No. 7 , DENT STARCHY AND No. 19, NON-STARCHY $x$ NO. 8 , DENT STARCHY.

\begin{tabular}{|c|c|c|c|c|c|c|}
\hline Ear No. & S & $s$ & Total & Ratio per 4 & Dev. & P. E. \\
\hline$(19 \times 7)-2$. & $\begin{array}{l}297 \\
486\end{array}$ & $\begin{array}{r}74 \\
156\end{array}$ & $\begin{array}{l}371 \\
642\end{array}$ & $\begin{array}{l}3.2020: 0.7980 \\
3.0280: 0.9720\end{array}$ & $\begin{array}{l}0.2020 \\
0.0280\end{array}$ & $\begin{array}{l}0.0607 \\
0.0461\end{array}$ \\
\hline$(19 \times 7)-5-1$ & 304 & 109 & 413 & $2.9444: 1.0556$ & 0.0556 & 0.0575 \\
\hline $\begin{aligned} &(19 \times 8)-1 \\
& \text { (1 }8)-2 \\
& \text { “ }-3 \\
& \text { “ }-4 \\
& \text { “ }-4 \\
&(\end{aligned}$ & $\begin{array}{l}183 \\
464 \\
449 \\
303 \\
414\end{array}$ & $\begin{array}{r}64 \\
152 \\
151 \\
96 \\
139\end{array}$ & $\begin{array}{l}247 \\
616 \\
600 \\
399 \\
553\end{array}$ & $\begin{array}{l}2.9636: 1.0364 \\
3.0128: 0.9872 \\
2.9932: 1.0068 \\
3.0376: 0.9624 \\
2.9948: 1.0052\end{array}$ & $\begin{array}{l}0.0364 \\
0.0128 \\
0.0068 \\
0.0376 \\
0.0052\end{array}$ & $\begin{array}{l}0.0743 \\
0.0471 \\
0.0477 \\
0.0585 \\
0.0507\end{array}$ \\
\hline
\end{tabular}

ance very different from the well-filled pericarp of the true starchy seeds of the same family. These seeds will be selected for starchiness and if uniform ears are finally obtained, will be crossed with non-starchy again to see if their behavior is the same as normal starchy maize. Provisionally one is forced to one of two conclusions. Either homozygous recessives (and likewise dominants) are not complete segregates, but products of a partial quantitative separation of genes allowing traces of the dominant character to remain, traces which may sometimes accumulate sufficienily to bring out the dominant character: or, progressive variations are constantly taking place in small numbers, most often along paths that have been passed before.

TABLE 8 .

NO. 60 , POP STARCHY X NO. 54 , NON-STARCHY.

\begin{tabular}{|c|c|c|c|c|c|c|}
\hline Ear No. & S & $s$ & Total & Ratio per 4 & Dev. & P. E. \\
\hline 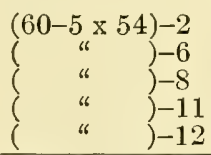 & $\begin{array}{l}274 \\
273 \\
163 \\
191 \\
249\end{array}$ & $\begin{array}{r}82 \\
102 \\
53 \\
58 \\
84\end{array}$ & $\begin{array}{l}356 \\
375 \\
216 \\
249 \\
333\end{array}$ & $\begin{array}{l}3.0788: 0.9212 \\
2.9120: 1.0880 \\
3.0184: 0.9816 \\
3.0684: 0.9316 \\
2.9908: 1.0092\end{array}$ & $\begin{array}{l}0.0788 \\
0.0880 \\
0.0184 \\
0.0684 \\
1.0092\end{array}$ & $\begin{array}{l}0.0619 \\
0.0603 \\
0.0795 \\
0.0740 \\
0.0640\end{array}$ \\
\hline 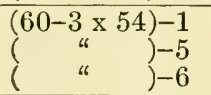 & $\begin{array}{l}296 \\
260 \\
243\end{array}$ & $\begin{array}{r}87 \\
107 \\
73\end{array}$ & $\begin{array}{l}383 \\
367 \\
316\end{array}$ & $\begin{array}{l}3.0912: 0.9088 \\
2.8336: 1.1664 \\
3.0760: 0.9240\end{array}$ & $\begin{array}{l}0.0912 \\
0.1664 \\
0.0760\end{array}$ & $\begin{array}{l}0.0597 \\
0.0610 \\
0.0657\end{array}$ \\
\hline $\begin{array}{r}(60-8 \times 54)-1 \\
6 \quad)-8\end{array}$ & $\begin{array}{l}227 \\
224\end{array}$ & $\begin{array}{l}67 \\
71\end{array}$ & $\begin{array}{l}294 \\
295\end{array}$ & $\begin{array}{l}3.0884: 0.9116 \\
3.0372: 0.9628\end{array}$ & $\begin{array}{l}0.0884 \\
0.0372\end{array}$ & $\begin{array}{l}0.0681 \\
0.0680\end{array}$ \\
\hline
\end{tabular}


It is our opinion that dominant starchiness - if it is the same dominant starchiness - has been formed anew. It occurs too rarely to support a partial segregation theory such as Morgan's (:10). If it is asked why starchiness is the character that arises anew rather than another variation, it is suggested that the peculiar chemical structure of the germ cell of maize may be such that a molecular readjustment is much more likely to bring about starchiness than any other variation. Such a path of least resistance for variations might account for the many cases in animals and plants where the same variation has apparently occurred again and again.

\section{Conclusion.}

These starchy and non-starchy crosses represent a much larger number of individuals than have ever before been studied in accurately controlled pedigree cultures. Taking them as a whole they show that the mechanism by which the members of an allelomorphic pair are distributed among the gametes, is accurate. The aberrant ratios sometimes obtained are what should be expected by the Law of Error. They are not inherited, and we believe this to show that there is no such thing as prepotency per se which would cause abnormal ratios. We might extend this conclusion further and say that there is no conclusive evidence of a failure of segregation of male gametes or of selective fertilization (Lock :06), or of partial gametic coupling that presupposes gametes bearing opposite genes to be formed in unequal numbers (Bateson and Punnett :08). Disbelief in prepotency of the kind described above does not indicate disbelief in different "potencies" as described by Davenport $(: 10)$. Different potencies, that is various degrees of manifestation of the same character due to its modification during development by the action of other developing genes possessed by the individual, is a different thing and is entirely logical. In prepotency or potency of this kind segregations are perfectly normal, and modifications which occur in characters are due to the gametic constitution of the individual.

The aberrant ratios obtained by Correns in the pop-sugar cross referred to above, may have been due to modification by other unknown characters possessed by the parents, but it 
seems more likely that they were due to improper classification of dominants and recessives for the reason that recessives in such crosses although hyaline and easily classified microscopically often do fill the pericarp with endosperm material owing to the small size of the seed.

If then, in cases of simple mono-hybrids where there are no complications, a ratio of $3.0031: 0.9969 \pm .0066$ is obtained; are we not compelled to take the view that segregation occurs at the reduction division? Could any less exact division give the distribution of genes necessary for such exact recombinations? Of course it has long been suspected that this was the time of segregation, but Bateson (:09 p. 271) has felt that obstacles were in the way of interpreting the chromosomes as such important bearers of hereditary qualities. These obstacles were three in number; first, it is objected that no correspondence has been shown between visible differences of type (except sex) and chromosome differences; second, that no correspondence between complexity of type and chromosome numbers has been shown; and third, that bud sports are somatic segregates. There are, it seems to us, no real obstacles here. One should expect that the quality of the chromosome and not shape or number, is the important fact. It is even likely that most of the important morphological characters are carried by all of the chromosomes, hence a doubling of chromosome number as has occurred in Oenothera gigas may be relatively unimportant. The case of bud sports is also fairly clear since Winkler (:09) has shown that a graft hybrid between the black night shade and the tomato proved to have the sum of the haploid numbers of the two parents and not the sum of the diploid numbers. The somatic cell then has a regulatory apparatus of its own. What might be called the normal bud sport (other sports probably occur from abnormal cell divisions) is probably due to the fusion of two somatic cells of a heterozygote, followed by a reduction, in which one of the homozygote forms appears. It must be not understood however that because Bateson's objections are considered surmountable, we therefore believe it to be proved that the chromosomes are the sole bearers of hereditary characters and that the reduction division is the time of Mendelian segregation. Judgment must still be suspended on these matters. 
TABLE 9 .

EARS FROM $F_{2}$ GENERATION PLANTS OF STARCHY AND NON-STARCHY CROSSES.

Starchy Seeds Planted.

\begin{tabular}{|c|c|c|}
\hline Selection & Heterozygous S & Homozygous S \\
\hline 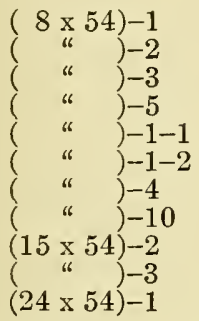 & $\begin{array}{r}6 \\
4 \\
30 \\
75 \\
67 \\
44 \\
71 \\
48 \\
46 \\
25 \\
28\end{array}$ & $\begin{array}{r}4 \\
5 \\
17 \\
31 \\
32 \\
25 \\
38 \\
28 \\
13 \\
17 \\
14\end{array}$ \\
\hline Total & 444 & 224 \\
\hline Ratio & 1.93 & 1 \\
\hline
\end{tabular}

TABLE 10

RANDOM COMPARISON OF DIAMETER OF STARCH GRAINS.

Extracted Starchy Seeds from $(8 \times 54)-1$ and Semi-Starchy and Non-Starchy from $(8 \times 54)-1-6$.

\begin{tabular}{|c|c|c|c|c|c|c|c|c|c|c|c|c|}
\hline Diam. in mm. & .009 & .017 & .034 & .052 & .069 & .086 & .103 & 12 & .138 & .155 & Total \\
\hline $\begin{array}{c}\text { No. variates } \\
\text { from starchy } \\
\text { seeds }\end{array}$ & $\ldots$ & 1 & 9 & 23 & 34 & 66 & 36 & 16 & 12 & 3 & 198 \\
\hline $\begin{array}{c}\text { No. variates } \\
\text { from semi-starchy } \\
\text { seeds }\end{array}$ & $\ldots$ & 17 & 52 & 57 & 48 & 17 & 11 & 5 & $\ldots$ & $\ldots$ & 227 \\
\hline $\begin{array}{c}\text { No. variates } \\
\text { from non-starchy } \\
\text { seeds }\end{array}$ & 34 & 94 & 52 & 13 & $\ldots$ & $\ldots$ & $\ldots$ & $\ldots$ & $\ldots$ & $\ldots$ & 193 \\
\hline
\end{tabular}




\section{Yellow and Non-yellow Endosperm.}

Correns (:01) and Lock (:06) each found a yellow color in the endosperm which behaved with its absence as a single allelomorphic pair. We have found two * yellow colors in the endosperm each behaving when crossed with its absence, as an independent allelomorphic pair. A part of the experiments with these characters has been described in a previous paper (East :10). In this paper some further data are presented.

Both of these yellow colors, although they behave in inheritance as separate entities are either identical or very similar in composition. They are insoluble in water, somewhat soluble in alcohol and easily soluble in ether, chloroform, benzine, benzol and carbon bisulphide. They occur in rhombic plates in the starch cells and possibly also in the chromoplasts although this is not certain. From these facts it might be supposed that they were hydrocarbons with compositions similar to carotin. They do not give the general reactions however which the fatty pigments or lipochromes - of which carotin is an example give with sulphuric acid or iodine dissolved in aqueous potassium iodide. Independent of their solubility reactions, this would class them with the anthochlorins (Courchet '88).

Considering the importance to Mendelian theory of the discovery that two similar and possibly identical characters may each act with its own absence as an independent allelomorphic pair, further chemical investigations are being made which will be reported in a separate paper. It may simply be stated here that as far as is known these colors are indistinguishable, but as they behave differently in crosses they will be known as $Y_{1}$ and $Y_{2}$.

A number of crosses were made between yellow and nonyellow which gave only $3: 1$ ratios. The remaining crosses shown in Tables 11-16 each showed one or more ears with dihybrid ratios.

* Lock mentioned that light yellow seeds appeared in his crosses, but he classed them as whites which vitiates his study of Mendelian numerical proportions. 
TABLE 11.

F 2 SEEDS FROM CROSS OF NO. 1 WHITE DENT $\mathrm{X}$ NO. 7 YELLOW DENT.

\begin{tabular}{|c|c|c|c|}
\hline Ear No. & $\mathrm{Y}$ & $y$ & Ratio Approx. \\
\hline$(1 \times 7)-1$ & 587 & 212 & $3: 1$ \\
$(1 \times 7)-2$ & 127 & 30 & $3: 1$ \\
\hline
\end{tabular}

Table 11 gives the results from two selfed ears of No. 1 white dent crossed with No. 7 yellow dent. They approximate 3 to 1 ratios although ear No. 1 has an excess of non-yellow and ear No. 2 an excess of yellow seeds. This cross proved to be too late for the Connecticut climate and the resulting $\mathrm{F}_{3}$ seeds were immature and difficult to classify. Yellow was dominant and appeared as Xenia in the $F_{1}$ seeds but the $F_{2}$ seeds varied in different ears in a peculiar manner. Where there was sufficient soft starchy matter in the caps of the seeds the heterozygotes were considerably lighter colored at the cap than when the seeds possessed more corneous starch. The same phenomenon occurred in reciprocal crosses; so that when there was sufficient soft starchy matter the heterozygotes could be distinguished from the homozygotes either way the cross was made. (See cross of floury yellow with non-yellow.)

Ear $(1 \times 7)-1 Y$ gave only one selfed ear with 126 yellows of various shades, 14 white, and 3 doubtful seeds. The mother seed was probably $Y_{1} Y_{2} y_{1} y_{2}$. Several open field ears from yellows with white caps all proved to be heterozygous, thus proving the above statement regarding Xenia. The crop from the white seeds proved pure for non-yellow. 
TABLE $11 \mathrm{~A}$.

$\mathrm{F}_{3}$ SEEDS OF EAR NO. 2 OF CROSS SHOWN IN TABLE 11.

Yellow Seeds Planted.

\begin{tabular}{|c|c|c|c|}
\hline Ear No. & $\mathrm{Y}$ & $y$ & Ratio Approx. \\
\hline 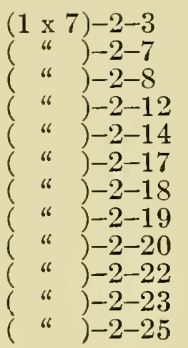 & $\begin{array}{l}423 \\
351 \\
375 \\
343 \\
577 \\
286 \\
209 \\
360 \\
341 \\
319 \\
408 \\
633\end{array}$ & $\begin{array}{r}108 \\
108 \\
120 \\
111 \\
19 \\
58 \\
87 \\
135 \\
105 \\
92 \\
168 \\
40\end{array}$ & $\begin{array}{c}3: 1 \\
3: 1 \\
3: 1 \\
3: 1 \\
\text { Pure yellow } \\
3: 1 \\
3: 1 \\
3: 1 \\
3: 1 \\
3: 1 \\
3: 1 \\
15: 1\end{array}$ \\
\hline
\end{tabular}

Table 11a shows the results from planting $(1 \times 7)-2 \mathrm{Y}$ seeds. Ears Nos. 3 and 17 have an excess of yellow seeds. Possibly they were $15: 1$ ratios in which the yellows were very light and could only have been classified with certainty by growing the supposed whites another generation. The remaining ears all showed $3: 1$ ratios except ear No. 25. This ear was clearly a $15: 1$ ratio. The crop from $(1 \times 7)-2 y$ (extracted whites) gave 12 pure white ears, showing that the classification of the $\mathrm{F}_{2}$ seeds was correct.

A cross between No. 5 white flint and No. 6 yellow dent (Tables 12 and 12a) showed in all cases complete dominance of yellow. In the $\mathrm{F}_{1}$ seeds which were of course flinty like the mother, there was no soft starch in the cap and the heterozygotes were exactly like pure yellow flint seeds. In the $\mathrm{F}_{1}$ plants the $\mathrm{F}_{2}$ homogygous and heterozygous yellow seeds were also indistinguishable. It was necessary to grow them to distinguish heterozygous yellow from homozygous yellow. In the $F_{2}$ plants with $\mathrm{F}_{3}$ seeds, however, there was a considerable segregation of dented ears from flint ears. Here as in the cross of $(1 \times 7)$ it was fairly easy to distinguish heterozygous yellows from homozygous yellows when the seeds of the former had a well developed soft starchy zone in the cap.

Although as has been stated the $F_{1}$ seeds were all exactly 
like pure yellow flint seeds, they nevertheless belonged to two classes. The Xenia seeds $\left(F_{1}\right.$ seeds) of the hybrid ear contained 159 seeds which were dark yellow and 145 seeds which were a considerably lighter yellow. This striking phenomenon was not understood until another generation was grown from the seeds. Table 12 showing the selfed ears resulting from the dark seeds, and Table 12a showing the selfed ears resulting from the light seeds make this matter plain. Excluding ear ( $5 \times 6)-9$ from Table 12 because it evidently came from a pure yellow seed grown in this family through an error, and ear (5x6)-11a from Table $12 \mathrm{a}$ which evidently grew from a selfpollinated seed of the mother No. 5, it is clear that the No. 6 plant furnishing the pollen for the cross was homozygous for one yellow and heterozygous for the other. The classification into light and dark yellows was somewhat arbitrary and therefore some ears in Table 12 gave ratios of $3: 1$ and some ears in Table 12a gave ratios of $15: 1$ but the fact that about onehalf of the $F_{1}$ seeds had a gametic formula of $Y_{1} y_{1} Y_{2} y_{2}$ and

TABLE 12.

$\mathrm{F}_{2}$ SEEDS FROM CROSS OF NO. 5 White FLiNT $\mathrm{x}$ NO. 6 Yellow DENT.

Dark Yellow Seeds Planted.

\begin{tabular}{|c|c|c|c|}
\hline Ear No. & $\mathrm{Y}$ & $y$ & Ratio Approx. \\
\hline $\begin{array}{l}(5 \times 6)-1 \\
\left(\begin{array}{c}5 \\
\text { “ }\end{array}\right)-2 \\
\text { “ })-3 \\
\text { “ })-7 \\
\text { “ })-8 \\
(\text { “ })-10 \\
(\text { “ })-11 \\
(\text { “ })-12 \\
(\text { “ })-13 \\
\text { “ })-14 \\
\text { “ })-15\end{array}$ & $\begin{array}{l}326 \\
316 \\
313 \\
354 \\
331 \\
307 \\
475 \\
298 \\
368 \\
363 \\
489 \\
427\end{array}$ & $\begin{array}{r}29 \\
27 \\
28 \\
122 \\
109 \\
20 \\
25 \\
113 \\
19 \\
35 \\
29 \\
118\end{array}$ & $\begin{aligned} & 15: 1 \\
& 15: 1 \\
& 15: 1 \\
& 3: 1 \\
& 3: 1 \\
& \text { Pure yellow } \\
& 15: 1 \\
& 3: 1 \\
& 15: 1 \\
& 15: 1 \\
& 15: 1 \\
& 3: 1\end{aligned}$ \\
\hline
\end{tabular}

one-half the formula $Y_{1} y_{1}$, or $Y_{2} y_{2}$, is certain. Ear $(5 \times 6)-7 a$ is the only ratio in doubt. It is probably $15: 1$ as the yellows were very light and difficult to classify, and some were probably placed with the non-yellows. 
TABLE $12 \mathrm{~A}$.

F. SEEDS FROM SAME CROSS AS SHOWN IN TABLE 12.

Light Yellow Seeds Planted.

\begin{tabular}{|c|c|c|c|}
\hline Ear No. & $\mathrm{Y}$ & $y$ & Ratio Approx. \\
\hline 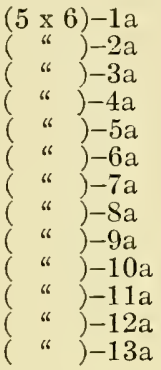 & $\begin{array}{l}359 \\
144 \\
173 \\
433 \\
557 \\
316 \\
450 \\
229 \\
325 \\
227 \\
318 \\
256\end{array}$ & $\begin{array}{r}117 \\
54 \\
63 \\
136 \\
35 \\
120 \\
49 \\
86 \\
115 \\
87 \\
434 \\
118 \\
93\end{array}$ & $\begin{aligned} 3 & : 1 \\
3 & : 1 \\
3 & : 1 \\
3 & \vdots 1 \\
15 & \vdots 1 \\
3 & : 1 \\
10 & : 1 \\
3 & : 1 \\
3 & : 1 \\
3 & : 1 \\
\text { Pure } & \text { white } \\
3 & : 1 \\
3 & : 1\end{aligned}$ \\
\hline
\end{tabular}

Tables 13, 13a, b, c, d, show results from an opposite cross. No. 11, yellow flint was the female parent and No. 8, white dent was the male parent. There was no effect of Xenia, as the $F_{1}$ hybrid seeds were as yellow as the pure No. 11. Table 13 shows the results from the $F_{1}$ hybrid seeds. Every ear approximates a $3: 1$ ratio except ears $(11 \times 8)-7$ and $(11 \times 8)-8$. Ear $(11 \times 8)-7$ is shown afterwards by Tables $13 \mathrm{~b}$ and $\mathrm{c}$ to have been in reality a $15: 1$ ratio. In other words it was a $Y_{1} y_{1} Y_{2} y_{2}$

TABLE 13.

F 2 SEEDS FROM CROSS OF NO. 11, YELLOW FLINT $\mathrm{X}$ NO. 8, WHITE DENT Yellow Seeds Planted.

\begin{tabular}{|c|c|c|c|}
\hline Ear No. & Y & $y$ & Ratio Approx. \\
\hline 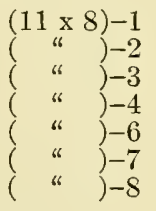 & $\begin{array}{l}358 \\
124 \\
389 \\
340 \\
252 \\
454 \\
204\end{array}$ & $\begin{array}{c}154 \\
41 \\
127 \\
96 \\
83 \\
145^{*} \\
70^{* *}\end{array}$ & $\begin{array}{l:l}3 & : 1 \\
3 & : 1 \\
3 & : 1 \\
3 & : 1 \\
3 & : 1 \\
3 & : 1 \\
3 & : 1\end{array}$ \\
\hline
\end{tabular}

*** Proved to be a mixture of $\mathrm{Y} y$ and $\mathrm{y}$, with preponderance of $\mathrm{Y} y$. 
ear. Ear (11 x 8)-8 probably was also of the same character as about half of the seeds classed as white proved to be heterozygous. Table $13 \mathrm{~d}$ shows only two ears out of eight to have been other than white but an inspection of the open field crop showed such a large proportion of apparently heterozygous ears, that this ratio is probably not the real one.

Ear (11 $\times 8)-2$ proved to be $Y_{1} \mathrm{y}_{1}$ or $\mathrm{Y}_{2} \mathrm{y}_{2}$ as is shown in Table 13a. There is a ratio of about 2 heterozygous to 1 homozygous ears.

\section{TABLE 13A.}

Fs SEEDS OF EAR NO. 2 OF CROSS SHOWN IN TABLE 13.

Yellow Seeds Planted.

\begin{tabular}{|c|c|c|c|}
\hline Ear No. & $\mathrm{Y}$ & $y$ & Ratio Approx. \\
\hline 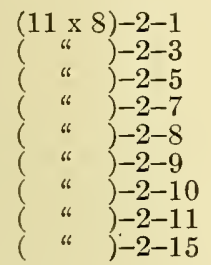 & $\begin{array}{r}275 \\
237 \\
244 \\
374 \\
344 \\
280 \\
99 \\
173 \\
274\end{array}$ & $\begin{array}{r}75 \\
71 \\
113 \\
31 \\
38 \\
75\end{array}$ & $\begin{array}{c}\text { Pure yellow } \\
3: 1 \\
3: 1 \\
\text { Pure yellow } \\
3: 1 \\
\text { Pure yellow } \\
3: 1 \\
3: 1 \\
3: 1\end{array}$ \\
\hline
\end{tabular}

Ear (11 x 8)-7 was evidently wrongly classified as is shown in Tables $13 \mathrm{~b}$ and 13c. Ear $(11 \times 8)-7-1$ is probably a $15: 1$ ratio. If this is true then there were 2 ears with gametic formula $\mathrm{Y}_{1} \mathrm{y}_{1} \mathrm{Y}_{2} \mathrm{y}_{2}, 2$ ears with gametic formulæ $\mathrm{Y}_{1} \mathrm{y}_{1}$ or $\mathrm{Y}_{2} \mathrm{y}_{2}, 1$ ear with formula $Y_{1} Y_{1} Y_{2} Y_{2}$ [Ear (11 x 8)-7-9], and 3 ears with formulæ $\mathrm{y}_{1} \mathrm{y}_{2}$. The apparently white seeds from this ear were not all non-yellow, but partly pure and partly heterozygous light yellows. That is, they were $Y_{1} Y_{1}$ or $Y_{2} Y_{2}$ or $Y_{1} y_{1}$ or $\mathrm{Y}_{2} \mathrm{y}_{2}$. 
TABLE 13B.

$F_{3}$ SEEDS OF EAR NO. 7 OF CROSS SHOWN IN TABLE 13.

Yellow Seeds Planted.

\begin{tabular}{|c|c|c|c|}
\hline Ear No. & $\mathrm{Y}$ & $y$ & Ratio Approx. \\
\hline 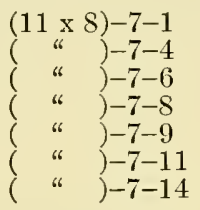 & $\begin{array}{r}207 \\
253 \\
193 \\
163 \\
456 \\
108 \\
88\end{array}$ & $\begin{array}{r}25 \\
68 \\
73 \\
79 \\
35 \\
35\end{array}$ & $\begin{aligned} 8 & : 1 \\
3 & : 1 \\
3 & : 1 \\
3 & : 1 \\
\text { Pure } & \text { yellow } \\
3 & : 1 \\
15 & : 1\end{aligned}$ \\
\hline
\end{tabular}

TABLE $13 \mathrm{C}$.

F 3 SEEDS OF EAR NO. 7 OF CROSS SHOWN IN TABLE 13.

Apparently White Seeds Planted.

\begin{tabular}{|c|c|c|c|}
\hline Ear No. & $\mathrm{Y}$ & $y$ & Ratio Approx. \\
\hline 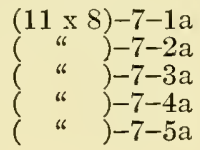 & $\begin{array}{l}271 \\
323 \\
\ldots\end{array}$ & $\begin{array}{l}504 \\
330 \\
117 \\
300\end{array}$ & $\begin{array}{c}\text { Pure non-yellow } \\
\text { Pure light yellow } \\
\text { Pure non-yellow } \\
3: 1 \\
\text { Pure non-yellow }\end{array}$ \\
\hline
\end{tabular}

TABLE $13 \mathrm{D}$.

$\mathrm{F}_{3}$ SEEDS OF EAR NO. 8 OF CROSS SHOWN IN TABLE 13.

White Seeds Planted.

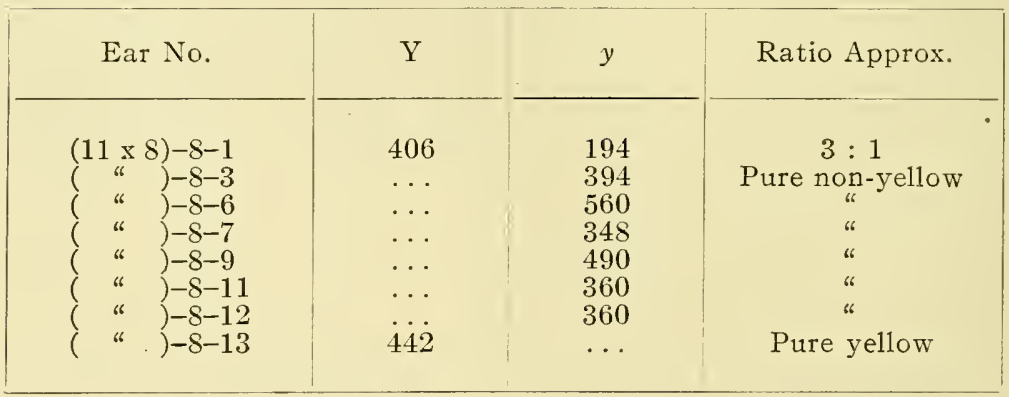


TABLE 14.

$\mathrm{F}_{2}$ SEEDS FROM CROSS OF NO. 11 STURGES' yeLLOW FLINT $\mathrm{x}$ NO. 24 SANFORD'S WHITE FLINT.

Yellow Seeds Planted.

\begin{tabular}{|c|c|c|c|}
\hline Ear No. & $Y$ & $y$ & Ratio Approx. \\
\cline { 2 - 3 }$(11 \times 24)-3$ & 467 & 164 & $3: 1$ \\
$($ " " $)-4$ & 320 & 137 & $3: 1$ \\
$($ " " $)-5$ & 499 & 142 & $3: 1$ \\
& 356 & 116 & $3: 1$ \\
\hline
\end{tabular}

Table 14 shows the results from selfing the $\mathrm{F}_{1}$ seeds of a cross between No. 11, yellow flint and No. 24 white flint. There was no effect of Xenia. The ears gave $3: 1$ ratios and the extracted non-yellows proved to be pure in the $F_{3}$ generation.

TABLE 15.

F2 SEEDS FROM CROSS OF NO. 15 LONGFELLOW FLINT $\mathrm{x}$ No. 8 WHITE DENT.

Yellow Seeds Planted.

\begin{tabular}{|c|c|c|c|}
\hline Ear No. & $\mathrm{Y}$ & $y$ & Ratio Approx. \\
\hline 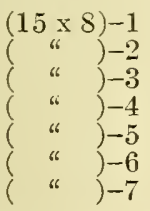 & $\begin{array}{l}305 \\
166 \\
246 \\
428 \\
393 \\
353 \\
480\end{array}$ & $\begin{array}{r}73 \\
12 \\
85 \\
142 \\
124 \\
106 \\
140\end{array}$ & $\begin{aligned} 3 & : 1 \\
15 & : 1 \\
3 & : 1 \\
3 & : 1 \\
3 & : 1 \\
3 & : 1 \\
3 & : 1\end{aligned}$ \\
\hline
\end{tabular}

Table 15 gives the results from selfing the $F_{1}$ seeds of a cross between No. 15, Longfellow yellow flint and No. 8, white dent. There was no appearance of Xenia in the $F_{1}$ seeds. The $F_{2}$ seeds segregated in $3: 1$ ratios with the exception of ear (15 x 8)2. This ear was originally classified as bearing 128 yellow and 50 non-yellow seeds. The $\mathrm{F}_{3}$ seeds produced by the supposed whites, however, showed the correct ratio to have been 166 yellow and 12 non-yellow. The whites proved true in three other ears. The white seeds from ear $(15 \times 8)-1$ were not 
grown, and therefore the large excess of yellow seeds cannot be explained. It is possible of course that this ear as well as one or two others that were not planted really had light yellows classified as whites. If this were true one might consider that the original mother plant was homozygous for one yellow and heterozygous for the second. It seems not improbable that this was the case, for the same results were obtained in two other instances.

TABLE 16.

F$_{2}$ SEEDS FROM CROSS OF NO. 19 WHITE SWEET $\mathrm{X}$ NO. 7

YELLOW DENT.

Yellow Seeds Planted.

\begin{tabular}{|c|c|c|c|}
\hline Ear No. & Y & $y$ & Ratio Approx. \\
\cline { 1 - 2 }$(19 \times 7)-2$ & 277 & 77 & $3: 1$ \\
$($ (" $)-5$ & 599 & 43 & $15: 1$ \\
\hline
\end{tabular}

One other cross, No. 19 non-yellow sweet and No. 7 yellow dent (Table 16), gave di-hybrid ratios. The hybrid seeds were yellow starchy varying somewhat in shade. Only two selfed ears were obtained from the $F_{1}$ seeds. As shown in Table 16 one is a $3: 1$ ratio and one is a 15:1 ratio. Here again is evidence that the male parent was homozygous for one yellow and heterozygous for the second yellow. To be sure there is a slight excess of non-yellows in ear $(19 \times 7)-5$, but this is accounted for in the $\mathrm{F}_{3}$ generation. The supposed non-yellows gave one heterozygous yellow to seventeen non-yellows. The true ratio

TABLE 16A.

F 3 SEEDS OF EAR 5 OF CROSS SHOWN IN TABLE 16.

Dark Yellow Starchy Seeds Planted.

\begin{tabular}{|c|c|c|c|}
\hline Ear No. & $\mathrm{Y}$ & $y$ & Ratio Approx. \\
\cline { 1 - 2 }$(19 \times 7)-5-1$ & 315 & 98 & $3: 1$ \\
(" ") $-5-6$ & 320 & 97 & $3: 1$ \\
(" $)-5-9$ & 19 & 1 & $15: 1$ \\
(" $)-5-12$ & 203 & 14 & $15: 1$ \\
\hline
\end{tabular}


then is $601: 41$ which is very close to theoretical expectancy. The results from planting the yellow starchy seeds of $(19 \times 7)-5$ are shown in Table 16a. Unfortunately the admixture of segregates with wrinkled endosperm made these a little difficult to classify, but there is scarcely a doubt that 2 ears were monohybrids and three ears di-hybrids, although no dependence can be placed on ear $(19 \times 7)-5-9$ with only 20 seeds. No pure yellows were obtained from these seeds unless ear $(19 \times 7)-5-9$ were of this class. The deficiency of these data was supplied by the crop of the yellow sweet $\mathrm{F}_{2}$ seeds of the same ear. Twelve selfed ears were obtained. They are not given in a table because we were not able to prove the classification by growing for another generation, and it is difficult to make exact visible classifications of yellow and non-yellow sugar seeds. There is scarcely any doubt however that two ears were pure for both yellows (seeds all dark yellow), two pure for light yellow, (seeds all light yellow) three heterozygous for one yellow (seeds light yellow and white), one at least and probably two heterozygous for two yellows (seeds dark yellow, light yellow and white) and the rest homozyous for one yellow and heterozygous for one yellow (seeds dark yellow and light yellow).

This family gave by far the best demonstration of two yellows as far as the eye is concerned. The ears homozygous for two yellows would never have been classed as the same variety with those homozygous for one yellow. Nearly all the seeds were absolutely distinct, and yet when they were arranged in a series there would always be a number that were difficult to place.

Table 17 gives the $F_{2}$ segregates of a mono-hybrid cross between No. 10 white flour and No. 6 yellow dent. There seems to be no question of a di-hybrid ratio, but the cross is interesting for another reason. The heterozygous seeds are lighter than the homozygous so that the effect of Xenia is shown either way the cross is made; that is, Xenia is shown both where white flour is crossed with yellow, and where yellow flour is crossed with white. The effect is the same as that shown when light starchy caps are formed when a starchy yellow dent is pollinated by a non-yellow, but as in this case the whole seed is floury, therefore it is all changed to lighter yellow. 
It might be mentioned that No. 60 yellow pop crossed with No. 2 white, and No. 9 yellow dent crossed with No. 10 flour also show Xenia. The hybrid seeds become so much whiter that there is no difficulty in distinguishing the greater part of them from homozygous yellows.

TABLE 17 .

F2 SEEDS FROM CROSS OF NO. 10 WHITE FLOUR AND NO. 6 YELLOW DENT.

Yellow Seeds Planted.

\begin{tabular}{|c|c|c|c|c|c|}
\hline Ear No. & Dark Y & Light Y & Total Y & $y$ & Ratio Approx. \\
\hline 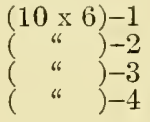 & $\begin{array}{l}162 \\
141 \\
175 \\
131\end{array}$ & $\begin{array}{l}357 \\
242 \\
301 \\
243\end{array}$ & $\begin{array}{l}519 \\
383 \\
476 \\
374\end{array}$ & $\begin{array}{l}187 \\
119 \\
156 \\
127\end{array}$ & $\begin{array}{l}3: 1 \\
3: 1 \\
3: 1 \\
3: 1\end{array}$ \\
\hline
\end{tabular}

Conclusions.

This completes the list of crosses in which new facts have been observed in regard to yellow endosperm. Other crosses might be described where simple mono-hybrid ratios were obtained, but these have already been described by Lock. The di-hybrid ratios have been described in greater detail because they belong to a class of facts having a very important theoretical bearing on the Mendelian hypothesis, which is discussed later in the paper.

It should perhaps be stated that Correns' other general facts have been corroborated. The pure extracted dominants of the $\mathrm{F}_{3}$ generation have appeared in about the general ratio of 1 homozygote to 2 heterozygotes when dealing with monohybrids. There have been insufficient numbers to determine the exact ratio of extracted dominants when dealing with di-hybrids, but in both cases the $\mathrm{F}_{4}$ generations have in every case bred true. This fact we hold to be more important than the ratio. It may look somewhat queer to say that the extracted $\mathrm{F}_{2}$ non-yellows have always bred true, when a number of cases have been described in which the seeds that were thought to be non-yellows, proved to be heterozygous yellows. This 


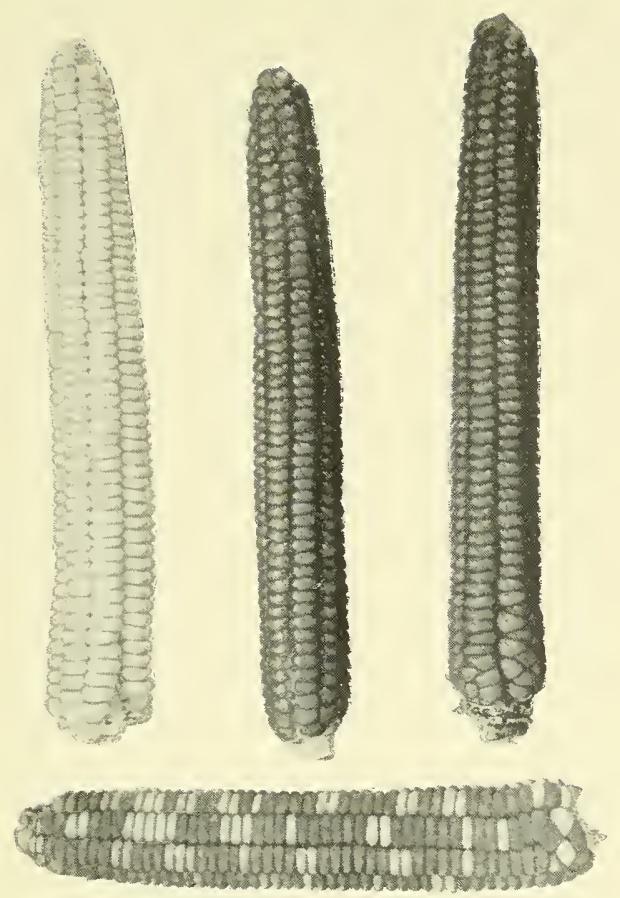

a. At left, No. $2+$ Rhode Island white cap (white endosperm), at right, No. I5 Longfellow (yellow endosperm). In center, hybrid showing dominance of yellow. Below. F2 seeds showing segregation.

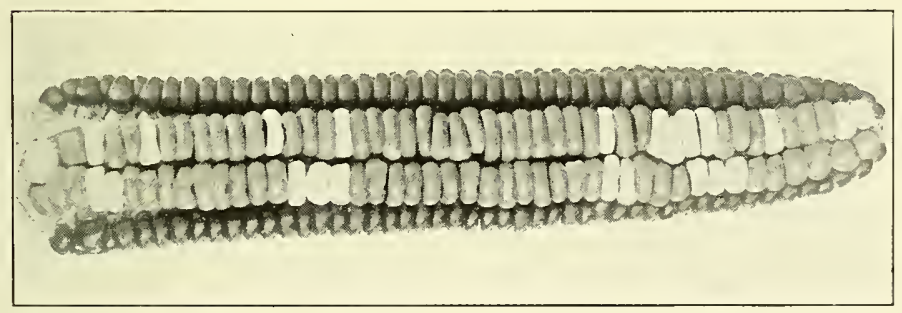

b. An ear showing dominance of red pericarp in $F_{1}$. The pericarp has been removed from two rows of seeds, showing mono-hybrid segregation of $\mathrm{F}_{2}$ endosperms beneath it into yellow and non-yellow.

Segregation of Yellow and Non-Yellow Entosperm. 



\section{PLATE VI.}

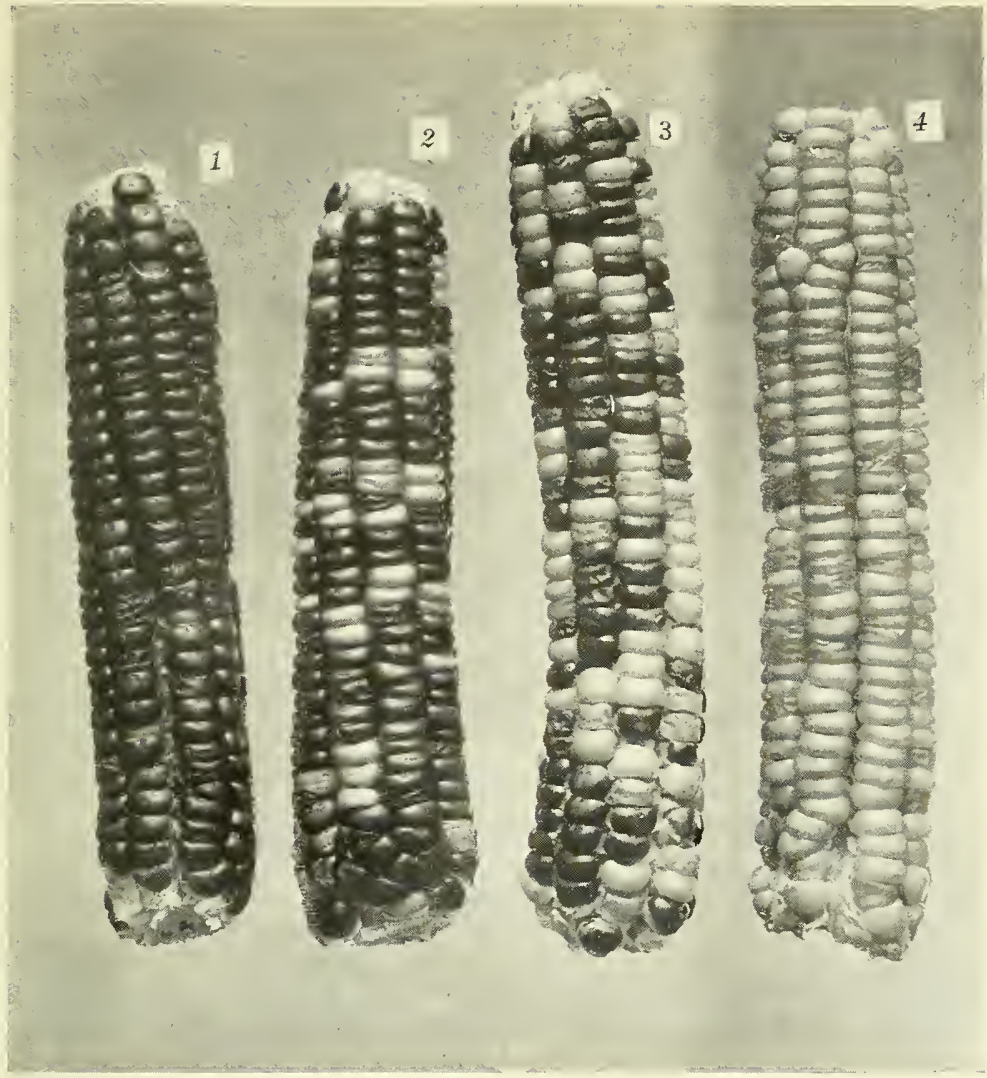

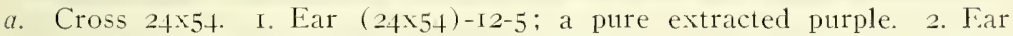
(24.54)-12-6: purples 208, non-purples 65, a $3: 1$ ratio. 3. Ear (24x5b)-I2-4; purples 147 , 110n-purples II7, a $9: 7$ ratio. 4. Ear $(2+\times 54)-12-3$; a pure extracted 110n-purple.
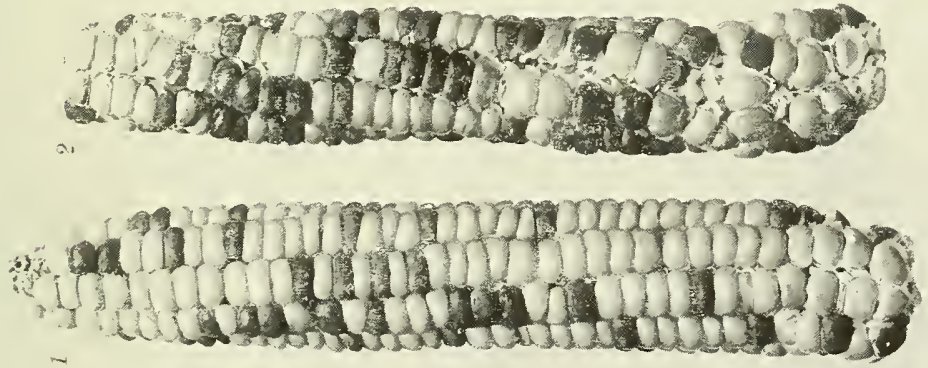

b. Purple seeds produced by random crossing of non-purple seeds of ear $(24 \times 54)-\mathrm{I} 2$ shown in Table ISg. I. Ear $(24 \times 54)-12-9 \times 12 \times 8$; ratio I purple: 3 110n-purple. 2. Ear (24x5f) I2-IIxI2xio; ratio I purple: 1 non-purple. 

is due to the simple fact that the seeds with the gametic formula $Y_{1} y_{1}$ or $Y_{2} y_{2}$ vary in color intensity so that it is generally impossible to classify correctly from 1 to 5 seeds per ear. These $F_{2}$ seeds prove their gametic structure in the $F_{3}$ generation; and those that have behaved as pure extracted non-yellows in $F_{3}$ have never given anything but pure non-yellows in the $\mathrm{F}_{4}$ generation.

The occurrence of the two yellow colors casts a further doubt upon the correctness of Lock's work since his main object was to show the truth of Mendel's mathematical conclusions when dealing with large numbers. Our results both here and in the case of the purple aleurone cells show the futility of not making crosses between individuals and of not selfing individual $F_{1}$ plants. This is a further excuse for presenting in detail the individual crosses between starchy and non-starchy races with the same object as Lock.

\section{Purple and Non-purple aleurone cells.}

The consideration of the inheritance of this character includes also that of a hypostatic red color which appears in crosses between the various purple and non-purple families. The pigments are both fairly easily soluble in water. They are seen first in the aleurone cells of the maturing seeds a few days after fertilization. When the seed is mature the red color becomes an intense dark rose madder, and the purple becomes almost black. Several tests of each pigment were made by macerating the aleurone cells in 50\% alcohol and testing the filtrate. With lead subacetate both turned green and a green precipitate separated. The precipitate from the red seeds was somewhat darker and turned greenish brown on evaporation while that from the purple seeds remained a lighter green. Ferrous sulphate added to the red pigment produced but little if any change in color although a dirty precipitate separated on shaking. When added to the blue pigment, however, a dark blue precipitate separated leaving the liquid colorless. This precipitate left a blue residue on evaporation, while the residue from the red pigment was simply a slight discoloration, dark, but with no distinct color except possibly a redness at the edges. Ferric chloride however gave markedly different reactions in the two cases. Added to the red pigment an orange 
color was produced which became somewhat darker on evaporation. The precipitation was slight. Added to the blue pigment the color was first greenish with blue edges. This turned dark blue and a bluish precipitate separated which later turned green and remained so on evaporation. With ferric alum there was no change except that each pigment became more intense in color. Sodium hydroxide formed brownish green precipitates, darker with the purple. Acids gave red colorations which were lighter with the red pigment. The acid and alkali tests are evidently the usual reactions with vegetable color "indicators" and differ only through the various amounts of pigment present.

It is recognized that tests such as these are arbitrary in nature and cannot form the basis of conclusions as to the chemical composition of the pigments. It seems certain however that they differ somewhat in composition, although they are probably different stages of oxidation of the same color base.

It will be seen in the following pages that purple crossed with different strains of non-purple gave different results. This is clearly due to the various gametic formulæ possessed by the different whites. It may also be that the purples differ somewhat among themselves in unseen characters even though they were pure for purple when selfed. Our analysis of the large amount of data which follows shows that there is simple Mendelian segregation and recombination of several factors and that there is really no confusion of results such as led Correns and Lock to advance various supplementary hypotheses to account for the facts. The use of the color factor C, shows how Lock obtained his purples by crossing white seeds supposedly heterozygous for purple, with white; but it is impossible to analyze his data since individual pollinations were not made. A supplementary hypothesis of Correns should also. be mentioned because, if it were true it would necessitate a very different conception of the interpretation of the inheritance of all endosperm characters. Correns supposed that purple $X$ non-purple always gave purple while non-purple $X$ purple sometimes gave non-purple and sometimes gave purple. He accounted for this by the supposition that since the endosperm nucleus is formed by the union of two maternal nuclei with one paternal nuclets, therefore the maternal endosperm characters 
would often dominate the paternal characters through the effect of the greater amount of maternal nuclear material. This is never the case and the fact is quite important. If Correns' supposition were true and the amount of nuclear matter determined the characters to be formed, no Mendelian segregation of endosperm characters and their recombination by chance matings could be demonstrated. Since all of our data shows it to be untrue, it follows that the quality and not the quantity of nuclear material is the important thing. The nucleus evidently regenerates or throws off material to come to its proper adjustment for the performance of its functions, and always in accordance with the quality of its structure.

In order to facilitate a consideration of the data, it will be presented in families. Each family comprises the progeny resulting from a particular cross. They are taken up in the order of increasing complexity.

\section{Family (24 and 54)}

This family includes all of the progeny of the cross of No. 24 white flint with No. 54 Black Mexican sweet, this being the variety with purple aleurone cells. The Black Mexican which furnished the pollen for this cross had proved true to the purple color for three generations, but pollen for the crosses of the different hybrid families came from several different ears. For this reason there is no certainty that the purple aleurone parent had the same gametic structure in each family. The data for the above family are reported in the sub-divisions of Tables 18 to 20 . In these tables there is no correlation of the purple and starchy characters, there being a simple $3: 1$ relationship of starchy and non-starchy seeds in both the case where purples and non-purples were obtained in $\mathrm{F}_{2}$ in the ratio of $3: 1$ and where they are obtained in the ratio of $9: 7$. We may therefore leave this character out of consideration and consider only the purple character.

The $\mathrm{F}_{1}$ seeds formed in the hybrid ear were all purple. Upon growing these seeds nine selfed ears were obtained with the ratios of purples to non-purples shown in Table 18. The purple color of these segregates was of full depth and covered the entire seed with one or two exceptions. These exceptions were zygotic variations due to heterozygosis and were quite 
different from the partial or light purples obtained in other families. In the latter case it was due to a transmissible gametic factor which will be explained later. Table 18 shows the ratio of purples to non-purples to be $3: 1$ in the case of seven ears and $9: 7$ approximately in the case of two ears. This immediately suggests the mono-hybrid ratio in the first case and a di-hybrid ratio in the second case. That this is the true state of affairs is shown by the behavior of the seeds of these ears in later generations. The progeny of the purple seeds of ear $(24 \times 54)-1$ (Table $18 \mathrm{a}$ ) were either pure purples or heterozygous purples segregating in the ratio of $3: 1$. The nonpurple seeds of the same ear (Table 18b) produced only nonpurples. The same ratio was obtained from purple seeds of ear No. (24 x 54)-11 shown in Table 18c.

The fact that $F_{3}$ extracted non-purple seeds continued to breed true is shown by the results of the $F_{4}$ generation shown in Table 18d. Extracted purple starchy seeds were also planted from Ear No. (24 x 54)-1-4 and ten selfed ears proved pure. Twenty-six ears were also obtained from the open field crop which were also pure purple, six being pure starchy and twenty heterozygous starchy.

These continued $3: 1$ ratios with purity of the extracted homozygote are what should be expected from the progeny of the mono-hybrid ears of Table 18 . If the $9: 7$ ratios given by ears No. 9 and No. 12 of Table 18 are true di-hybrid ratios resulting from the interaction of two factors both of which are necessary for the production of the purple color, one should expect in the $\mathrm{F}_{3}$ generation but one pure purple out of nine to occur and the remaining ears to be about $50 \%$ monohybrids with a $3: 1$ ratio and $50 \%$ di-hybrids with a $9: 7$ ratio. The progeny of ear No. (24 x 54)-12 (Tables $18 \mathrm{e}, 18 \mathrm{f}$ ) shows how nearly these expectations are confirmed. Out of a total of nineteen selfed ears two were pure purple, ten were monohybrids and seven were di-hybrids. It must be concluded therefore that the purple color is due to the action of the factor $\mathrm{P}$ upon another color factor $\mathrm{C}$, which is probably similar in nature to that which Bateson found in sweet peas. The gametic structure of No. 24, the non-purple variety, evidently differed in the ovules of the seeds of the original hybrid ear. Part of them lacked both $\mathrm{P}$ and $\mathrm{C}$ and gave a $9: 7$ ratio when crossed 
with the purple (C P), and part of them contained either $\mathrm{P}$ or $\mathrm{C}$ and therefore gave a mono-hybrid ratio when crossed with $\mathrm{C} \mathrm{P}$. If one supposes $\mathrm{C}$ to be contained by the non-purple in the first case then the result is as follows, $\mathrm{Cp} \times \mathrm{C} \mathrm{P}=\mathrm{C} \mathrm{C} \mathrm{P} \mathrm{p.}$ The gametes formed differ only in presence or absence of $\mathrm{P}$ and a simple mono-hybrid ratio is obtained in the $F_{2}$ generation. In the second case the cross is $\mathrm{c} \mathrm{p} \times \mathrm{C} \mathrm{P}=\mathrm{CcP}$, and the $\mathrm{F}_{2}$ populations have the formulae and ratios $9 \mathrm{C} \mathrm{P}: 3 \mathrm{C}: 3 \mathrm{P}: 1$ $\mathrm{c} p$, the first nine being purple and the last seven being white. This being the case the various non-purple seeds of $\mathrm{F}_{2}$ should prove true non-purples when selfed but should sometimes give purples when crossed. The non-purples exist in the following ratios:

$$
\begin{array}{lllll}
1 & \mathrm{C} & \mathrm{C} & \mathrm{p} & \mathrm{p} \\
2 & \mathrm{C} & \mathrm{c} & \mathrm{p} & \mathrm{p} \\
1 & \mathrm{c} & \mathrm{c} & \mathrm{P} & \mathrm{P} \\
2 & \mathrm{c} & \mathrm{c} & \mathrm{P} & \mathrm{p} \\
1 & \mathrm{c} & \mathrm{c} & \mathrm{p} & \mathrm{p}
\end{array}
$$

When crossed at random there are $7 \times 6=42$ possible combinations of which 24 should give all non-purple and 18 some purples. Of these eighteen ears 2 should be pure purples, 8 purples and non-purples in the ratio $1: 1$, and 8 purples and non-purples in the ratio of $1: 3$. In Tables $18 \mathrm{~g}$ and $18 \mathrm{~h}$ besides the selfed non-purples seven combinations of different nonpurples are shown, besides several reciprocal crosses. Of these one combination and its reciprocal gives a $1: 1$ ratio and one combination and its reciprocal gives a $1: 3$ ratio.

None of the $\mathrm{F}_{2}$ seeds of the selfed ears of this cross showed any seeds with red aleurone cells. Among the open field ears containing $\mathrm{F}_{2}$ seeds however, were noticed several seeds with aleurone cells of a peculiar blue color and several of the red color. Five selfed ears were obtained from the blue aleurone seeds (Table 19). Four of these ears gave 9 colored ( $P$ and $R$ ) seeds to 7 non-colored and one gave a simple mono-hybrid ratio in which no reds were found. The red seeds varied in shade until the darkest seemed to the eye to be purple. They could be separated accurately only by a microscopic examination of sections of the aleurone cells. The purples (the blue seeds proved to be exactly like ordinary purple seeds) occurred 
in greater numbers than the reds but the exact ratios were not determined in this family, because their parentage was not certain.

The red seeds found in the open field ears also proved to be heterozygous for red as shown by Table 20 . They gave simple $3: 1$ ratios except ear No. 1 which proved to be pure red although heterozygous for starchiness. $\mathrm{F}_{3}$ seeds were obtained from the red seeds of ear No. 8 as is shown in Tables 20a and 20b. It happened that in this small number five pure red ears were obtained and only three ears that were heterozygous and segregated in the ratio of $3: 1$.

Besides the ears shown in Table 20a, two ears from extracted red seeds were crossed with pure extracted non-purples (whites) of the $\mathrm{F}_{3}$ generation of cross $(24 \times 54)$. Ear No. 1 gave 125 purples and 123 non-purples. Ear No. 2 gave 108 purples and 124 non-purples. The red ears, the maternal parents of the crosses, were evidently heterozygous and therefore a $1: 1$ ratio was obtained. The non-purple which furnished the pollen must have carried the $\mathrm{P}$ factor which oxidized the seeds which otherwise would have become red to the purple color. This fact proves the epistatic nature of $\mathrm{P}$ over $\mathrm{R}$ and is a further proof of the di-hybrid nature of the purple color. Another ear crossed with non-purples of the same family as above gave all purple seeds. This ear evidently was homozygous for red and all of its seeds were oxidized to purple. Two other of these red ears were crossed with extracted purples of the same cross from which came the extracted whites used above. The seeds of the resulting ears were all purple. (See Plate 8a.)

Several red non-starchy seeds from ear ( $24 \times \mathrm{R}$ )-16-8 (Table $20 \mathrm{~b}$ ) were also planted. Three selfed ears resulted in two pure for red and one giving 248 reds to 60 non-reds, a $3: 1$ ratio. One ear of this lot was crossed with the same extracted purples used in crossing the starchy, red seeds resulting in an ear with all purple seeds. Another ear was crossed with one of the extracted non-purples used in crossing the red starchy seeds and resulted in an ear with 119 purple starchy and 124 nonpurple starchy seeds. The results from the non-starchy seeds of this family were therefore the same as those from the starchy seeds.

The non-red seeds from ( $24 \times \mathrm{R})-16-8$ both starchy and non- 
starchy bred true to the non-red character. Four crosses between individual ears of this lot were made and the resulting seeds were all non-red. This is the result which should be expected from an ear giving a mono-hybrid ratio as did ear (24 $\times$ R) -8 and shows that the purples resulting from the crosses between the non-purples coming from the $9: 7$ ratios were not accidental.

TABLE 18.

$\mathrm{F}_{2}$ SEEDS FROM CROSS OF NO. 24 WHITE FLINT $\mathrm{X}$ NO. 54 PURPLE ALEURONE NON-STARCHY.

Purple Aleurone Starchy (PS) Seeds Planted.

\begin{tabular}{|c|c|c|c|c|c|c|c|}
\hline Ear No. & PS & Ps & $\mathrm{pS}$ & ps & Total $\mathrm{P}$ & Total p & $\begin{array}{l}\text { Ratio } \\
\text { Approx. }\end{array}$ \\
\hline 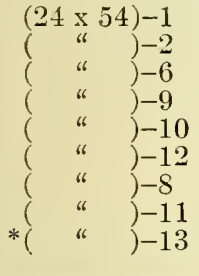 & $\begin{array}{r}207 \\
170 \\
197 \\
83 \\
166 \\
153 \\
159 \\
166 \\
205\end{array}$ & $\begin{array}{l}67 \\
54 \\
65 \\
44 \\
40 \\
40 \\
41 \\
55 \\
81\end{array}$ & $\begin{array}{r}67 \\
49 \\
59 \\
72 \\
46 \\
115 \\
41 \\
47 \\
59\end{array}$ & $\begin{array}{l}27 \\
19 \\
24 \\
25 \\
19 \\
40 \\
23 \\
22 \\
25\end{array}$ & $\begin{array}{l}274 \\
224 \\
262 \\
127 \\
206 \\
193 \\
200 \\
221 \\
286\end{array}$ & $\begin{array}{r}94 \\
68 \\
83 \\
97 \\
65 \\
155 \\
64 \\
84 \\
84\end{array}$ & $\begin{array}{l:l}3 & : 1 \\
3 & : 1 \\
3 & : 1 \\
9 & : 7 \\
3: & 1 \\
9 & : 7 \\
3: & 1 \\
3 & : 1 \\
3: & 1\end{array}$ \\
\hline
\end{tabular}

* All purple seeds were full dark purples except a few splashed purples from this ear.

TABLE 18A.

$\mathrm{F}_{3}$ SEEDS OF EAR 1 OF SAME CROSS AS TABLE 18.

Purple Aleurone Starchy (PS) Seeds Planted.

\begin{tabular}{|c|c|c|c|c|c|c|c|}
\hline Ear No. & PS & Ps & $\mathrm{pS}$ & ps & Total P & Total p & $\begin{array}{c}\text { Ratio } \\
\text { Approx. }\end{array}$ \\
\hline 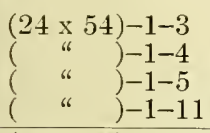 & $\begin{array}{l}\cdots \\
\cdots \\
\cdots\end{array}$ & $\begin{array}{l}\cdots \\
\cdots \\
\cdots\end{array}$ & $\begin{array}{l}\cdots \\
\cdots \\
\cdots \\
\cdots\end{array}$ & $\begin{array}{l}\cdots \\
\cdots \\
\cdots \\
\end{array}$ & $\begin{array}{r}144 \\
384 \\
96 \\
320 \\
\end{array}$ & $\begin{array}{l}\cdots \\
\cdots \\
\cdots\end{array}$ & $\begin{array}{l}\text { Pure P } \\
\text { Pure P } \\
\text { Pure P } \\
\text { Pure P }\end{array}$ \\
\hline 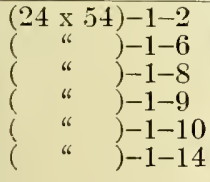 & $\begin{array}{r}161 \\
171 \\
180 \\
79 \\
255 \\
195\end{array}$ & $\begin{array}{l}55 \\
56 \\
71 \\
29 \\
\cdots\end{array}$ & $\begin{array}{l}46 \\
52 \\
55 \\
27 \\
91 \\
80\end{array}$ & $\begin{array}{r}13 \\
19 \\
19 \\
7 \\
\cdots \\
\cdots\end{array}$ & $\begin{array}{l}216 \\
227 \\
251 \\
108 \\
255 \\
195\end{array}$ & $\begin{array}{l}59 \\
71 \\
74 \\
34 \\
91 \\
80\end{array}$ & 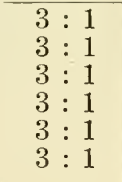 \\
\hline Total & & $\cdots$ & $\cdots$ & $\cdots$ & 1251 & 410 & \\
\hline
\end{tabular}


TABLE 18B.

$F_{3}$ SEEDS OF EAR 1 OF SAME CROSS AS TABle 18.

Non-Purple Aleurone Starchy ( $p s)$ Seeds Planted.

\begin{tabular}{|c|c|c|c|}
\hline Ear No. & $\mathrm{P}$ & $p$ & Ratio Approx. \\
\hline 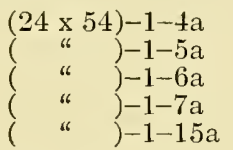 & $\begin{array}{l}\ldots \\
\cdots \\
\cdots \\
\cdots\end{array}$ & $\begin{array}{l}208 \\
312 \\
362 \\
320 \\
296\end{array}$ & $\begin{array}{c}\text { Pure white } \\
\text { " } \\
\text { " } \\
\text { " }\end{array}$ \\
\hline
\end{tabular}

TABLE 18C.

F 3 SEEDS OF EAR 11 (TABLE 18A) OF SAME CROSS AS TABLE 18.

Purple Aleurone Non-Starchy (Ps) Seeds Planted.

\begin{tabular}{|c|c|c|c|}
\hline Ear No. & Ps & ps & Ratio Approx. \\
\hline 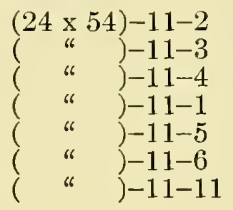 & $\begin{array}{r}312 \\
368 \\
280 \\
240 \\
197 \\
205 \\
40\end{array}$ & $\begin{array}{l}\cdots \\
\cdots \\
82 \\
78 \\
52 \\
12\end{array}$ & $\begin{array}{c}\text { Pure } \mathrm{P} \\
\text { " } \\
3: 1 \\
3: 1 \\
3: 1 \\
3: 1\end{array}$ \\
\hline Total Het. & 682 & 224 & \\
\hline
\end{tabular}

TABLE $18 \mathrm{D}$.

F $_{4}$ SEEDS OF EAR ( $\left.24 \times 54\right)-1-6$ (EXTRACTED PS. TABLE 18B) OF SAME CROSS AS TABLE 18.

Non-Purple Starchy (ps) Seeds Planted.

\begin{tabular}{|c|c|c|}
\hline Ear No. & ps & PS \\
\hline 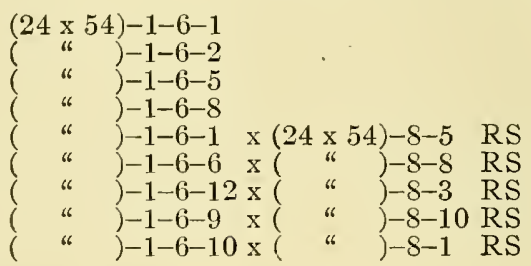 & $\begin{array}{l}\text { All } \\
" \\
" \\
\ldots \\
\cdots \\
\cdots \\
\cdots\end{array}$ & $\begin{array}{c}\text { A11 } \\
\text { " } \\
\text { " }\end{array}$ \\
\hline
\end{tabular}

Open-field crop all white. 

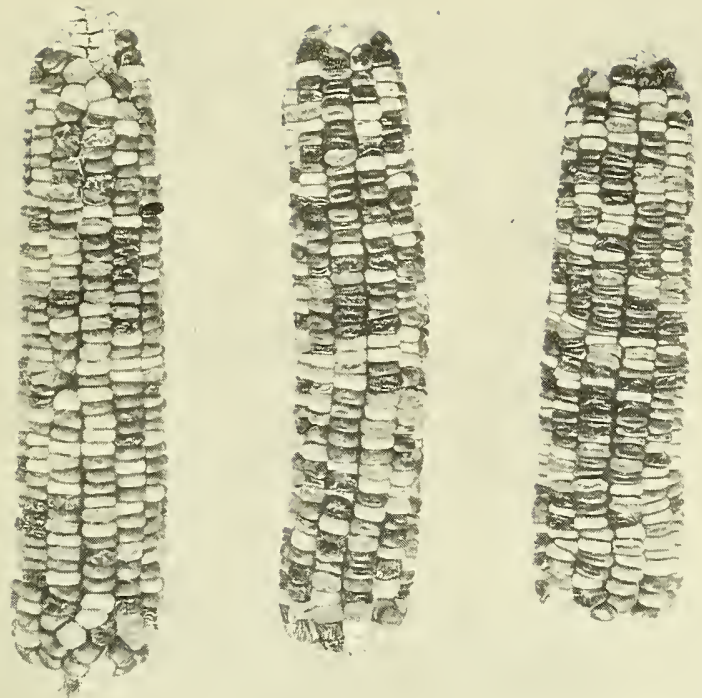

a. Flint and dent segregates from $\mathrm{F}_{2}$ of cross $8 \mathrm{x}_{54}$. Flint character carried by No. 54 .

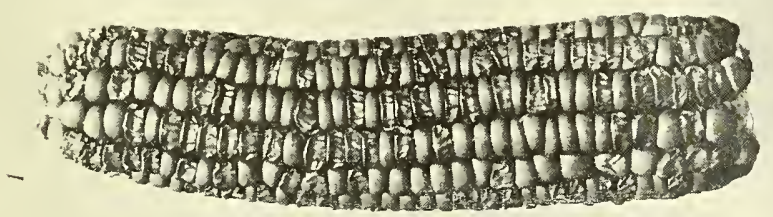

b. F3 types from cross $8 \times 54$. I. Pure extracted purple (PPCC). 2. Pure extracted parti-colored ((PPcc). 3. Pure extracted non-purple ( $\mathrm{ppCC}$ or $\mathrm{ppcc}$ ). 

TABLE $18 \mathrm{E}$.

Fs SEEdS OF EAR ( $24 \times 54)-12$ OF SAME CROSS AS TABLE 18.

Purple Starchy (PS) Seeds Planted.

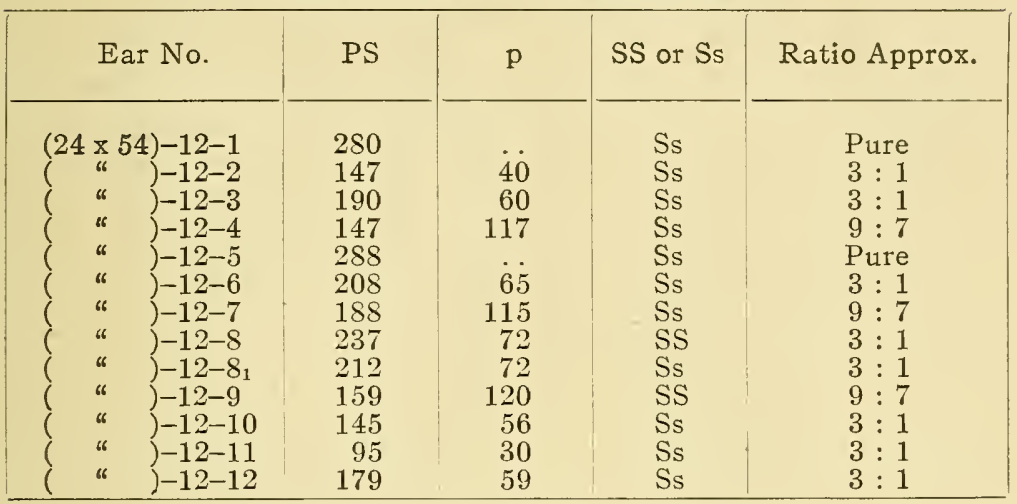

TABLE $18 \mathrm{~F}$.

$F_{3}$ SEeds of EAR $(24 \times 54)-12$ of SAME CRoss as table 18. Purple Non-Starchy (Ps) Seeds Planted.

\begin{tabular}{|c|c|c|c|}
\hline Ear No. & $\mathrm{P}$ & $\mathrm{p}$ & Ratio Approx. \\
\hline 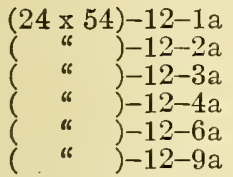 & $\begin{array}{r}160 \\
186 \\
137 \\
97 \\
109 \\
123\end{array}$ & $\begin{array}{r}53 \\
64 \\
115 \\
65 \\
80 \\
120\end{array}$ & $\begin{array}{l}3: 1 \\
3: 1 \\
9: 7 \\
9: 7 \\
9: 7 \\
9: 7\end{array}$ \\
\hline
\end{tabular}

TABLE $18 \mathrm{G}$.

Fs SEEDS OF EAR ( $24 \times 54)-12$ OF SAME CROSS AS TABLE 18. Non-purple Starchy $(p S)$ Seeds Planted.

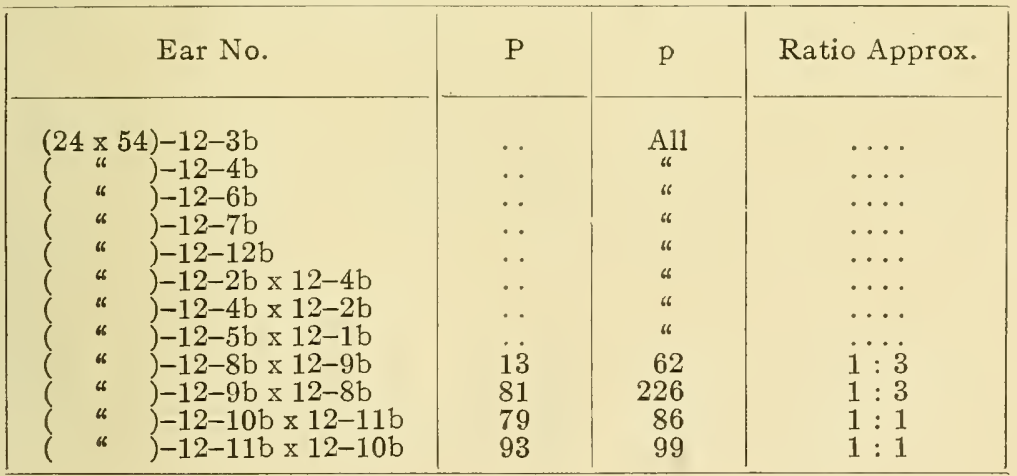


TABLE $18 \mathrm{H}$.

F 3 SEEDS OF EAR $(24 \times 54)-12$ OF SAME CROSS AS TABLE 18.

Non-Purple Non-Starchy ( $p s)$ Seeds Planted.

\begin{tabular}{|c|c|c|c|}
\hline Ear No. & $\mathrm{P}$ & $\mathrm{p}$ & \\
\hline 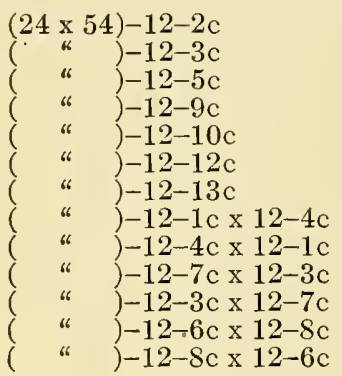 & $\begin{array}{l}\cdots \\
\cdots \\
\cdots \\
\cdots \\
\cdots \\
\cdots \\
\cdots \\
\cdots \\
\cdots\end{array}$ & $\begin{array}{l}\text { All } \\
" \\
" \\
" \\
" \\
" \\
" \\
" \\
" \\
" \\
"\end{array}$ & - \\
\hline
\end{tabular}

TABLE 19.

F $_{2}$ SEEDS FROM CROSS BETWEEN NO. 24 , White FLINT AND No. XP PURPLE ALEURONE.

Purple Aleurone Starchy (PS) Seeds Planted.

\begin{tabular}{|c|c|c|c|c|}
\hline Ear No. & $P+R$ & $\mathrm{p}$ & $\begin{array}{c}\text { Ratio } \\
\text { Approx. }\end{array}$ & Notes \\
\hline$(24 \times \mathrm{P})-16-2$ & 287 & 192 & $9: 7$ & \multirow{5}{*}{$\begin{array}{l}\text { SS: some seeds } \\
\text { red } \\
\text { ss: few P's } \\
\text { strongly colored } \\
\text { ss: few P's } \\
\text { strongly colored } \\
\text { Ss: } 84 \text { P's } \\
\text { lighter at cap } \\
\text { ss: } 69 \text { P's } \\
\text { lighter at cap }\end{array}$} \\
\hline ( “ ) $)-16-5$ & 141 & 117 & $9: 7$ & \\
\hline ( “ $)-16-6$ & 165 & 115 & $9: 7$ & \\
\hline$($ ( " $)-16-7$ & 278 & 89 & $3: 1$ & \\
\hline ( “ ) $)-16-8$ & 253 & 193 & $9: 7$ & \\
\hline
\end{tabular}

TABLE 20.

F2 SEEDS FROM CROSS BETWEEN NO. 24 WHITE FLINT AND NO. XR RED ALEURONE.

Red Aleurone Starchy (RS) Seeds Planted.

\begin{tabular}{|c|c|c|c|c|c|c|c|}
\hline Ear No. & RS & Rs & $\mathrm{rS}$ & rs & Total R & Total r & $\begin{array}{c}\text { Ratio } \\
\text { Approx. }\end{array}$ \\
\hline 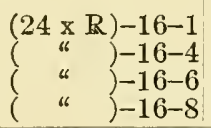 & $\begin{array}{r}160 \\
26 \\
140 \\
195\end{array}$ & $\begin{array}{l}52 \\
12 \\
43 \\
73\end{array}$ & $\begin{array}{l}13 \\
53 \\
41\end{array}$ & $\begin{array}{r}3 \\
22 \\
19\end{array}$ & $\begin{array}{r}212 \\
38 \\
183 \\
268 \\
\end{array}$ & $\begin{array}{l}16 \\
75 \\
60\end{array}$ & $\begin{array}{c}\text { Pure red } \\
3: 1 \\
3: 1 \\
3: 1\end{array}$ \\
\hline
\end{tabular}


TABLE 20A.

F 3 SEEDS OF EAR $(24 \times \mathrm{R})-16-8$ OF SAME CROSS AS TABLE 20.

Red Aleurone Starchy (RS) Seeds Planted.

\begin{tabular}{|c|c|c|c|}
\hline Ear No. & $\mathrm{R}$ & $r$ & Ratio Approx. \\
\hline $\begin{array}{r}(24 \times \mathrm{R})-16-8-3 \\
\text { (“) }-16-8-4 \\
(\text { “ })-16-8-5 \\
\text { (" })-16-8-6 \\
\text { " })-16-8-8\end{array}$ & $\begin{array}{r}360 \\
161 \\
60 \\
172 \\
320\end{array}$ & $\begin{array}{l}\dot{6} \dot{5} \\
\dot{5} \dot{3} \\
\cdots\end{array}$ & $\begin{array}{l}\text { Pure red } \\
3: 1 \\
\text { Pure red } \\
3: 1 \\
\text { Pure red }\end{array}$ \\
\hline
\end{tabular}

TABLE $20 \mathrm{~B}$.

F $_{3}$ SEEDS OF EAR $(24 \times \mathrm{R})-16-8$ OF SAME CROSS AS TABLE 20. Red Aleurone Non-Starchy (Rs) Seeds Planted.

\begin{tabular}{|c|c|c|c|}
\hline Ear No. & $\mathrm{R}$ & $\mathrm{r}$ & Ratio Approx. \\
\hline $\begin{array}{r}(24 \times \mathrm{R})-16-8-1 \mathrm{a} \\
\text { " } \quad)-16-8-2 \mathrm{a} \\
\text { " } \quad)-16-8-3 \mathrm{a}\end{array}$ & $\begin{array}{l}160 \\
248 \\
280\end{array}$ & $\begin{array}{l}60 \\
\ldots\end{array}$ & $\begin{array}{c}\text { Pure red } \\
3: 1 \\
\text { Pure red }\end{array}$ \\
\hline
\end{tabular}

\section{Family ( $8 \times 54)$}

The $F_{1}$ Xenia seeds of the cross between No. 8 non-purple dent starchy and No. 54 purple non-starchy were all purple in color. Four selfed ears were obtained when these hybrid seeds were planted. The segregation of the $\mathrm{F}_{2}$ seeds is shown in Table 21. A new phenomenon of peculiar interest appeared in this family. A certain number of seeds were solid dark purple, others were splashed dark purple, others were a very faint purple and have been called particolored, while still others were without the purple color. The splashed dark purples were seeds that had a break in the purple color; that is the purple color was dark but appeared in patches. These splashed purples are found in all of the purple-non-purple crosses except the family * just described. It seems evident then that they are due to the interaction of characters which

\footnotetext{
* Only one or two splashed purples were ever found in family (24 x 54).
} 
happen to be absent from the ( $24 \times 54)$ family; but at the same time they are zygotic variations which are not inherited, for their progeny are exactly like the progeny of the dark purple seeds. Further, these patches are not in a regular pattern nor does the selection of seeds of this nature have the slightest tendency to fix the phenomenon as a separate character. There is reason for believing however that no homozygous purples (C C P P) are ever of this nature, and that the splashing is simply due to incomplete dominance, but caused by a factor or factors brought in by the non-purple parent.

The fact that particolored or very light purples which transmitted the character also appeared in this family made it seem probable that a new character had appeared, making the family a tri-hybrid. But this is not the simplest interpretation. We have seen in the other family that the behavior of purple is best interpreted as the interaction of two factors $\mathrm{C}$ and $\mathrm{P}$. In this family the hypothesis that either $\mathrm{Cp}$ or $\mathrm{cP}$ seeds are not pure whites but very light purples is supported by all of the data. At first sight it seems more reasonable that they should have the formula $\mathrm{Cp}$. If in accordance with older interpretations of color inheritance, the purple color is formed by an enzyme, $\mathrm{P}$ acting upon a chromogen $\mathrm{C}$ it is more reasonable to suppose that in the presence of the chromogen an exceedingly small amount of the enzyme might give rise to the particolored seeds, than it is to believe that the normal amount of enzyme would form the purple color with a trace of chromogen. The reason for this statement rests upon the well known fact that enzymes are organic catalysers and can accelerate reactions involving quantities very disproportionate to their own amount. There is an objection to this interpretation, however, for when particolored seeds are crossed with those having red aleurone cells and which therefore have the gametic formula $\mathrm{R} C$, they invariably give purples. This proves that the gametic formula of the particolored seeds is $\mathrm{c} \mathrm{P}$ and they are so designated in the tables.

The suggestive work of Miss Wheldale (:09,:09a, :10) in correlating the results of biological chemistry with those of genetics, has made it very probable that a basic chromogen is present in all flowers which are able to form a sap color, and that the complexities of color inheritance may be referred to 

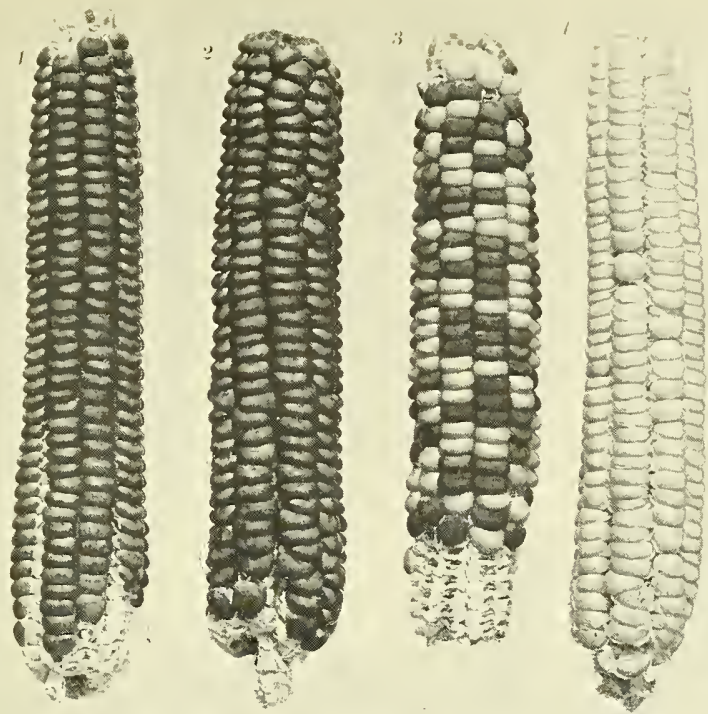

a. I. Pure purple aleurone resulting from crossing pure extracted red aleurone with pure purple. 2. Same result from crossing pure extracted red aleurone with colorless aleurone. 3. Seeds half purple resulting from crossing heterozygous red aleurone with colorless aleurone. 4. Result from selfing the male parent of 3 .
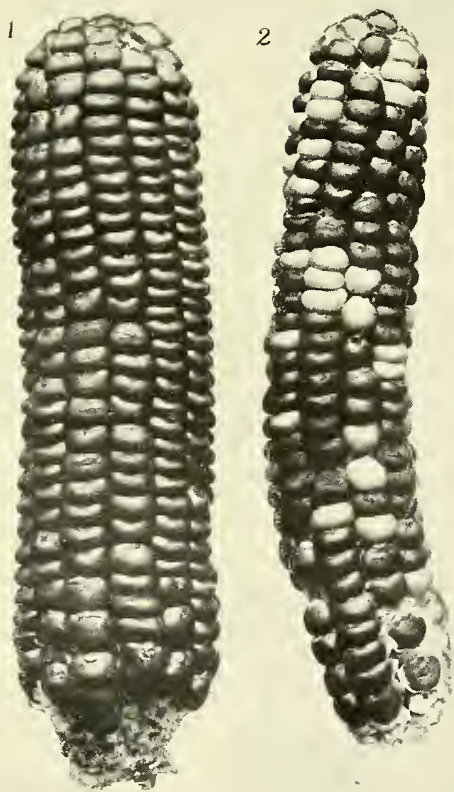

b. I. $(24 \times 54) 8-3$ pure extracted red aleurone. 2. (24x54)-8-6 heterozygous red aleurone. Cut does not show color value when compared with Fig $a$.

Inheritance of Aleurone Color. 

the dual nature of the oxydases necessary for the formation of the color compounds. It is quite likely that the color in the aleurone cells of maize is similar in nature to flower color; and, as we fully agree with Miss Whedale's conclusions, none of our factors $\mathrm{C}, \mathrm{R}$ and $\mathrm{P}$ are to be regarded as chromogens. The argument above is in agreement with this viewpoint. If one wishes to denote a chromogen, the addition of an $\mathrm{X}$ to represent it, common to both families, makes no difference in the interpretation of the results.

If we are dealing with a di-hybrid ratio, one pure purple ear out of every nine should be expected in the $F_{2}$ generation. Tables 21a and $21 \mathrm{~b}$ show that one such ear was obtained out of seventeen ears. If the total purple seeds and the sum of the particolored and white seeds is considered in Tables 21, 21a and $21 \mathrm{~b}$ a close approximation to a $9: 7$ ratio is obtained. If the particolored seeds could in every instance be distinguished from whites the ratio of purples to particoloreds to whites should be $9: 3: 4$. It will be noticed however that in the ears from which this ratio should be expected there is generally an excess of whites. This is explained by the fact that particoloreds especially when non-starchy are not always distinguishable from whites. The last two ears shown in Table 21d are in fact ears grown from seeds which were originally classed as whites. If this hypothesis in regard to the particolored is true, one should expect the purple $F_{2}$ seeds to give in the $F_{3}$ generation, one ear pure purple, two ears showing segregates of purple and particolored in the ratio of $3: 1$, two ears showing segregates of purple and non-purple in the ratio of $3: 1$, and four ears showing purples, particolored and non-purples in the ratio $9: 3: 4$. Among the ears received (Tables 21a, 21b) there were one of the first class, six of the second class, three of the third class and seven of the fourth class.

Tables $21 \mathrm{c}$ and $21 \mathrm{~d}$ show the results from growing the particolored seeds of the same ear, No. $(8 \times 54)-1$. One ear should be pure particolored to two showing segregates of particolored and non-purple in the ratio of $3: 1$. Out of the fifteen ears obtained three were evidently of the first class and twelve of the second class.

In all of these tables the progeny of hybrid starchy seeds segregated normally.

Seeds classified as non-purples were also planted from this 
same ear No. $(8 \times 54)-1$. The thirteen selfed ears resulting as progeny of starchy seeds all proved to be non-purple. Two particolored ears, however, appeared in the eight selfed ears resulting from planting non-purple, non-starchy seeds. This showed that there was more difficulty in classifying the nonstarchy non-purples than in classifying starchy non-purples. Non-purple seeds planted from ear No. $(8 \times 54)-5$ also gave a few particolored progeny.

Four thousand seeds from tested whites of the $\mathrm{F}_{3}$ seeds were planted in an isolated plot the next season and were allowed to inter-cross naturally. If we were dealing with di-hybrid nonpurples in this case, such inter-crossing should give some purples, such as were obtained in the $(24 \times 54)$ family. The resulting crop of this large number of plants however were all true nonpurples, proving that we were dealing with non-purples with formulæ either $\mathrm{CC}, \mathrm{Cc}$ or cc. Further proof of the constitution of the particolored is shown in the following facts. No particoloreds ever gave full purples. Furthermore, pure extracted particoloreds (c c P P) from ear No. (8 x 54)-1-13b of Table 21c were grown for another generation and their gametic structure tested by various crosses. Several of these ears were selfed and all proved to be pure particoloreds (ccPP). Three different ears were crossed with pure extracted purples from progeny of ear No. $(24 \times 54)-1-4$. As would be expected all of the seeds were purple. Two of the ears however had a decided reddish purple color while one was dark purple without the reddish tint. Four ears were crossed with extracted red seeds (RRCC). All produced purple seeds. Nine ears were crossed with plants of the progeny of the non-purples of ear No. $(24 \times 54)-12$. It will be remembered that this ear gave a ratio of nine purples to seven non-purples. The seven non-purples would have the following formulæ: 1 PPcc, 2 Ppcc, 1 ppCC, 2 ppCc, 1 ppcc. Crossing the particoloreds at random with pollen of individual plants of this lot should give on the average one ear with all purple seeds when pollinated by ppCC, two ears with $50 \%$ purple and $50 \%$ particolored when pollinated by $\mathrm{ppCc}$, four ears pure particolored when pollinated by PPcc, Ppcc or ppcc. Nine ears were obtained of which one had all purple seeds, three had $50 \%$ purple and $50 \%$ particolored with a total of 308 purple seeds to 294 particolored seeds and five were all 
particolored. It should be mentioned, however, that the particolored seeds obtained by crosses with the whites of this (24 x 54) family in which the (ccPP) seeds were not particolored, gave seeds which averaged much lighter in appearance than the pure particolored. In other words particoloreds crossed with whites of other families show imperfect dominance of particolored. Some gene common to both parents of the $(8 \times 54)$ family, therefore, accounts for the production of the color.

These two families differed in no other endosperm character except presence and absence of starchiness. No correlation of any kind was observed between these two allelomorphic pairs.

TABLE $21^{*}$.

F2 SEEDS FROM CROSS BETWEEN NO. 8 NON-PURPLE DENT STARCHY AND NO. 54 PURPLE NON-STARCHY.

Purple Seeds Planted.

\begin{tabular}{|c|c|c|c|c|c|}
\hline Ear No. & $\mathrm{CP}$ & $\mathrm{cP}$ & Cp or $\mathrm{cp}$ & $\begin{array}{l}\text { Total } \\
\text { Purple }\end{array}$ & $\begin{array}{c}\text { Total } \\
\text { Non-Purple }\end{array}$ \\
\hline 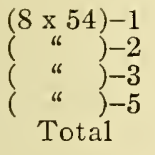 & $\begin{array}{l}297 \\
230 \\
\ldots \\
\ldots \\
\ldots\end{array}$ & $\begin{array}{l}75 \\
75 \\
\cdots \\
\cdots \\
\cdots\end{array}$ & $\begin{array}{l}146 \\
172 \\
\cdots \\
\cdots\end{array}$ & $\begin{array}{r}297 \\
230 \\
302 \\
270 \\
1099\end{array}$ & $\begin{array}{l}221 \\
247 \\
239 \\
229 \\
936\end{array}$ \\
\hline
\end{tabular}

* There were 1,514 starchy and 521 non-starchy seeds. 
TABLE 21A*.

$F_{3}$ SEEDS OF EAR NO. ( $\left.\times 54\right)-1$ OF TABLE 21.

Purple Starchy (PCS) Seeds Planted.

\begin{tabular}{|c|c|c|c|c|c|c|}
\hline Ear No. & CP & $c P$ & Cp or $\mathrm{cp}$ & $\begin{array}{l}\text { Total } \\
\text { Purple }\end{array}$ & $\begin{array}{c}\text { Total } \\
\text { Non-Pur. }\end{array}$ & $\begin{array}{l}\text { Starch- } \\
\text { iness }\end{array}$ \\
\hline 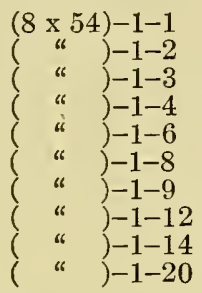 & $\begin{array}{r}233 \\
16 \\
238 \\
321 \\
239 \\
223 \\
285 \\
160 \\
126\end{array}$ & $\begin{array}{r}70 \\
6 \\
69 \\
86 \\
106 \\
106 \\
65 \\
33 \\
54\end{array}$ & $\begin{array}{r}7 \\
\ldots \\
\ldots \\
9 \\
93 \\
95 \\
66 \\
111 \\
\ldots\end{array}$ & $\begin{array}{r}233 \\
16 \\
238 \\
321 \\
312 \\
239 \\
223 \\
285 \\
160 \\
126\end{array}$ & $\begin{array}{r}70 \\
13 \\
69 \\
86 \\
199 \\
160 \\
66 \\
144 \\
54\end{array}$ & $\begin{array}{l}\text { SS } \\
\text { Ss } \\
\text { Ss } \\
\text { Ss } \\
\text { Ss } \\
\text { Ss } \\
\text { SS } \\
\text { SS } \\
\text { Ss } \\
\text { SS }\end{array}$ \\
\hline
\end{tabular}

* There were 1,362 starchy and 435 non-starchy seeds in the Ss ears.

TABLE $21 \mathrm{~B}$.

F 3 SEEDS OF EAR NO. $(8 \times 54)-1$ OF TABLE 21.

Purple Non-Starchy (PCs) Seeds Planted.

\begin{tabular}{|c|c|c|c|c|c|}
\hline Ear No. & $\mathrm{CP}$ & $\mathrm{cP}$ & $\mathrm{Cp}$ or $\mathrm{cp}$ & $\begin{array}{l}\text { Total } \\
\text { Purple }\end{array}$ & $\begin{array}{c}\text { Total } \\
\text { Non-Purple }\end{array}$ \\
\hline$\left\{\begin{array}{c}(8 \times 54)-1-1 a \\
\text { “ })-1-3 a \\
“ \quad)-1-4 a \\
“ \quad)-1-6 a \\
\text { “ })-1-10 a \\
\text { “ })-1-11 a\end{array}\right.$ & $\begin{array}{r}229 \\
236 \\
295 \\
260 \\
86 \\
239 \\
223\end{array}$ & $\begin{array}{l}44 \\
\dot{86} \\
20 \\
89 \\
55\end{array}$ & $\begin{array}{r}79 \\
116 \\
93 \\
\ddot{3} \dot{8} \\
\ddot{8} \dot{8}\end{array}$ & $\begin{array}{r}229 \\
236 \\
295 \\
260 \\
86 \\
239 \\
223\end{array}$ & $\begin{array}{r}79 \\
160 \\
93 \\
86 \\
58 \\
89 \\
143\end{array}$ \\
\hline
\end{tabular}


INHERITANCE OF ALEURONE COLOR.

TABLE $21 C^{*}$.

F, SEEDS OF EAR NO. $(8 \times 54)-1$ OF TABLE 21.

Particolored Starchy (cPS) Seeds Planted.

\begin{tabular}{|c|c|c|c|}
\hline Ear No. & $\mathrm{cP}$ & $\mathrm{Cp}$ or $\mathrm{cp}$ & Starchiness \\
\hline 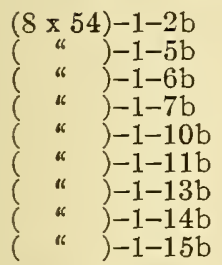 & $\begin{array}{l}322 \\
402 \\
115 \\
150 \\
386 \\
254 \\
427 \\
262 \\
256\end{array}$ & $\begin{array}{r}99 \\
70 \\
64 \\
\ddot{92} \\
1 \dot{1} \dot{2} \\
133\end{array}$ & $\begin{array}{l}\text { SS } \\
\text { SS } \\
\text { Ss } \\
\text { SS } \\
\text { SS } \\
\text { Ss } \\
\text { Ss } \\
\text { SS } \\
\text { Ss }\end{array}$ \\
\hline
\end{tabular}

* There were 1,026 starchy and 321 non-starchy seeds in the Ss ears.

TABLE $21 \mathrm{D}$.

F 3 SEEDS OF EAR NO. $(8 \times 54)-1$ OF TABLE 21.

Particolored Non-Starchy ( $c P s$ ) Seeds Planted.

\begin{tabular}{|c|c|c|}
\hline Ear No. & $\mathrm{cP}$ & $\mathrm{Cp}$ or $\mathrm{cp}$ \\
\hline $\begin{array}{c}(8 \times 54)-1-2 c \\
(\text { “ })-1-3 c \\
(" \quad)-1-4 c \\
\text { " })-1-5 c \\
\text { " })-1-1 w \\
\text { " })-1-12 w\end{array}$ & $\begin{array}{l}149 \\
364 \\
168 \\
123 \\
230 \\
131\end{array}$ & $\begin{array}{r}110 \\
\because \ddot{89} \\
59 \\
115 \\
99\end{array}$ \\
\hline
\end{tabular}




\section{Family (15 x 54).}

This family brings in a third allelomorphic pair namely presence and absence of yellow in the endosperm. No. 15 is Longfellow pure for the presence of starchiness and for a single yellow factor. This cross was made to find out whether there were further differences in the behavior of the purple factor when crossed with other non-purples, and it was thought that the yellow endosperm might prove a disturbing factor. This is not the case for the $\mathrm{F}_{1}$ seeds were all purple with the exception that a few splashed purples, which behaved like the normal hybrid purples, also occurred in this family. Eight ears were obtained by growing the $F_{1}$ seeds, and starchiness and yellowness were found to segregate in a normal manner. There was a total of $1765 \mathrm{Y}$ to $604 \mathrm{y}$ and $1746 \mathrm{~S}$ to $623 \mathrm{~s}$ seeds.

There is only one fact of particular interest in this family. Table 22 shows the eight selfed $F_{1}$ ears grown from the purplestarchy hybrid seeds, containing the $\mathrm{F}_{2}$ seeds. It will be noticed that in the table, six of the ears appear to show monohybrid segregation and two of them di-hybrid segregation. This is not really the case. All of the ears giving the $3: 1$ ratio were also di-hybrids. The figures in the column headed "Purple" contained purples, splashed purples and particoloreds. Some unknown cause produces many seeds in this cross that are heavily splashed with purple. These always behaved as heterozygous purples, although the heterozygous purples were not always splashed, but were generally full colored purples. The particoloreds are seeds containing the $\mathrm{P}$ factor but lacking the $\mathrm{C}$ factor as in cross $(8 \times 54)$. The difficulty here was to distinguish by sight all of the splashed purples (P C) from the particoloreds $(\mathrm{Pc})$. They were all included in the table therefore as "Purples."

The ears ( $15 \times 54)-2$ and ( $15 \times 54)-3$ did not show particolored seeds, but that the same gametes were concerned is shown by the following data. Theoretically, if ear (15 x 54)-2 is a di-hybrid the purple seeds when selfed should give 1 ear with all purple seeds, 4 ears with 3 purple seeds to 1 nonpurple seed and 4 ears with 9 purple seeds to 7 non-purple seeds. Twelve selfed ears were obtained in the next generation. One had all purple seeds. Seven had purple and non-purple seeds 
at the ratio of $9: 7$, there being a total of 1035 purple and 763 non-purple seeds. Four had purple and non-purple seeds at the ratio of $3: 1$, there being a total of 480 purple to 162 nonpurple seeds. It should be remarked that in two of these ears a few very light particolored seeds were found, showing that the seemingly aberrant ear ( $15 \times 54)-2$ had a slight tendency to throw particoloreds like the other ears of the family. There is also some evidence that microscopical examination of the embryo stem would show particoloreds in the ordinary ratio.

The non-purples from this ear were also grown. Eighteen selfed ears were obtained. All of them were true to non-purple. Two of them had a few particolored seeds ( 6 in one case and 14 in another). These seeds might possibly have been produced by the contamination of a few grains of foreign pollen, but they might very well be white seeds of the formula $\mathrm{Pc}$ which were showing the racial tendency to a slight production of pigment (i. e. particoloreds).

Non-purples from the other aberrant ear No. (15 x 54)-3 were also grown and when selfed gave only non-purples. Three intercrosses and their reciprocals were made between different plants from this lot. It happened that no purple seeds were obtained as should be expected in a portion of the cases, as explained before. That the non-purples did differ in composition among themselves was shown however by crossing a pure particolored (PPcc) of the $(8 \times 54)$ family with pollen from one of our nonpurples, ear No. $(15 \times 54)-3-10$. The ear resulting from the cross had 179 purple seeds and 168 particolored seeds. This $1: 1$ ratio could only have been obtained from a non-purple heterozygous for $\mathrm{C}(\mathrm{Cc})$. As a non-purple with the formula Cc could only have been obtained from a di-hybrid cross, it is proved that all of the ears of this family were di-hybrids. The complete gametic structure of the hybrid seeds, speaking of endosperm characters only, is $\mathrm{YySsCcPp}$. 
TABLE 22.

F2 SEEDS FROM CROSS BETWEEN NO. 15 NON-PURPLE YELLOW STARCHY AND NO. 54 PURPLE NON-STARCHY.

Purple Seeds Planted.

\begin{tabular}{|c|c|c|c|}
\hline Ear No. & Purple* & Non-Purple & Ratio Approx. \\
\hline 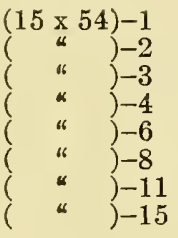 & $\begin{array}{l}138 \\
203 \\
109 \\
250 \\
201 \\
307 \\
254 \\
239\end{array}$ & $\begin{array}{r}45 \\
135 \\
83 \\
84 \\
61 \\
91 \\
93 \\
76\end{array}$ & $\begin{aligned} 9+3 & : 3+1 \\
9 & : 7 \\
9 & : 7 \\
9+3 & : 3+1 \\
9+3 & : 3+1 \\
9+3 & : 3+1 \\
9+3 & : 3+1 \\
9+3 & : 3+1\end{aligned}$ \\
\hline
\end{tabular}

* Every ear except ears 2 and 3 contained splashed purples which act as heterozygous purples in inheritance and particoloreds which act as if they had the gametic formula (cP), but the intergradations were so gradual that it was impossible to make an accurate classification. The matter is not worth mentioning here except for the reason that persons who had not had experience with the behavior of purple and non-purple crosses in other families would be utterly at loss for a classification and it would be necessary for them to grow each individual seed for another generation to determine its gametic formula.

\section{Family (18 x 58)}

No. 18, the female parent of this cross is a small non-purple sugar maize which usually has twelve rows. The purple parent is a small eight-rowed flint. The $\mathrm{F}_{1}$ seeds were purple. Only one selfed ear was obtained from the $F_{1}$ plants through an unfortunate loss of pollen. The segregation of $\mathrm{F}_{2}$ seeds is shown in Table 23. The hybrid"seeds have the gametic formula Pp RrCc. The seeds with the formula $P R$ and probably also with the formula $\mathrm{P}$ give particoloreds or very light purples as they did in family $8 \times 54$. They were very light however and the 138 seeds classed as whites.or non-purples contained some particoloreds as is shown in the $\mathrm{F}_{3}$ generation. Theoretically in the $\mathrm{F}_{2}$ generation there should be 36 purples $(27 \mathrm{PRC}+9 \mathrm{PC})$, 9 reds (RC), 12 particoloreds $(9 \mathrm{PR}+3 \mathrm{P})$ and 7 whites $(3 \mathrm{C}+3$ 

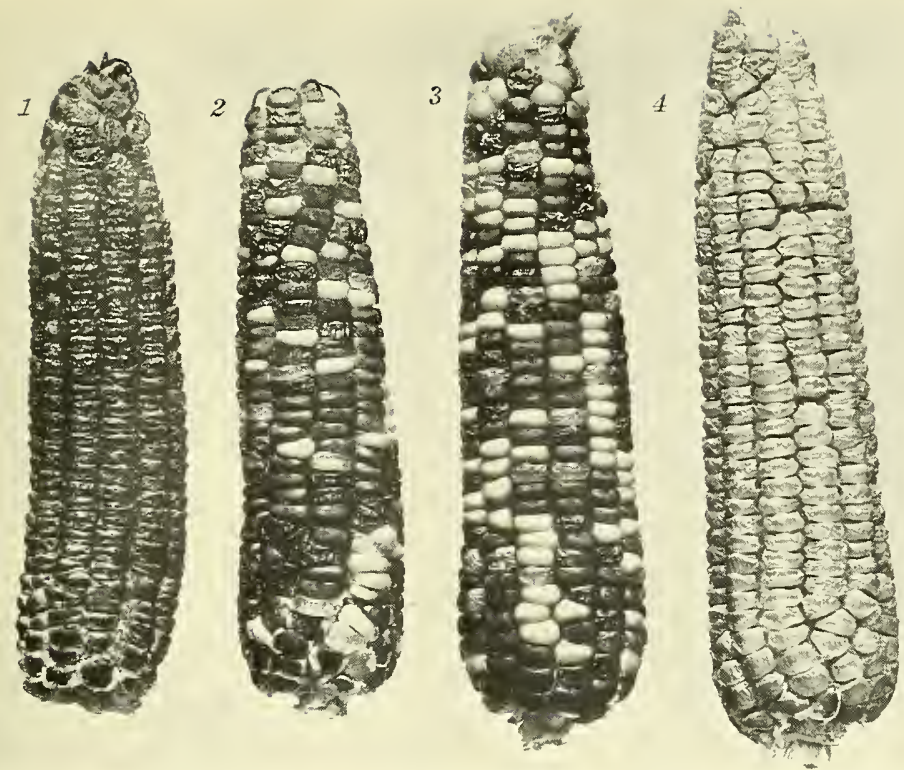

a. F3 color segregates from cross ( $\left.8 x_{5} 8\right)$. I. Pure extracted purple. 2. 3. Ears from heterozygous plants. +. Pure extracted inon-purple.

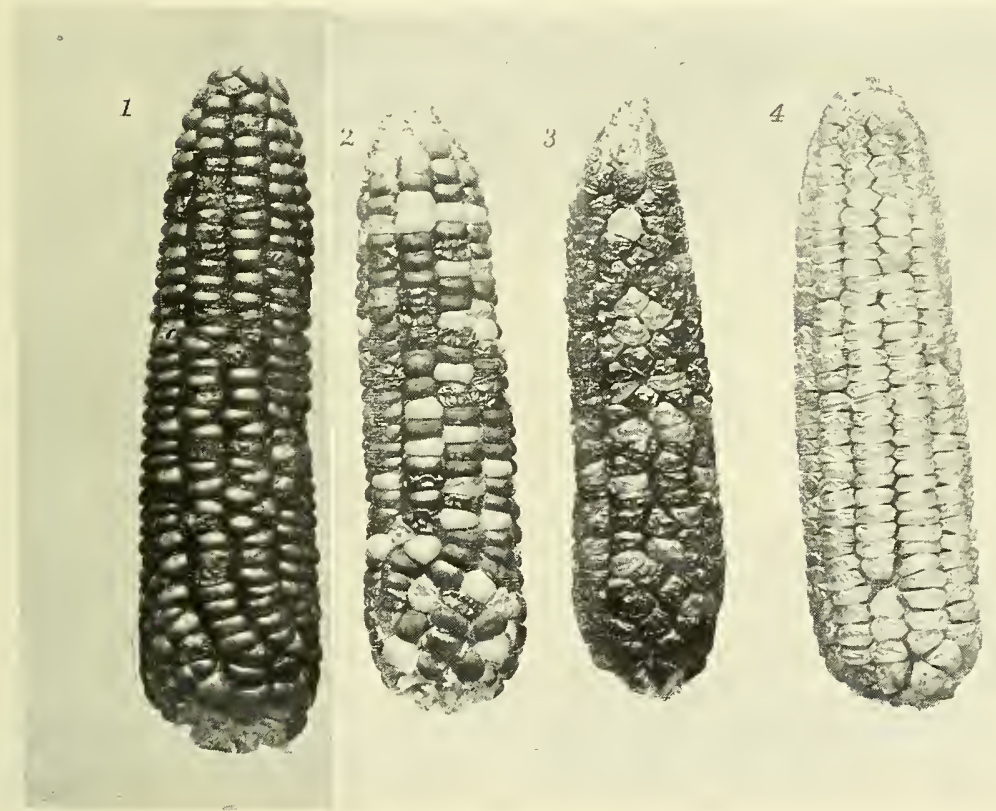

b. $\mathrm{F}_{3}$ color segregates from cross $\left(\mathrm{I}_{8 \times 5} 8\right)$. I. Pure extracted red. 2, 3. Ears from heterozygous plants. 4. Pure extracted non-resl. Proper color values are not shown.

Inheritance of Aleurone Color. 

$\mathrm{R}+1$ prc). There is an excess of whites because the particoloreds could not be classified easily, so it might be said that there should be 36 purples: 9 reds: 19 particoloreds and whites. In the one ear obtained there is still an excess of the last class, but the behavior of the seeds in the $\mathrm{F}_{3}$ generation proves the gametic constitution of the parents. Tables $23 \mathrm{a}$ and $23 \mathrm{~b}$ give the results from planting purple $\mathrm{F}_{2}$ seeds. The last four ears shown in Table 23a were planted from splashed purples but they gave the same result as the full purples. We may conclude therefore that splashed purples behave the same as selfcolored purples in inheritance. Theoretically the entire lot of purples should have the following gametic constitutions and proportions:

\begin{tabular}{|c|c|c|c|}
\hline lass & 1. & 1 P P R R C C & Pure purple. \\
\hline “ & 2. & $2 \mathrm{P} \mathrm{p} \mathrm{R} \mathrm{R} \mathrm{C} \mathrm{C}$ & $=3$ purple: 1 red. \\
\hline “ & 3. & $2 \mathrm{PPR}$ P C & Pure purple. \\
\hline " & 4. & 2 P P R R C c & $=3$ purple: 1 white. \\
\hline “ & 5. & $4 \mathrm{Pp} \mathrm{R} \mathrm{r} \mathrm{C} \mathrm{C}$ & $=12$ purple: 3 red: 1 white. \\
\hline “ & 6. & 4 & $\begin{array}{c}=9 \text { purple: } 3 \text { red: } 4 \text { white. } 3 \\
\text { being particolored. }\end{array}$ \\
\hline " & 7. & $\mathrm{R} \mathrm{r} \mathrm{C} \mathrm{c}$ & $\begin{array}{l}=12 \text { purples: } 4 \text { white. } 3 \text { being part- } \\
\text { icolored. }\end{array}$ \\
\hline " & 8. & $\mathrm{R} \mathrm{r} \mathrm{C} \mathrm{c}$ & $\begin{array}{c}=36 \text { purples: } 9 \text { reds: } 19 \text { whites. } 12 \\
\text { being particolored. }\end{array}$ \\
\hline “ & 9. & $1 \mathrm{P}$ & Pure purple. \\
\hline "« & $\begin{array}{l}10 . \\
11 .\end{array}$ & $\left.\begin{array}{lllll}2 & \mathrm{P} & \mathrm{p} & \mathrm{C} & \mathrm{C} \\
2 & \mathrm{P} & \mathrm{P} & \mathrm{C} & \mathrm{c}\end{array}\right\}$ & $=3$ purples: 1 white. \\
\hline " & 12. & $4 \mathrm{Pp} \mathrm{C} \mathrm{c}$ & $\begin{array}{c}=9 \text { purples: } 7 \text { whites and parti- } \\
\text { coloreds. }\end{array}$ \\
\hline
\end{tabular}

These ears when selfed should give the proportions shown at the right of the above column. An examination of Tables 23a and $23 \mathrm{~b}$ show that out of the 23 selfed ears obtained the expected ratios were followed rather well. There were two pure purple ears, Classes 1,3 and $9 ; 2$ ears of Class $2 ; 3$ ears of Class $12 ; 4$ ears of Classes 4, 7, 10 and 11 which collectively give 3 purples; 1 white; 3 ears of Class 8 ; 9 ears of Classes 5 and 6 . The particolored seeds are very light in color and although they are classified as nearly as possible in the tables this classification should be considered only an approximation and not a reality. 
Particoloreds and whites are considered together in determining the gametic constitution of the ears. The particolored seeds proved to be true particoloreds of the same nature as those of family $(8 \times 54)$. The selfed ears resulting from such seeds of ear No. (18 $\times 58)-1$ of Table 23, gave no purples. Pure particoloreds ears and heterozygous particolored ears were obtained but no exact visual classification of the latter could be made and it was not considered worth while to determine their precise constitution by breeding.

The red segregates occurring in ear No. $(18 \times 58)-1$ were also tested in the $\mathrm{F}_{3}$ generation. Fifteen selfed ears were obtained and are shown in Table 23c. Among them were five pure red ears, six which threw reds and whites in the ratio of $9: 7$ and four which threw reds and whites in the ratio $3: 1$. The number of pure red ears obtained was slightly greater than should generally be expected but such a deviation should occur about once out of five times when dealing with lots of only fifteen ears. The selfed white segregates of ear No. (18 x 58)-1 of Table 23 yielded about one particolored ear either homozygous or heterozygous out of every four. This shows the error in trying to classify particolored and white seeds. There is no doubt however that when pure white segregates are planted they always breed true.

TABLE 23.

F 2 SEEDS OF CROSS BETWEEN NO. 18 NON-PURPLE NON-STARCHY AND NO. 58 PURPLE STARCHY.

\begin{tabular}{|c|c|c|c|c|}
\hline Ear No. & $\begin{array}{c}\text { Purple } \\
\text { PCR +PC }\end{array}$ & $\begin{array}{l}\text { Red } \\
\text { RC }\end{array}$ & $\begin{array}{c}\text { Particolored } \\
\text { PR + P }\end{array}$ & $\begin{array}{c}\text { Non-Purple } \\
+ \text { some P }\end{array}$ \\
\hline$(18 \times 58)-1$ & 191 & 56 & 42 & 138 \\
\hline
\end{tabular}


INHERITANCE OF ALEURONE COLOR.

TABLE $23 \mathrm{~A}$.

F 3 SEEDS OF EAR ( $18 \times 58)-1$ OF TABLE 23.

Purple Starchy Seeds Planted.

\begin{tabular}{|c|c|c|c|c|}
\hline Ear No. & Purple & Red & $\begin{array}{l}\text { * Parti- } \\
\text { colored }\end{array}$ & Non-Purple \\
\hline 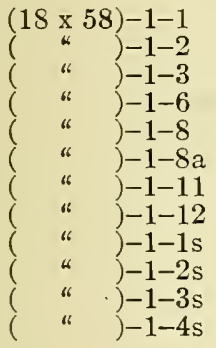 & $\begin{array}{r}167 \\
18 \\
41 \\
211 \\
221 \\
135 \\
80 \\
66 \\
240 \\
141 \\
121 \\
93\end{array}$ & $\begin{array}{r}49 \\
4 \\
13 \\
72 \\
\dot{6} \dot{5} \\
\ddot{1} \dot{7} \\
\ddot{4} \dot{8} \\
38 \\
21\end{array}$ & $\begin{array}{l}\ldots \\
\cdots \\
\cdots \\
6 \\
\cdots \\
\dot{1} \dot{2} \\
\dot{7} \dot{2} \\
\ddot{1} \dot{5}\end{array}$ & $\begin{array}{r}84 \\
\ldots \\
9 \\
96 \\
83 \\
17 \\
78 \\
65 \\
113 \\
60\end{array}$ \\
\hline
\end{tabular}

s Planted splashed purples.

* Particolored classification is only approximate.

TABLE 23B.

F 3 SEEDS OF EAR ( $18 \times 58)-1$ OF TABLE 23.

Purple Non-Starchy Seeds Planted.

\begin{tabular}{|c|c|c|c|c|}
\hline Ear No. & Purple & Red & $\begin{array}{l}\text { * Parti- } \\
\text { colored }\end{array}$ & Non-Purple \\
\hline 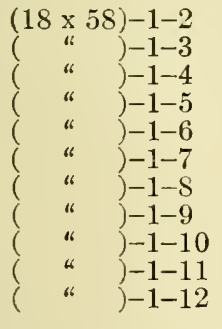 & $\begin{array}{r}49 \\
68 \\
183 \\
240 \\
22 \\
207 \\
184 \\
360 \\
186 \\
99 \\
84\end{array}$ & $\begin{array}{l}25 \\
20 \\
61 \\
\cdots \\
\cdots \\
\cdots \\
\cdots \\
22 \\
\cdots\end{array}$ & $\begin{array}{l}5 \\
\dot{6} \dot{1} \\
\cdots \\
\dot{2} \\
\dot{6} \\
41 \\
\cdots\end{array}$ & $\begin{array}{r}26 \\
66 \\
73 \\
\ddot{8} \\
147 \\
140 \\
\cdots \\
\cdots \\
\ddot{34}\end{array}$ \\
\hline
\end{tabular}

* Particolored classification is only approximate. 
TABLE $23 \mathrm{C}$.

F 3 SEEDS OF EAR $(18 \times 58)-1$ OF TABLE 23.

Red Starchy Seeds Planted.

\begin{tabular}{|c|c|c|c|c|}
\hline Ear No. & Purple & Red & Non-Purple & $\begin{array}{l}\text { Ratio } \\
\text { Approx. }\end{array}$ \\
\hline 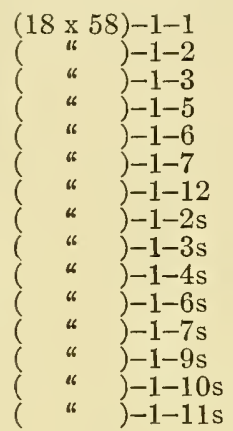 & $\begin{array}{l}\ldots \\
\cdots \\
\cdots \\
\cdots \\
\cdots \\
\cdots \\
\cdots \\
\cdots \\
\cdots \\
\cdots \\
\cdots\end{array}$ & $\begin{array}{r}222 \\
350 \\
222 \\
212 \\
195 \\
148 \\
187 \\
300 \\
350 \\
276 \\
209 \\
44 \\
237 \\
361 \\
206\end{array}$ & $\begin{array}{r}162 \\
380 \\
171 \\
115 \\
74 \\
102 \\
\cdots \\
\cdots \\
63 \\
35 \\
141 \\
61\end{array}$ & $\begin{array}{l}9: 7 \\
\text { Pure } \\
3: 1 \\
9: 7 \\
9: 7 \\
3: 1 \\
9: 7 \\
\text { Pure } \\
\text { Pure } \\
\text { Pure } \\
3: 1 \\
9: 7 \\
9: 7 \\
\text { Pure } \\
3: 1\end{array}$ \\
\hline
\end{tabular}

s Red sugar (s) seeds planted.

\section{Family (7 x 54)}

This cross introduces a combination of yellow endosperm and a dent character, the Leaming parent having long dented yellow seeds usually with formulæ $Y_{1} Y_{1} Y_{2} Y_{2}$. The current effect of the cross gave purple seeds some of which were splashed as in the previous case where yellow flint was the non-purple parent. There was nothing of special interest in the $F_{2}$ generation as the ears segregated purple and non-purple seeds in di-hybrid ratios without the appearance of particolored (cP) seeds. The characters in which these parent varieties differed segregated absolutely independently of each other.

\section{Family (17 x 54)}

The yellow flint which is the non-purple parent in this family is similar to No. 15. The ear is shorter, however, and has present a red pericarp color described under pericarp color as $\mathrm{R}_{4}$. The $F_{1}$ seeds were purple. They were sometimes splashed purples but more rarely than in the other crosses. The $\mathrm{F}_{2}$ seeds gave a simple mono-hybrid ratio but they were not followed into further generations. The plant of No. 17 used as the parent was homozygous therefore for either C. or P. 


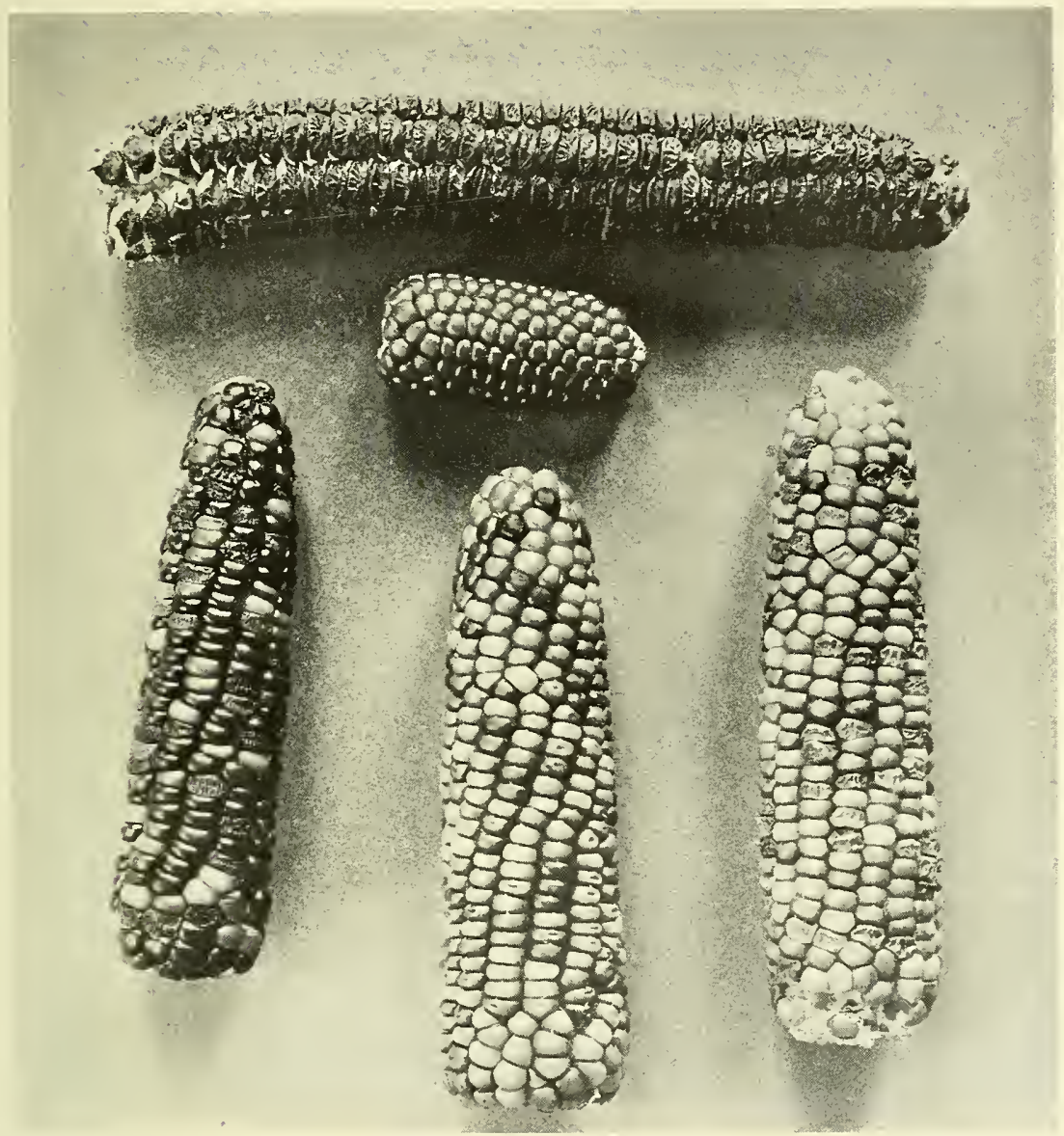

No, 5t. Black Mexican sugar and No. 60 Tom Thumb pop above. Below $F_{1}$ ears with $F_{2}$ seeds. At left ear from the family without factor inhibiting the formation of color in aleurone cells. Other ears contain this inhibiting factor (heterozygons in mother plants). 



\section{Family (19 x 54)}

No. 19 the female parent of this cross is a large sugar corn comparable in size with the large dent varieties. The $F_{1}$ seeds were deep purple and the $F_{2}$ seeds segregated in ratios exceedingly close to the theoretic number for mono-hybrids.

\section{Family $(60 \times 54)$}

No. 60 is a dwarf pop maize with a yellow endosperm, known as Tom Thumb. The individuals used as parents in the various crosses were pure Tom Thumbs but it is not certain that they were the product of a single selfed ear. They were grown from an ear which was self-pollinated, but because the silks appear in this variety while the young ear is entirely hidden in the axil of the leaf, it is less certain that foreign pollen was excluded from the bagged ears than it is in the case of our other crosses. The bags were slipped down into the leaf axil as firmly as possible but there was still some chance for cross pollination. This chance existed only among plants of the same variety, however, for no other pollen was mature at the same time. As several of these crosses were made upon different plants of variety No. 60 it is not strange therefore that one or two of the crosses acted as if parents with different gametic formulæ had been used. It does not follow that this was the case, for the Tom Thumb or the Black Mexican or both might have been heterozygous in some non-visible character.

The result of the immediate cross was different from our other crosses in which the purple aleurone cells were concerned; some of the seeds were dark purple, some were varying shades of light purple and some were white (i. e. non-purple). The behavior of the purple and non-purple hybrid seeds in the next generation showed conclusively that we were dealing neither with a reversal of dominance nor with a character in which the female gametes segregated normally and the male gametes abnormally as suggested by Correns, but with an entirely new dominant factor in which the Tom Thumb variety was probably heterozygous. This factor we take to be an actual inhibiting factor similar in action to the dominant white found in poultry. It is also analogous to the latter in that it does not always completely inhibit the development of color, in which case 
light purples similar in appearance to the particoloreds of earlier crosses develop. They are not like the particoloreds of family $(8 \times 54)$, however, for in the cross under consideration seeds with the gametic formula $\mathrm{cP}$ do not develop color. The light purples behave as if the inhibiting factor could vary zygotically so that in some cases light purples are developed while in others the color is completely inhibited, and also as if various amounts of color are developed in the presence of the inhibiting factor due to different combinations of other gametes. For example, it seems probable that more color may be developed in the presence of the inhibiting factor when the zygote is homozygous for the purple factor than when it is heterozygous. Further it seems less likely that any purple color develops when the inhibiting factor is homozygous than when it is heterozygous. This makes the segregating seeds of $F_{1}$ or $F_{2}$ ears very difficult to classify visually. The only accurate determination of the gametic structure of a seed is through its own further breeding.

Fifteen ears of Tom Thumb were crossed with the purple sugar corn, but only five crosses were selected from which to grow the $F_{2}$ generation. One of these, No. 60-5 x 54, had dark purple and non-purple seeds, while the other four crosses had only non-purple or very light purple seeds. It was a little unfortunate perhaps that this selection was made. The white seeds in cross $60-5 \times 54$ proved to be selfed Tom Thumbs, and the behavior of the purple hybrids showed that no inhibiting factor had been present in ear 60-5. The behavior of the crosses made on ears $60-2,60-3,60-8$ and $60-11$ showed that they had been homozygous in the inhibiting factor. No doubt a number of the other crosses would have shown that the maternal plants were heterozygous in the inhibiting factor.

For these reasons the data from cross $60-5 \times 54$, which may be called the purple family (without the inhibiting factor), have been listed in Table 24, while the other four crosses containing the inhibiting factor are shown in Table 25 .

The resulting $F_{2}$ seeds obtained by selfing the purple $F_{1}$ seeds of cross $60-5 \times 54$ shown in Table 24 were purples, reds and nonpurples. No light purples (particoloreds) appeared in this family. Splashed purples occurred as in other families, but as in other families all splashed purples were heterozygotes 
and not all heterozygotes were splashed purples, showing the phenomenon to be due - as before - to incomplete dominance caused by other factors. The only peculiar thing about this cross was the appearance and inheritance of the red color. The extracted reds bred true apparently and were hypostatic to purple as in other families, but they were purplish red (dark magenta) in appearance and not clear reds such as appear in other crosses. It is conceivable that this red is not the same red that appeared in the other crosses. It may be caused by something similar to what Wheldale $(: 10)$ has suggested may occur in stocks; viz. that the blue oxygenase may act in conjunction with the red peroxydase or vice versa. The only difficulty in alining the results obtained with the ordinary behavior of the known factors, is the fact that almost none of the ears of the $F_{3}$ generation show the same ratios as the $F_{2}$ generation.

The ratio obtained in this generation, 1843 purples: 188 reds: 545 non-purples immediately suggests $12: 1: 3$, which could be obtained from $\mathrm{F}_{1}$ seeds with a formula $\mathrm{Pp} \mathrm{Xx}$ CC RR where $\mathrm{X}$ is an inhibiting factor from the Tom Thumb which affects $\mathrm{R}$ but not $\mathrm{P}$. Our failure to obtain ears in $F_{3}$ with segregates of 9 purple; 3 red; 1 non-purple caused this hypothesis to be discarded. The same ratio could be obtained by supposing that there is a partial gametic coupling between $\mathrm{P}$ and $\mathrm{R}$ similar to that obtained by Bateson and Punnet (:08) between purple color and long pollen in the sweet pea. These authors suppose gametes to be produced after the general formula $7 \mathrm{AB}: 1 \mathrm{Ab}$ : $1 \mathrm{aB}: 7 \mathrm{ab}$, from which result zygotes $3 \mathrm{n}^{2}-(2 \mathrm{n}-1) \mathrm{AB}$ : $2 \mathrm{n}-1$ $A b: 2 n-1$ aB: $n^{2}-(2 n-1) a b$. Such an interpretation, while it may represent Bateson's and Punnett's facts, throws no light on the mechanics of heredity for there is no reasonable way known at present for such a segregation to come about. In our own case * no such excess of purples was obtained in the $\mathrm{F}_{3}$ generation. It seems better therefore to consider the results of the $\mathrm{F}_{2}$ generation in the light of the breeding records of the $\mathrm{F}_{3}$ generation. If this is done, the following interpretation fits the facts best. Tom Thumb, the female parent has the gametic formula pcR, and Black Mexican the male parent has

* Bateson and Punnett have never reported their $\mathrm{F}_{3}$ generation of sweet peas, although they state that it gave conflicting results. 
the formula PCR. The $F_{1}$ generation is therefore PpCcRR. If this is the true formula there is the following theoretical expectation in the $F_{2}$ and $F_{3}$ generations:

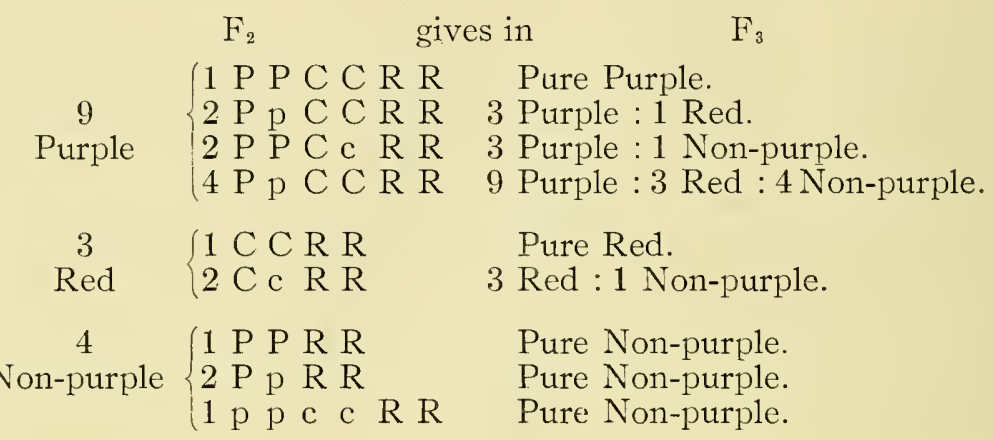

An examination of the $\mathrm{F}_{3}$ segregates given in Tables 24a-e show how nearly the experimental results accord with the theory. First notice that out of 55 ears obtained by selfing purples of the $\mathrm{F}_{2}$ generation, 20 segregated purples and nonpurples without reds. This is more than our own theory calls for (theoretically 12 out of 55), so that here is clear evidence that we do not have to deal with partial gametic coupling of the kind described by Bateson and Punnett. But, since the deficiency of reds in the $\mathrm{F}_{2}$ generation is too great to be due to chance and since there is a certain excess of purples in the $F_{3}$ generation, we must say frankly that we are dealing with something that we cannot yet explain.

The entire data from the 55 purple $\mathrm{F}_{2}$ seeds from which selfed ears were obtained may be classified as follows: 8 ears pure purple; 20 ears segregating purples and non-purples in the ratio of $3: 1 ; 9$ ears segregating purples and reds in the ratio of $3: 1 ; 1$ ear each segregating purples and reds in ratios of $5: 1$, $6: 1$ and $12: 1$; 11 ears segregating purples, reds and nonpurples in the ratio of $9: 3: 4 ; 3$ ears segregating purples, reds and non-purples in the ratio of $48: 3: 13$ or thereabouts.

From the red $\mathrm{F}_{2}$ seeds 13 selfed ears were obtained. Out of these, 3 were pure red and 10 segregated reds and non-reds in about the ratio of $3: 1$. It should be remarked, however, that in three cases the heterozygous reds gave a greater excess of reds than usually should be expected with chance mating. 
From the non-purple $\mathrm{F}_{2}$ seeds 16 selfed ears were obtained: 15 were pure non-purple while one gave 12 purples to 49 non-purples. As this is a poor ear, the 12 seeds may be due to foreign pollen, or a chance pollen grain possessing the inhibiting factor may have produced the $\mathrm{F}_{2}$ white seed from which the ear resulted.

With the plants resulting from non-purple $F_{2}$ seeds random intercrosses were also made. Of these 13 gave ears with all non-purple seeds and one gave an ear with 49 purples and reds and 140 non-purples.

These results generally follow our theory pretty closely, but there are abnormalities difficult to explain. We seem to be dealing with only two heterozygous factors - since 8 pure purples are obtained from 55 ears - yet tri-hybrids and tetrahybrids are possible which give such results. By our theory no whites should give purples when crossed at random. One such ear occurred. Was it an error? It is difficult to say. But if we were dealing with heterozygous red $(\mathrm{Rr})$ we should expect more than one ear out of 14 to give purples on random crossing. Furthermore, it can be seen by inspection that there are many reasons why we cannot be dealing with simply a heterozygous red factor. It is not denied however that several other unknown factors with a heterozygous red factor might interpret the facts. It does not seem possible to explain the results by any reasonable system of gametic coupling or by selective mating. $\mathrm{P}$ and $\mathrm{C}$ certainly are present in an heterozygous condition. $\mathrm{R}$ is probably homozygous although it was not found in the Black Mexican in other crosses. But this is not peculiar since the Black Mexican used in the cross can only be said to be pure for purple. On the other hand, the red does not appear to the eye to be exactly the same red which appeared in the other crosses. It is more purplish in color, as if it were a modified purple. Nevertheless it always bred true after extraction.

Let us now turn to what may be called the white side of this family. As was stated before ears 60-2, 60-3, 60-8 and 60-11 gave no dark purples when crossed with No. 54. (Some seeds were afterwards found to be very slightly purple.) One may conclude therefore that they (the maternal plants) were either homozygous for a factor that inhibits the development of the purple color; or, that there is a reversal of dominance, which is 
improbable. There were other ears that gave both purple and non-purple seeds in crosses. These were either heterozygous for an inhibiting factor or exhibited dominance of both purple and non-purple on the same ear which is still more improbable. None of these ears were followed into the $F_{2}$ generation, but progeny of all four of the ears of the first type were grown.

The results of the $\mathrm{F}_{2}$ generation from these ears are shown in Table 25. There is no reason why some of these families might not differ from others in invisible factors, for different plants of No. 60 were crossed with pollen from different plants of No. 54 . They are placed in one table here but certain differences in their behavior in $\mathrm{F}_{3}$ leads us to consider them separately. There is a total of 662 purples, 94 reds and 2838 light colored purples and non-purples. The reason for classing the light purples and non-purples together will be seen later.

The results of the $F_{3}$ generation as well as our experience with other crosses are such as exclude the possibility of a reversal of dominance. The purples did not breed true nor did the behavior of any of the classes indicate anything other than a normal Mendelian segregation involving several characters. Furthermore, a belief in reversal of dominance in our opinion strikes at the foundation stone of Mendelism. Not that dominance is an important part of Mendelism. It is not. Yet no analysis can be made of breeding records without following every individual for several generations if dominance is reversible. Of the thousands of extracted recessives that have bred true, many would have proved to be heterozygous dominants if dominance is reversible.

Taking the same $F_{1}$ gametic formula that served for the purple side of the family and adding an inhibiting factor I which comes from No. 60, gives the best interpretation of the data. This makes the $F_{1}$ formula PpCcIiRR. In $F_{2}$ the following classes would be expected:

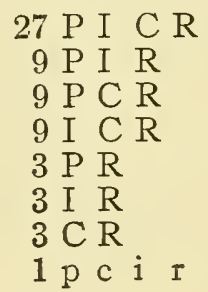

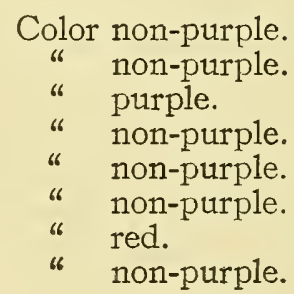


The ratio is 9 purple : 3 red : 52 non-purple. The experimental results given in Table 25 show that here also there is a deficiency of reds. Many light purples also appeared, but these were classed as non-purples. This was done because in $\mathrm{F}_{3}$ the light purples behaved as if they possessed the factor I in a heterozygous condition, the variation in color being due to the different combinations in which the factors $\mathrm{P}$ and $\mathrm{C}$ appeared.

With this theory the expectation in $\mathrm{F}_{3}$ is 52 non-purples and light purples giving:

28 Producing all Non-purple seeds.

$\begin{array}{lll}2 & \text { " } & 1 \text { Purple }: 3 \text { Non-purple. } \\ 4 & \text { " } & 3 \text { Purple }: 13 \text { Non-purple. } \\ 4 & \text { " } & 3 \text { Purple }: 1 \text { Red }: 12 \text { Non-purple. } \\ 8 & \text { " } & 9 \text { Purple }: 3 \text { Red }: 52 \text { Non-purple. } \\ 2 & \text { " } & 1 \text { Red }: 3 \text { Non-red. } \\ 4 & \text { " } 3 \text { Red }: 13 \text { Non-red. }\end{array}$

9 Purples giving:

1 Producing all Purple seeds.

$2 \quad$ " 3 Purple : 1 Red.

$2 \quad$ " 3 Purple : 1 Non-purple.

$4 \quad$ “ 9 Purple : 3 Red : 4 Non-purple.

3 Reds giving:

1 Producing all Red seeds.

2 " 3 Reds : 1 Non-red.

Let us now examine Tables $25 a-e$ which give the results from selfing the seeds of certain of the $\mathrm{F}_{2}$ ears. Table 25a shows the progeny of ear (60-3x54)-1. This ear gave the smallest proportion of purple seeds in $F_{2}$, and such purples as were produced in $F_{2}$ were lighter in color than normal full purples. In $\mathrm{F}_{3}$ the purples are again light in color. They are classed in with the nonpurples in the last column, those showing some color being given first. The first two ears are progeny of the darkest purples; one has purple and non-purple seeds in the ratio of $3: 1$ and one is pure purple. The next two ears planted from lighter purples show a difference between themselves. One gives 3 light purples : 1 non-purple, the other gives 1 purple : 2 non-purple. The latter probably came from an ear heterozygous for the inhibiting factor and the former from a real 
purple. Of those ears resulting from white seeds, one has 33 red seeds dark enough to be classed as real reds and a number of very light reds classed with the non-purples - a total of probably near $25 \%$ reds, while another gives light purples (and possibly light reds) and non-purples. The remaining ears are non-purples. Five plants from non-purple $\mathrm{F}_{2}$ seeds were also crossed, and gave all non-purple seeds. In reality, however, only two random crosses can be said to have been made, since the pollen of No. (60-3 x 54)-1-2 ES was used three times, while once the same plant was used as the mother. The progeny of ear (60-3 x 54)-1, therefore, behave like those of other ears of this family except that all of the progeny of purples are light in color. They give pure purples and purples segregating into 3 purples : 1 non-purple, but none are dark like normal purple ears. Some geneticists would probably interpret this as prepotency of the non-purple or rather lack of prepotency of the purple. But when one talks of prepotency he really confesses ignorance of the gametic constitution of his cultures. Is it not much more likely that the true reason for the production of these light purples lies in a fact more in keeping with what is known of hereditary phenomena? May not one say that here is a dominant purple character coming from the individual of unknown character of variety No. 54 which was used as the male parent? If the purple gene from the male parent was such as to give always a lighter purple in zygotic combinations where purple is visible then no dark purples would occur in the segregates resulting from crosees. Such results were obtained from four selfed plants. Two ears resulted from planting purples which were only slightly lighter than normal dark purples, such as the parents of ears (60-3 $\times 54)-1-1$ and (60-3 $\times 54)-1-2$, and two ears resulted from planting seeds quite light in color. (Table 25a).

Similar results were obtained from cross (60-8 x 54), of which the $\mathrm{F}_{3}$ generation from ear (60-8 $\left.\times 54\right)-8$ are shown in Table $25 \mathrm{e}$. Here eleven ears resulted from selfing seeds with the modified color if two red seeds are included. None of these ears had seeds dark in color, but the ratios are no doubt the same as those given in Tables $25 \mathrm{~b}-\mathrm{d}$. The general reduction of the amount of purple color, however, makes the error of classification too great for safe conclusions. There is even some doubt about 
the classification of the seeds from the $F_{2}$ generation of these two crosses (Table 25), but the results of the $\mathrm{F}_{3}$ generation are such as to give us considerable faith in them.

Tables $25 \mathrm{~b}$-d give a considerable number of $\mathrm{F}_{3}$ progeny from $\mathrm{F}_{2}$ seeds of three other ears. There seems to be no reason why they should not be considered together. From the purple $F_{2}$ seeds planted, twelve selfed ears were obtained. Three ears were pure purples of the normal shade. One ear gave a ratio of 3 purples : 1 red and two ears a ratio of 3 purples : 1 nonpurple. The other six ears gave purple, red and non-purple segregates. Four of these ears were clearly of the ratio $9: 3: 4$, but in the remaining two there was a considerable deficiency of red seeds. From the $\mathrm{F}_{2}$ red seeds planted, only one selfed ear was obtained. This ear gave red and non-red segregates in the ratio of $3: 1$.

A large number of selfed ears were obtained from the $F_{2}$ light purple and non-purple seeds. Ears of each of the classes expected by the proposed theory were obtained, as will be seen by an examination of the Tables $25 \mathrm{~b}$-d; but as the visual classification is arbitrary owing to the light color of most of the seeds, it could not be depended upon without further breeding. The light colored seeds are given first in the last column of the tables, followed by the seeds which were apparently non-purple. If one is a little charitable about the exactness of the classification the following conclusions can be drawn.

Both seeds which were apparently non-purple and seeds which were light purple in color in the $F_{2}$ generation gave light purple seeds among the $\mathrm{F}_{3}$ segregates. This fact proves both the impossibility of exact classification and the gametic identity of seeds slightly different in their appearance.

Two plants from light red seeds (Table 25b) were selfed. One resultant ear showed a ratio of 1 dark red : 3 light red and non-red; the other ear showed only light red and non-red seeds which were classed together. Thirty-six plants from light purple and from non-purple $F_{2}$ seeds were selfed. Of these, fifteen ears resulted from planting seeds classified as non-purple in $\mathrm{F}_{2}$. Only four of them threw dark purple segregates in $\mathrm{F}_{2}$. On the other hand only two of the ears resulting from selfed plants which were progeny of seeds classified as light purples, threw no dark purple segregates. It seems to us that this shows a 
fair classification of seeds heterozygous for the inhibiting factor A few seeds, however, were wrongly classified in the $F_{2}$ generation and proved their proper status in the $\mathrm{F}_{3}$ generation.

Out of the total of 36 selfed ears from light purple and nonpurple $\mathrm{F}_{2}$ seeds, 23 threw dark purple segregates and 13 produced only light purple and non-purple seeds. Of those ears which threw purple segregates, none of them had ratios of purple to light purple plus non-purple greater than might reasonably be expected by chance mating. The different ratios expected in $\mathrm{F}_{3}$ were followed rather well, although it is recognized that these ratios could not be determined accurately with such small numbers.

\section{Conclusions.}

There can be but little doubt that the factors I, C, P and R are concerned in this cross. Whether there is another factor which modifies the purple color or not, is a question that cannot yet be settled, because we have no data concerning the individual plant of No. 54 that formed the male parent; yet there seems to be no other way to account for the light purples in Table 25a and Table 25e. The ultimate analysis of the behavior of the $\mathrm{R}$ factor in this cross must also be left in abeyance. These unsettled questions however have no bearing upon two important conclusions which the evidence forces upon us. The first is that one should be exceedingly careful before he decides that the transmission of certain characters is an exception to the general law of Mendel. When a collection of white or nonpurple aleurone strains are promiscuously crossed with a purple aleurone maize, the results seem almost impossible to bring into conformity with simple Mendelian results, yet this confusion is brought about simply by the gametic differences of the non-purple races. If such confusion can result in the case of a simple color inheritance, much more care must be taken to analyze the transmission of more complex characters before subsidiary hypotheses are submitted.

The second important fact is in regard to prepotency. It has been shown that certain families of purple and non-purple hybrids produce very light purples when $\mathrm{P}$ exists alone without $\mathrm{C}$, while other families produce no color. No modification 
of the Mendelian ratio occurs, yet some transmissible difference in the two families gives this different result. Here is a probable explanation of prepotency. If these white families were mixed together, a mixture more easily imagined in the case of bisexual individuals, there would appear to be a difference in prepotency of the purple character. It therefore seems probable that prepotency is due only to a difference in gametic character which modifies somatic appearances and not to an actual modification of Mendelian chance ratios as others have suggested.

The behavior of the other families is so simple that we think there can now be no question but that the purple aleurone color behaves as a normal Mendelian character in inheritance. 
TABLE 24.

F 2 SEEDS OF CROSS BETWEEN NO. 60-5 NON-PURPLE POP AND NO. 54 PURPLE SWEET.

Purple Seeds Planted.

\begin{tabular}{|c|c|c|c|}
\hline Ear No. & Purple & Red & Non-Purple \\
\hline 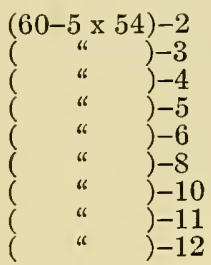 & $\begin{array}{r}271 \\
236 \\
92 \\
203 \\
272 \\
144 \\
198 \\
190 \\
237\end{array}$ & $\begin{array}{r}28 \\
21 \\
11 \\
36 \\
33 \\
14 \\
21 \\
4 \\
20\end{array}$ & $\begin{array}{l}57 \\
71 \\
33 \\
69 \\
71 \\
58 \\
55 \\
55 \\
76\end{array}$ \\
\hline Total & 1843 & 188 & 545 \\
\hline
\end{tabular}

TABLE $24 \mathrm{~A}$.

F 3 SEEDS OF EAR NO. (60-5 x 54)-2 OF TABLE 24.

\begin{tabular}{|c|c|c|c|c|}
\hline Ear No. & Planted from & Purple & Red & $\begin{array}{l}\text { Non- } \\
\text { Purple }\end{array}$ \\
\hline 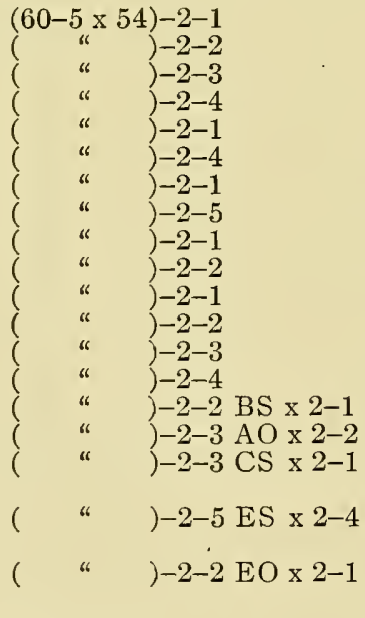 & 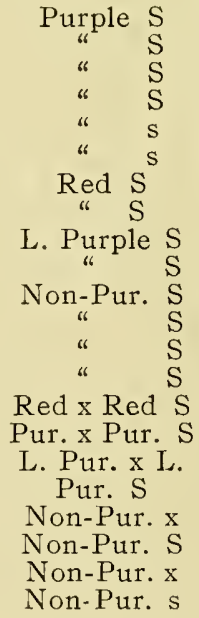 & $\begin{array}{r}277 \\
16 \\
176 \\
233 \\
209 \\
396 \\
\ldots \\
194 \\
167 \\
\ldots \\
\ldots \\
\ldots\end{array}$ & $\begin{array}{r}23 \\
\dot{4} \dot{5} \\
48 \\
49 \\
2 \dot{1} \dot{9} \\
\text { A11 } \\
27 \\
56 \\
\ldots \\
\ldots\end{array}$ & $\begin{array}{c}5 \\
69 \\
92 \\
72 \\
\ddot{91} \\
\ddot{71} \\
80 \\
\text { Pure } \\
\text { " } \\
\text { " }\end{array}$ \\
\hline
\end{tabular}


TABLE 24B.

F $_{3}$ SEEDS OF EAR NO. (60-5 X 54)-6 OF TABLE 24.

\begin{tabular}{|c|c|c|c|c|}
\hline Ear No. & Planted from & Purple & Red & $\begin{array}{l}\text { Non- } \\
\text { Purple }\end{array}$ \\
\hline 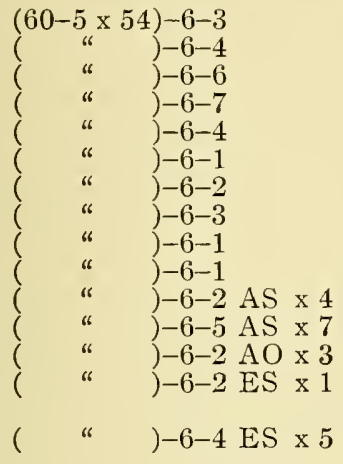 & 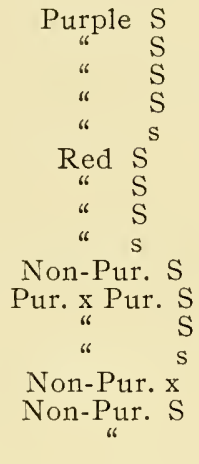 & $\begin{array}{r}87 \\
204 \\
262 \\
318 \\
265 \\
\ldots \\
\ldots \\
\ldots \\
\ldots \\
384 \\
420 \\
200 \\
\ldots\end{array}$ & $\begin{array}{c}24 \\
\ldots \\
\dot{5} \dot{S} \\
83 \\
135 \\
287 \\
164 \\
240 \\
\ldots \\
\ldots \\
\ldots \\
\ldots\end{array}$ & $\begin{array}{c}38 \\
60 \\
80 \\
\cdots \\
2 \dot{9} \\
76 \\
48 \\
71 \\
\text { Pure } \\
\ldots \\
\ldots \\
\text { Pure } \\
\text { “ }\end{array}$ \\
\hline
\end{tabular}

TABLE $24 \mathrm{C}$.

F 3 SEEDS OF EAR No. $(60-5 \times 54)-8$ of TABLE 24.

\begin{tabular}{|c|c|c|c|c|}
\hline Ear No. & Planted from & Purple & Red & $\begin{array}{l}\text { Non- } \\
\text { Purple }\end{array}$ \\
\hline 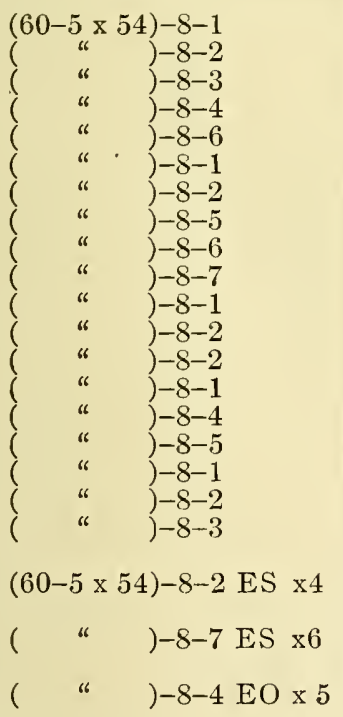 & 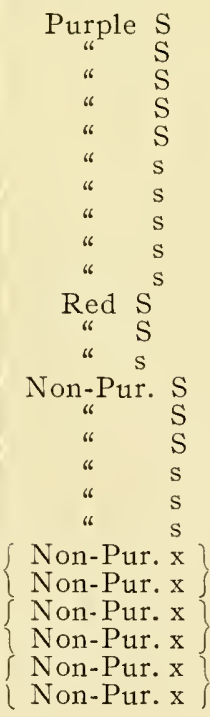 & $\begin{array}{l}125 \\
176 \\
212 \\
170 \\
183 \\
180 \\
182 \\
153 \\
217 \\
150 \\
\ldots \\
\ldots \\
\ldots \\
12 \\
\ldots \\
\ldots \\
\ldots\end{array}$ & $\begin{array}{c}55 \\
60 \\
\ldots \\
2 \dot{S} \\
35 \\
\ldots \\
\ldots \\
176 \\
182 \\
156 \\
\ldots \\
\ldots \\
\ldots \\
\ldots\end{array}$ & $\begin{array}{r}\cdots \\
\cdots \\
6 \dot{0} \\
65 \\
3 \dot{3} \\
71 \\
\dot{3} \dot{4} \\
\dot{5} \dot{7} \\
180 \\
40 \\
250 \\
250 \\
220 \\
240 \\
400 \\
140 \\
220\end{array}$ \\
\hline
\end{tabular}


TABLE 24D.

F 3 SEEDS OF EAR NO. $(60-5 \times 54)-11$ OF TABLE 24.

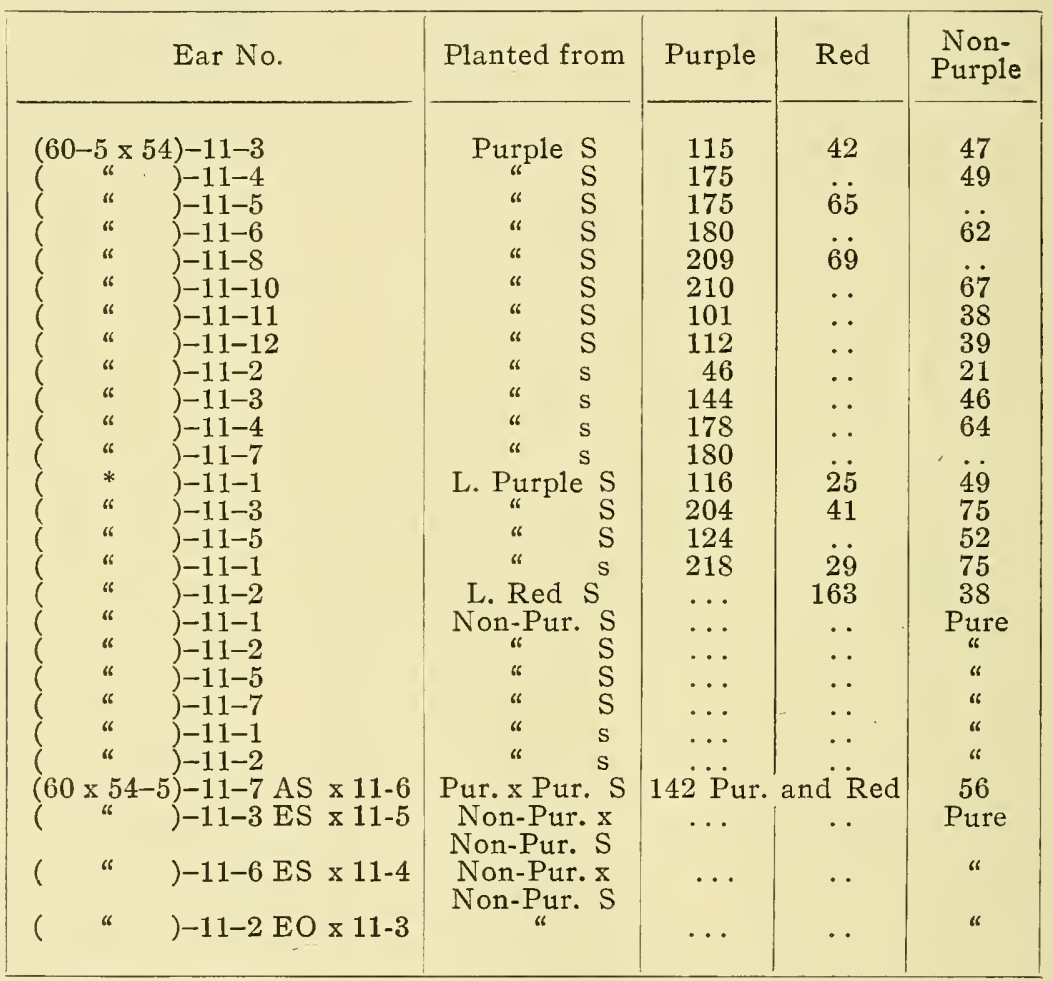


TABLE $24 \mathrm{E}$.

F $_{3}$ SEEDS OF EAR NO. (60-5 x 54)-12 OF TABLE 24.

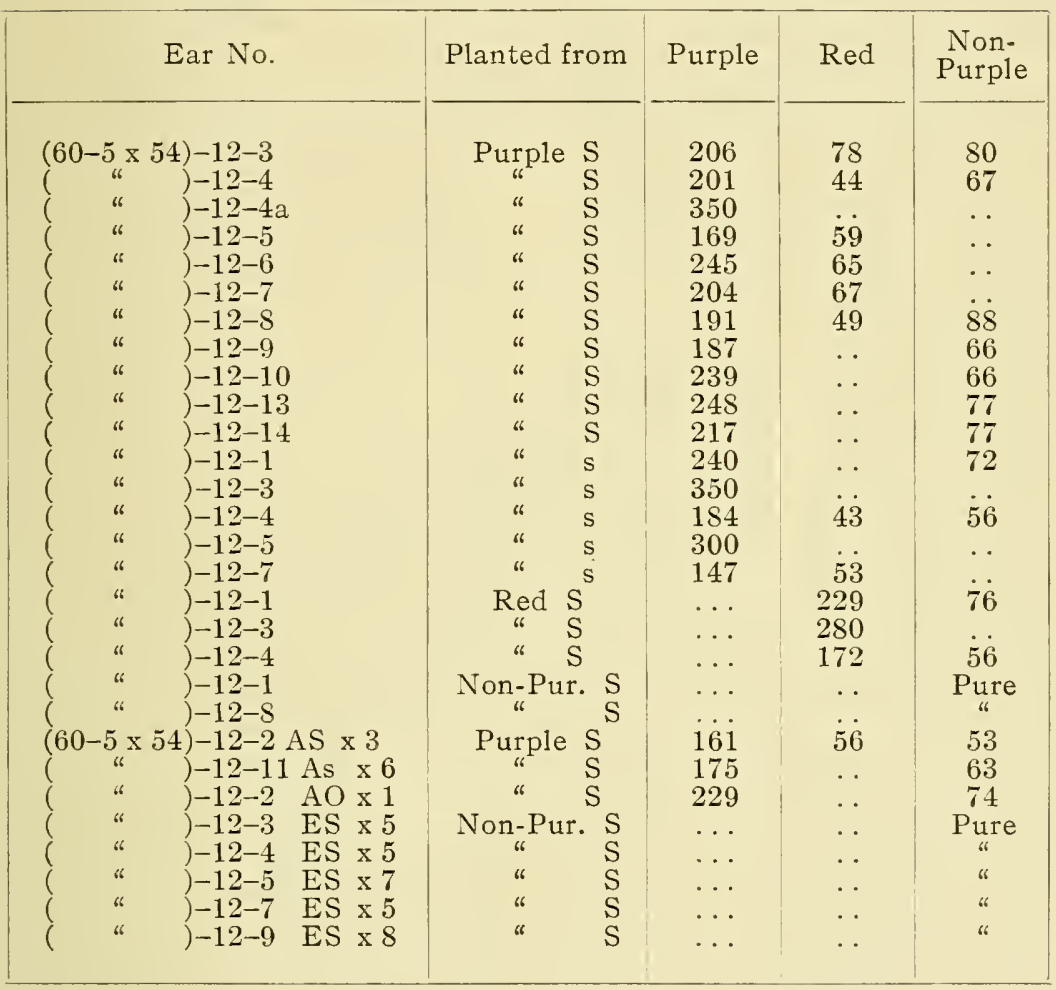


TABLE 25.

$F_{2}$ SEEDS OF CROSS BETWEEN NO. 60 NON-PURPLE POP AND No. 54 PURPLE SWEET.

Very Light Colored and White Seeds Planted.

\begin{tabular}{|c|c|c|c|}
\hline Ear No. & Purple & Red & L. Pur. + Non-Pur. \\
\hline 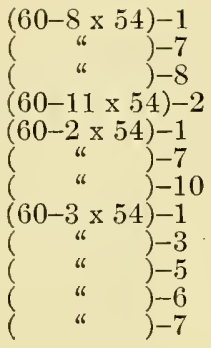 & $\begin{array}{l}83 \\
19 \\
35 \\
22 \\
68 \\
86 \\
89 \\
26 \\
46 \\
54 \\
65 \\
69\end{array}$ & $\begin{array}{r}5 \\
7 \\
4 \\
4 \\
15 \\
7 \\
14 \\
09 \\
7 \\
12 \\
6 \\
13\end{array}$ & $\begin{aligned} 66+135 & =201 \\
44+150 & =194 \\
41+215 & =256 \\
22+40 & =62 \\
96+159 & =255 \\
99+150 & =249 \\
69+148 & =217 \\
76+282 & =358 \\
87+140 & =227 \\
102+159 & =261 \\
113+144 & =257 \\
117+184 & =301\end{aligned}$ \\
\hline Total & 662 & 94 & 2838 \\
\hline
\end{tabular}

TABLE 25A.

F $_{3}$ SEEDS OF EAR NO. $(60-3 \times 54)-1$ OF TABLE 25.

\begin{tabular}{|c|c|c|c|c|}
\hline Ear No. & Planted from & Pur. & Red & $\begin{array}{l}\text { L. Pur. }+ \\
\text { Non-Pur. }\end{array}$ \\
\hline 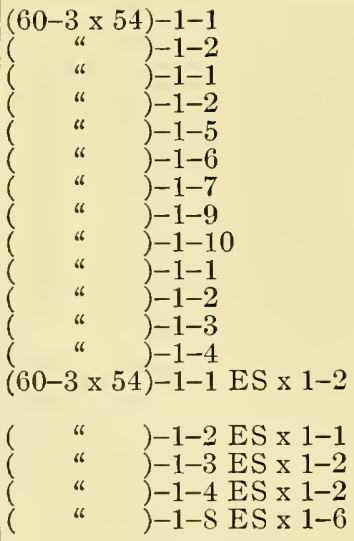 & $\begin{array}{cc}\text { Purple } & \text { S } \\
\text { L. Purple } & \text { S } \\
\text { “ } & \text { S } \\
\text { Non-Pur. } & \text { S } \\
\text { " } & \text { S } \\
\text { " } & \text { S } \\
\text { " } & \text { S } \\
\text { " } & \text { S } \\
\text { " } & \text { S } \\
\text { " } & \text { S } \\
\text { Non-Pur. } & \text { x } \\
\text { Non-Pur. } \\
\text { " } \\
\text { " } \\
\text { " }\end{array}$ & $\begin{array}{l}\ldots \\
\cdots \\
\cdots \\
\cdots \\
\cdots \\
\cdots \\
\cdots \\
\cdots\end{array}$ & $\begin{array}{l}\cdots \\
\cdots \\
\cdots \\
\cdots \\
33 \mathrm{~L} \\
\cdots \\
\cdots \\
\cdots \\
\cdots \\
\cdots \\
\cdots \\
\cdots \\
\cdots\end{array}$ & $\begin{array}{rl}235+76 & =311 \\
245 & =245 \\
217+69 & =286 \\
39+72 & =111 \\
0+384 & =384 \\
105+204 & =309 \\
380 & * \\
0+390 & =390 \\
0+280 & =280 \\
0+448 & =448 \\
0+200 & =200 \\
0+152 & =152 \\
0+280 & =280 \\
0+250 & =250 \\
0+258 & =258 \\
0+110 & =110 \\
0+308 & =308 \\
0+352 & =352\end{array}$ \\
\hline
\end{tabular}

* Light reds and non-reds. 
TABLE $25 \mathrm{~B}$.

F 3 SEEDS OF EAR NO. $(60-3 \times 54)-5$ OF TABLE 25.

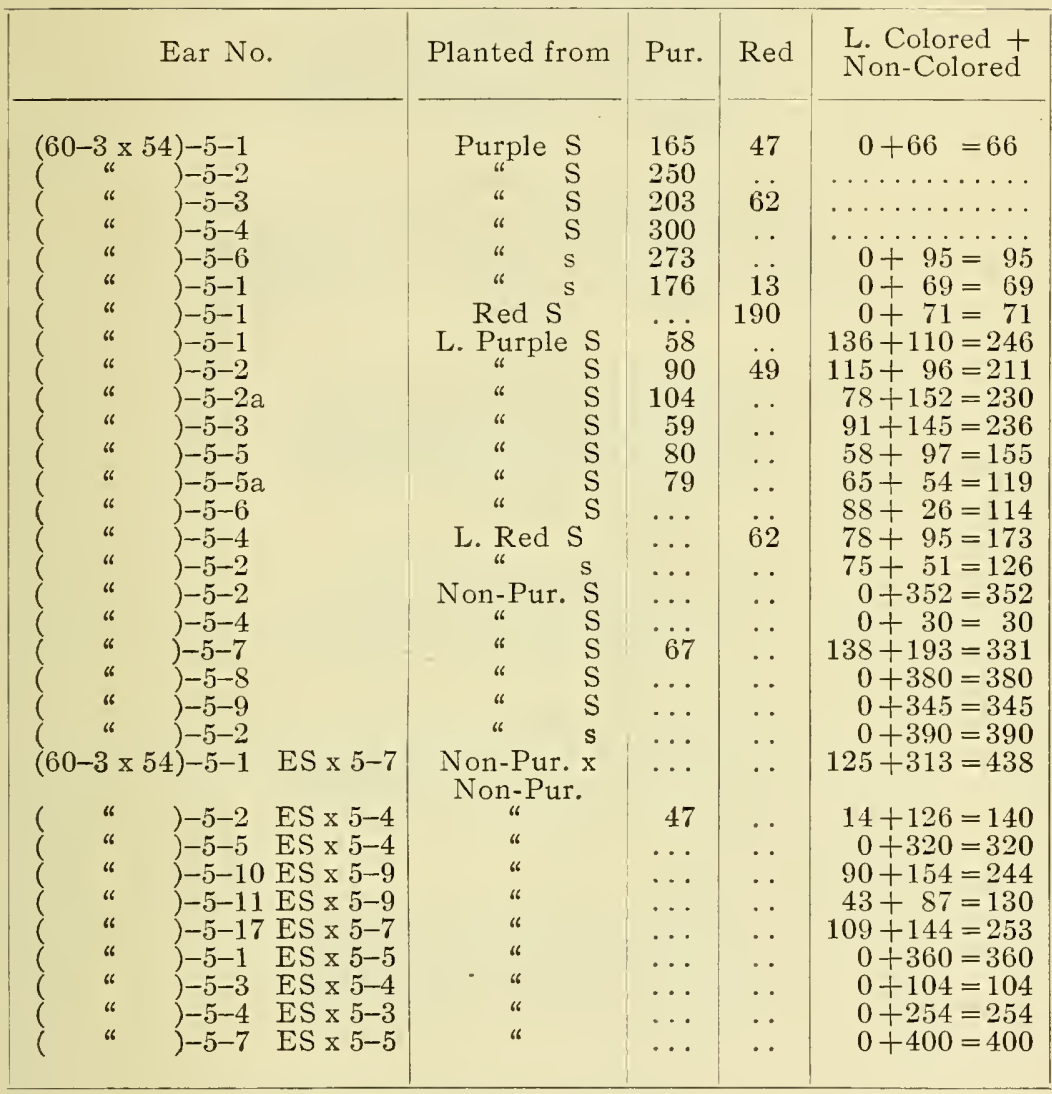


TABLE 25C.

F 3 SEEDS OF EAR NO. $(60-3 \times 54)-6$ OF TABLE 25.

\begin{tabular}{|c|c|c|c|c|}
\hline Ear No. & Planted from & Pur. & Red & L. Colored + \\
\hline 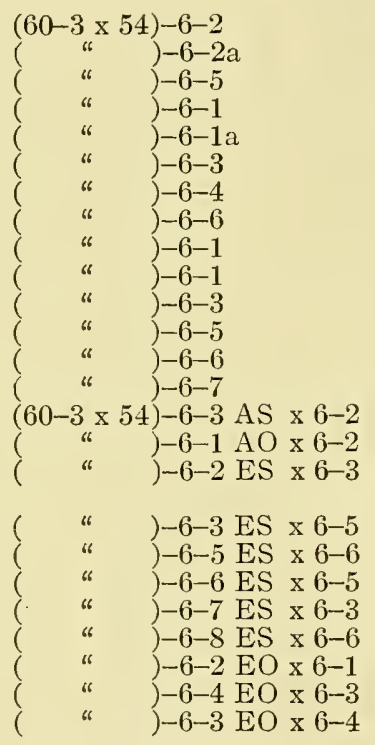 & $\begin{array}{cc}\text { Purple } & \text { S } \\
\text { " } & \text { S } \\
\text { L. Purple } & \text { S } \\
\text { " } & \text { S } \\
\text { " } & \text { S } \\
\text { " } & \text { S } \\
\text { " } & \text { S } \\
\text { Non-Pur. } & \text { S } \\
\text { " } & \text { S } \\
\text { " } & \text { S } \\
\text { " } & \text { S } \\
\text { Pur. x Pur. } \\
\text { "Pur. } \\
\text { Non-Pur. } \\
\text { Non-Pur. } \\
" \\
" \\
\text { " } \\
\text { " } \\
\text { " } \\
\text { " } \\
\text { " }\end{array}$ & $\begin{array}{r}180 \\
175 \\
138 \\
31 \\
49 \\
27 \\
66 \\
36 \\
90\end{array}$ & $\begin{array}{r}9 \\
20 \\
5 \\
\ldots \\
10 \\
\ldots \\
\cdots \\
\cdots \\
\ddot{3} \\
\cdots \\
\cdots \\
\ddot{5} 7 \\
\ldots\end{array}$ & $\begin{aligned} 0+71 & =71 \\
0+64 & =64 \\
0+40 & =40 \\
36+38 & =74 \\
68+49 & =117 \\
53+48 & =101 \\
63+61 & =124 \\
144+130 & =274 \\
108+142 & =250 \\
0+250 & =250 \\
70+106 & =176 \\
45+62 & =107 \\
0+152 & =152 \\
53+105 & =158 \\
88+80 & =168 \\
20.31 & =46 \\
15+31 & \\
0+380 & =380 \\
21+117 & =138 \\
78+122 & =200 \\
37+170 & =207 \\
65+61 & =126 \\
84+222 & =306 \\
33+26 & =59 \\
24+171 & =195\end{aligned}$ \\
\hline
\end{tabular}




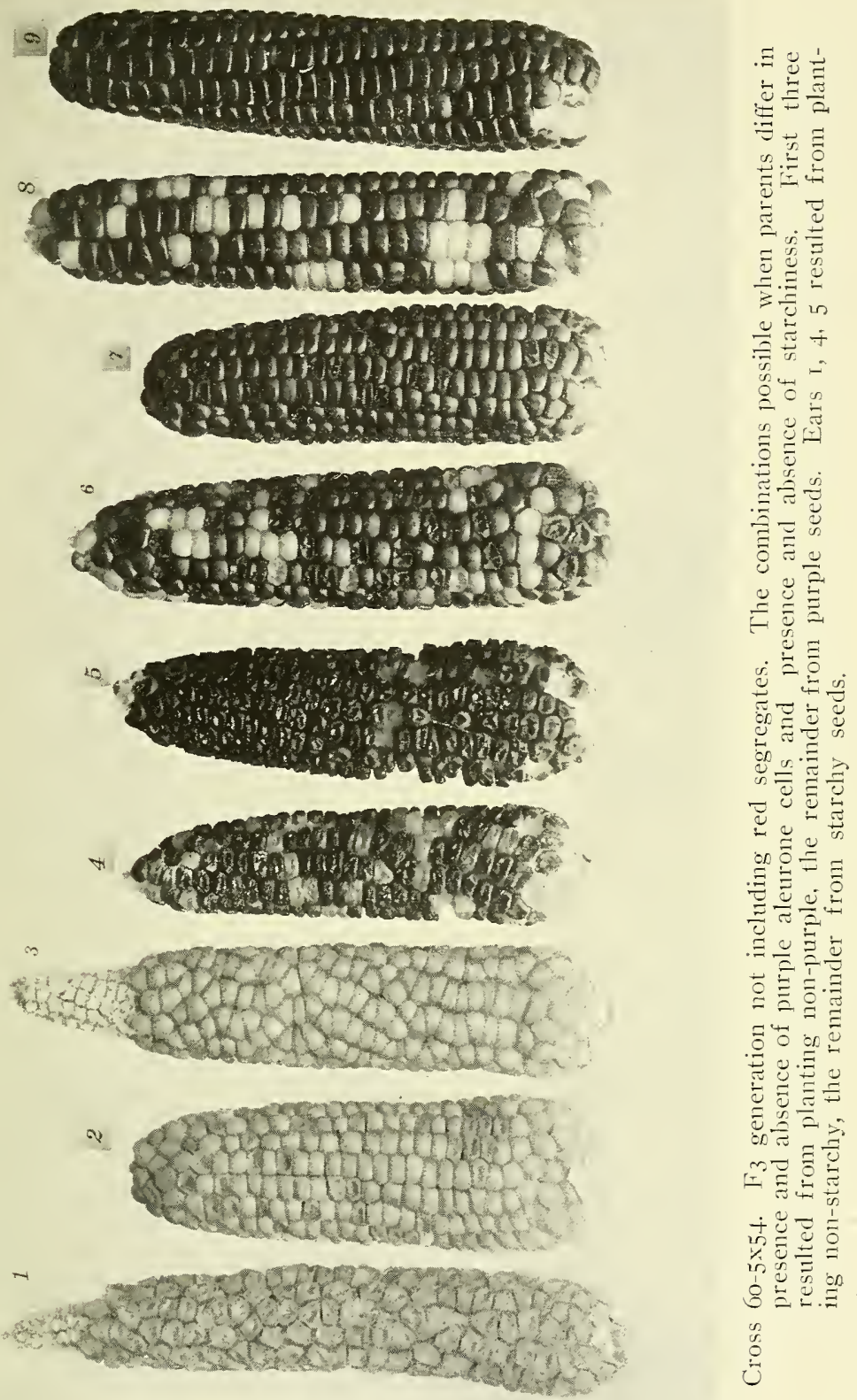

Inheritance of Aleurone Color. 

TABLE $25 \mathrm{D}$.

$\mathrm{F}_{3}$ SEeds OF EAR No. $(60-8 \times 54)-1$ of TABLE 25.

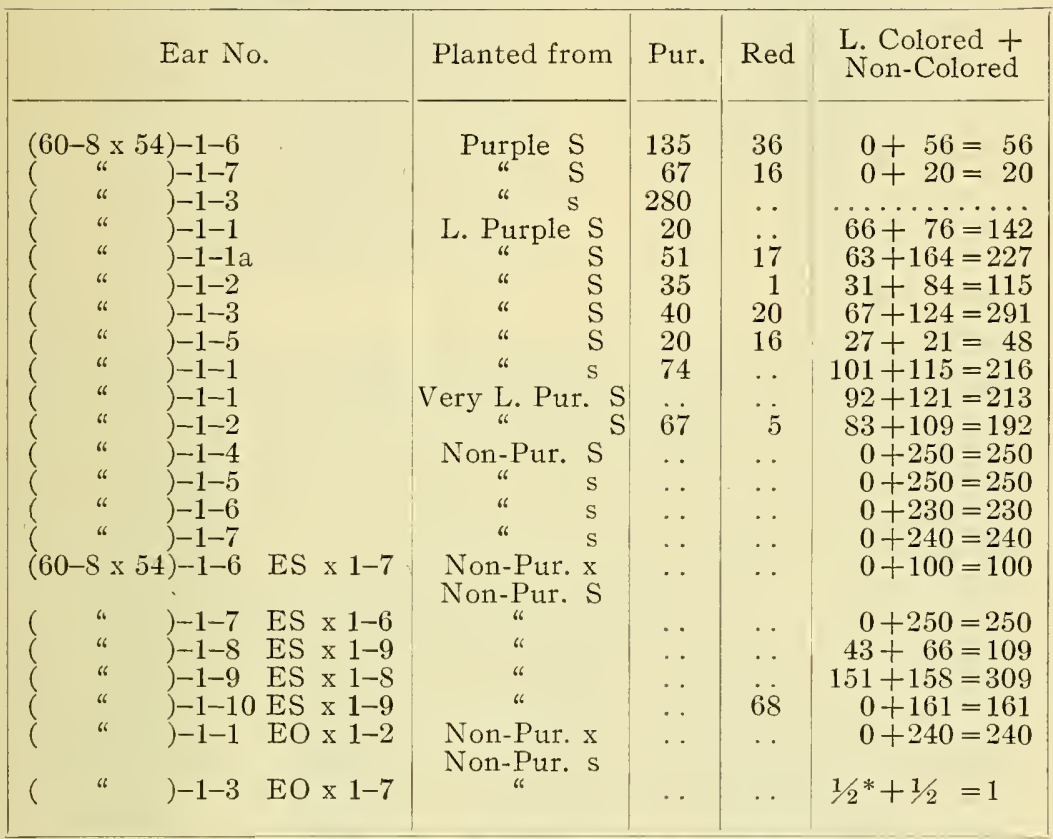

* Approximated. 
TABLE $25 \mathrm{E}$.

F $_{3}$ SEEDS OF EAR NO. $(60-8 \times 54)-8$ OF TABLE 25.

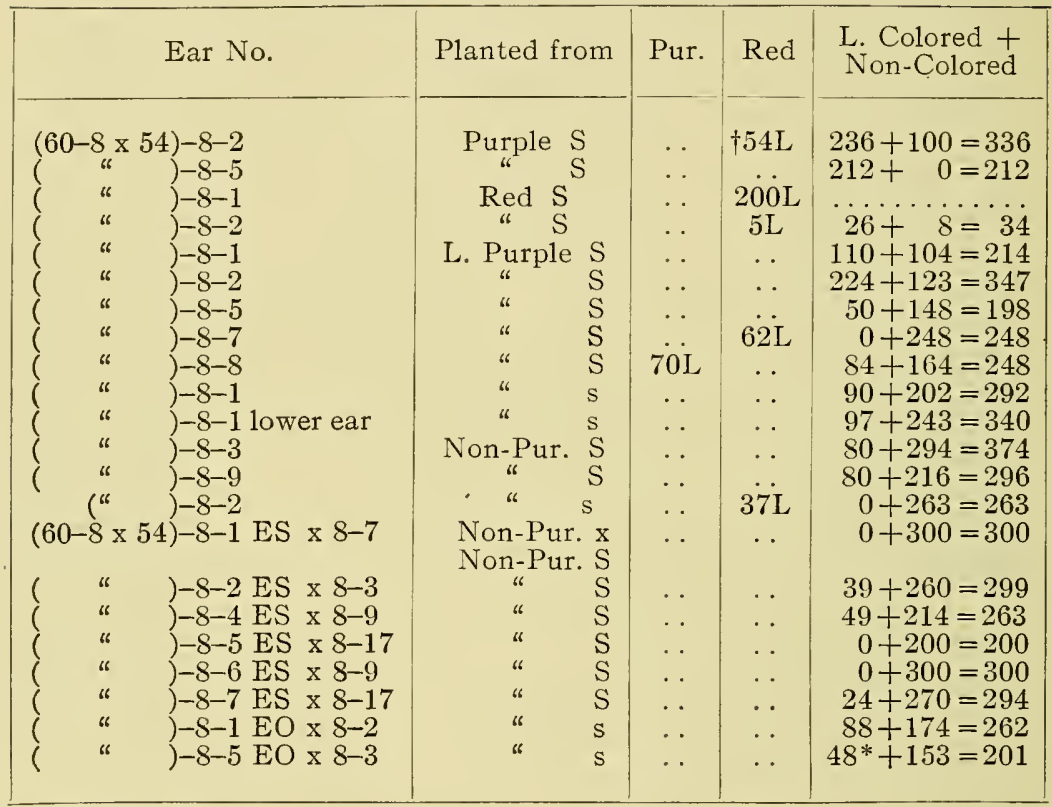

* Several seeds rather dark purple.

$\dagger$ Those marked $L$ are light in color but not nearly as light as those given in the last column. 


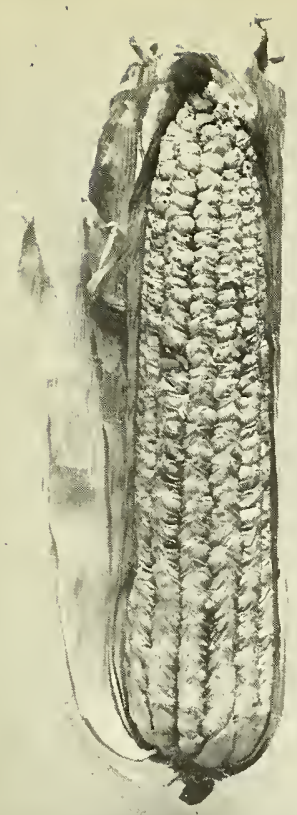

a. No. 2I. Podded maize.

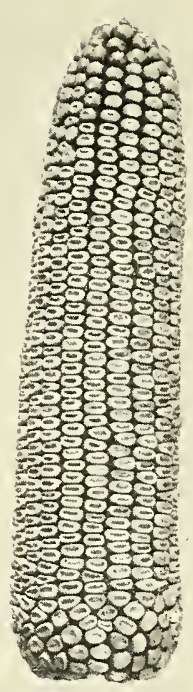

b. No. 7, non-podded maize.

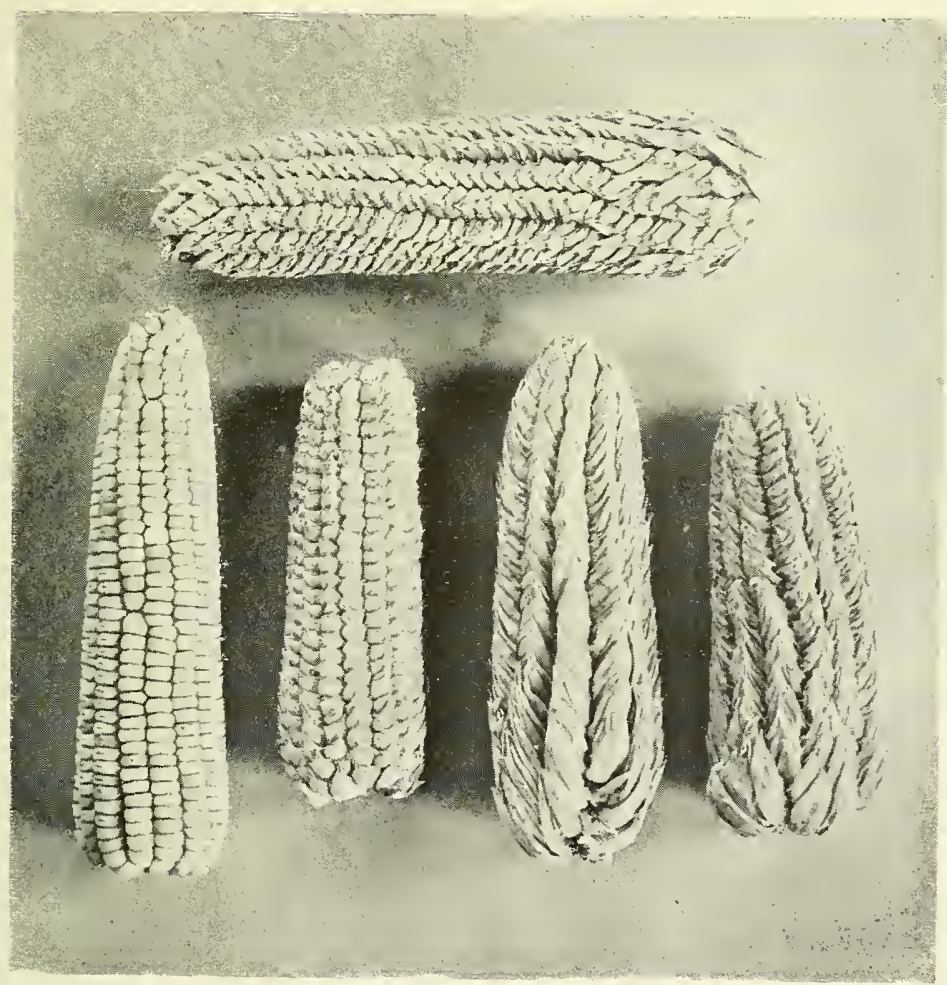

c. Cross $2 \mathrm{Ix} 7 . \mathrm{F}_{1}$ above; pod character fully dominant. $\mathrm{F}_{2}$ below; complete segregation in monohybrid ratio. INheritance of "Podden" Character. 



\section{PART III.}

XENIA.

The appearance of the endosperm in the $\mathrm{F}_{1}$ generation in the crosses discussed in Part II really include almost all of our observations of true Xenia, but the subject is sufficiently important to warrant a more systematic arrangement of the facts.

The word Xenia was proposed by Focke to denote the effect, if any, produced by the action of pollen upon the maternal tissue of the seed plant. The classical example of such effect was the endosperm of maize. After the discovery by Guignard ('99) and Nawaschin ('99) that the endosperm is in reality a part of the filial generation formed by the development of the endosperm nucleus after fusion with the second male nucleus of the pollen cell, De Vries ('99), Correns ('99) and Webber (:00) saw in this the explanation of the phenomenon in maize. These facts took away the only authentic illustration of Xenia in its original use - the effect of foreign pollen on maternal tissue. In this older sense the word is therefore of no value, and it may be used solely to describe the visible effect of the second male nucleus on the endosperm. Unfortunately, botanists have not been so prompt in discarding belief in the original meaning of Xenia as the zoologists in discarding telegony. In the experience of Correns, of Lock and of ourselves the effect of the second male nucleus has never extended to maternal tissue. One of the present authors has made several experiments in which pollination without fertilization (between infertile species) has had an effect on maternal tissue, (parthenocarpie), but this effect was simply that of a chemical stimulus or irritant producing cell division in the carpels.

The visible effects of double fertilization have been found in the following cases, in all of which the parents have been selfed strains that precluded errors in the observations. Nonstarchy seeded plants crossed with starchy seeded plants always 
show starchiness. Starchiness is completely dominant, therefore the reciprocal cross, bringing in the "opposing" character, never shows Xenia.

Yellow endosperm is also completely dominant in most cases. Non-yellow crossed with yellow endosperm therefore shows Xenia while the reciprocal shows no Xenia. Three exceptions to this rule were found, however. In the large races of dent maize where the zone of soft starch at the summit of the seed is extensive, the heterozygous yellow is somewhat lighter in color than the homozygous yellow, and Xenia appears when the cross is made either way. It shows as a cap of lighter color than the homozygous yellow. When floury yellow races are crossed with floury white races this lighter color of the heterozygote extends throughout the seed. In this case difference in color is always great enough to be noticed by a careful observer in either cross, but where the cap only is floury the color intergrades to that of the homozygous yellow. When dealing with races with corneous endosperms, such as the flint and pop varieties, there is so little difference in color that the homozygous yellow is generally indistinguishable from the heterozygous yellow; therefore Xenia occurs only when the white is the female parent. Even here, however, we have found two different cases where a few heterozygous yellows were distinguishable from homozygous yellows when the latter were used as the female.

Both the red and the purple colors in the aleurone cells behave in the same way as regards Xenia. When the two parents differ only in these characters, they are completely dominant and Xenia occurs only when they are possessed by the male parent. Even in the race in which a slight purple color appeared when the color factor was absent (P c instead of P C) the same slight color appeared when it was used as the male upon a race in which $\mathrm{P}$ and $\mathrm{C}$ were both absent. Furthermore when this race was crossed either way with a white race bearing the color factor ( $\mathrm{P}$ c x p C or $\mathrm{p} \mathrm{Cx} \mathrm{P} \mathrm{c),} \mathrm{the} \mathrm{full} \mathrm{purple} \mathrm{developed} \mathrm{and}$ appeared as Xenia. The red color undoubtedly behaves in the same way although we have made no original crosses dealing with these conditions. Again, two pure white races $(\mathrm{P} \mathrm{C}$ and $\mathrm{p} \mathrm{C)}$ which show not the slightest color may bring together 
the two factors $\mathrm{P}$ and $\mathrm{C}$ necessary for full development of the purple color, and Xenia results when either is the female parent.

The next and last case in which we have observed Xenia is that in which the white parent possesses a character that inhibits the development of red or purple aleurone cells. Correns and Lock probably used races containing this character but they did not distinguish it from a recessive white or simple absence of the purple character. They therefore concluded that when a white race was crossed with a purple, Xenia sometimes results and sometimes does not result, and that no change occurs when the purple is the female parent. The true state of affairs is just the opposite of this. When a white containing the inhibitor is the male parent, a white seed results, and while the same result is obtained in the reciprocal cross it is of course unnoticed when the white is the female parent. Sometimes the purple is not fully inhibited and then a light purple results no matter which parent is the mother.

If one considers these observations as a whole, the following law regarding Xenia may be formulated:

When two races differ in a single visible endosperm character in which dominance is complete, Xenia occurs only when the dominant parent is the male; when they differ in a single visible endosperm character in which dominance is incomplete or in two characters both of which are necessary for the development of the visible difference, Xenia occurs when either is the male.

Correns observed that in every case where Xenia may be expected to occur, the seeds showing Xenia were always hybrids. This fact was assumed to prove that the second male nucleus always bears the same characters as the one that fuses with the egg cell to form the embryo. For this reason Mendelian segregation of the gametes must have occurred previous to the division of the pollen nucleus. Our observations are entirely in accord with those of Correns. The latter author and also Webber observed several cases where Xenia occurred in only one-half of the endosperm. These rare phenomena which are probably similar in nature to the gynandromorphs occurring in insects, they both interpreted as the independent development of the endosperm nucleus and the second male nucleus. We have observed many instances of this phenomenon and have grown a number of them to see if the tendency was inherited 
but without positive results. Correns' and Webber's explanation of the cause of these seeds is probably correct, yet the suspicion cannot be avoided that if the two nuclei can develop independently then the female nucleus ought sometimes to develop to the total exclusion of the male. If this were true a seed showing no Xenia where it is to be expected, should sometimes prove to be a hybrid. This has never occurred in our work, a fact in disagreement with the work of Webber. It may be possible then that the cause of these seeds is Mendelian segregation in somatic tissue, such as often occurs in bud sports. This could be proved if there occurred among the $F_{1}$ seeds of a cross in which the parents differed in two characters, an individual in which the characters were segregated differently: for example, if a white sweet maize were pollinated with a yellow starchy race, and a seed developed having one half yellow sweet and the other half white starchy. The matter is simply mentioned because it is important to biological theory, and it was thought that some experimentalist might happen upon such an individual.

It is thought that Webber's idea that seeds with splashed purple aleurone cells are due to mosaic development of cell descendants of the endosperm nucleus and of the second male nucleus, is incorrect. If this idea were true, in cases where the endosperm is heterozygous yellow, this character also should be mosaic. Such cases have never been reported. It therefore seems better to consider the splashed purples as cases of incomplete dominance caused by other factors as was explained in greater detail earlier in the paper. 


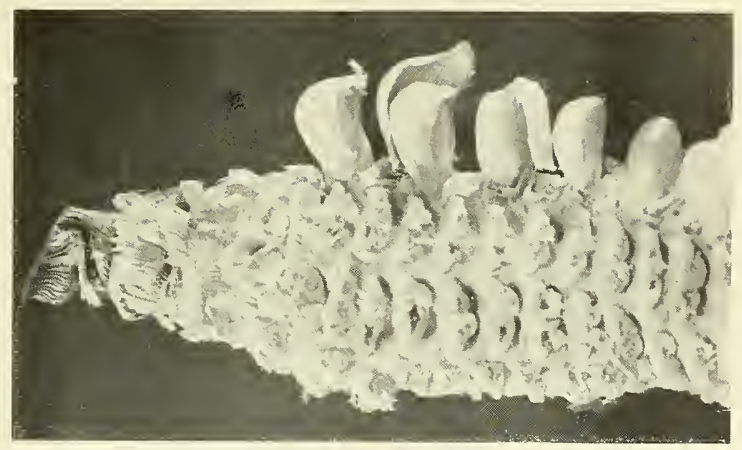

a. Podded maize. The four husks successively removed showing naked seed at right. The double rowed condition characteristic of all maize varieties is seen most clearly.

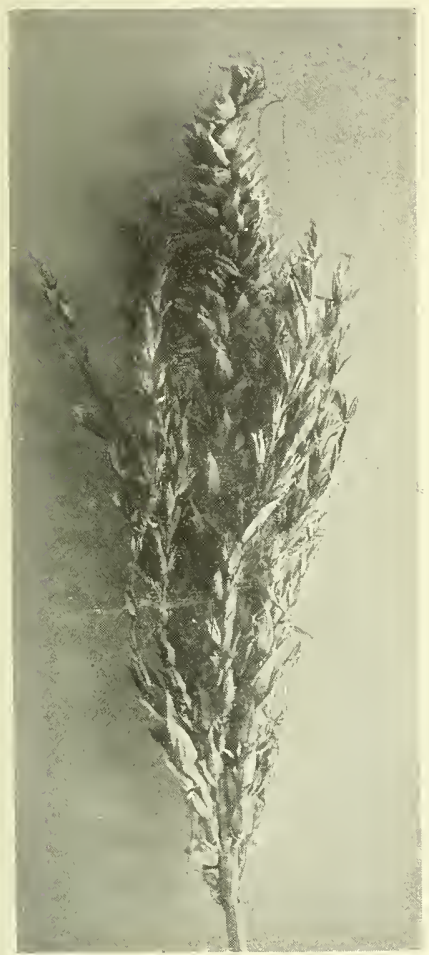

$b$.

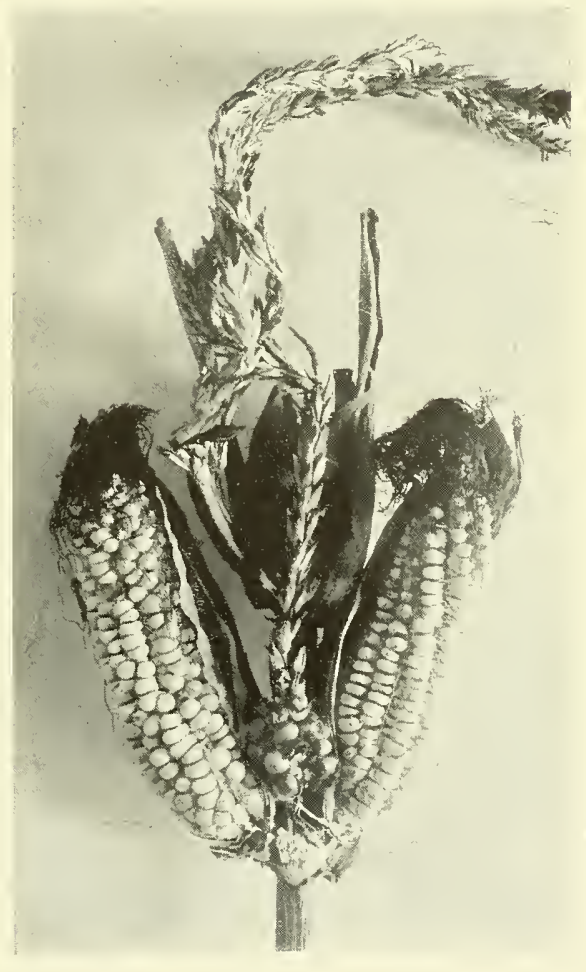

c.

Male spikes (tassels) showing development of seeds. $b$, a dominant F2 plant; $c$, a recessive $F_{2}$ plant. Segregation is persistent in this cross, $21 \times 7$. 


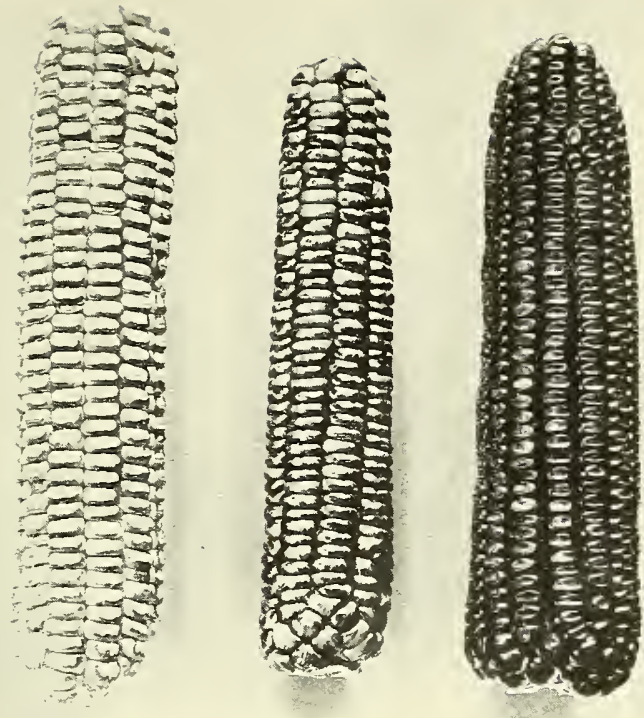

a. At left, the color which develops in sunlight- $R_{4}$; in center variegated or mosaic seeds-R2; at right, common red pericarp-RI.
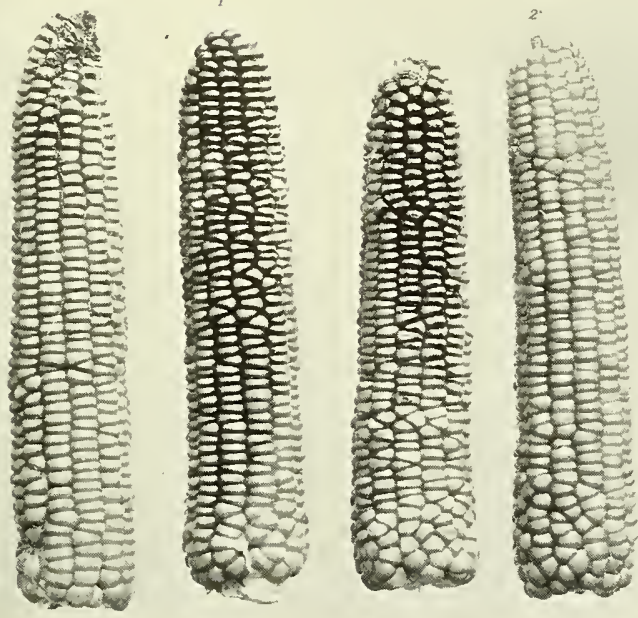

b. Segregation of pericarp color $\mathrm{R}_{4}$ in $\mathrm{F}_{2}$ of cross 5 xII. Amount of color dereloped is variable depending on light conditions during maturation. 



\section{PART IV. \\ PLANT CHARACTERS.}

In this part of the paper the inheritance of normal plant characters is considered. These characters in general have no effect upon the endosperm - the new generation - and therefore do not show as Xenia in the daughter seeds of the ear that has been crossed.

\section{Podded and Podless Maize.}

The inheritance of the podded character is interesting because it is a shining example of a case where a gross morphological character behaves as a simple Mendelian mono-hybrid. No. 21 a podded maize was crossed with a common Leaming dent like No. 7 , but not of the same stock. The $F_{1}$ generation was as perfectly podded as the podded parent. There was of course some variation in the length of the husks of the seeds, a variation apparently physiological in character depending upon the vigor of the mother plant, but this variation was no greater in the $F_{1}$ generation than it was in the pure podded maize. The $\mathrm{F}_{2}$ generation yielded 64 podded and 21 non-podded individuals. The latter were without any trace of husk and were not distinguishable from ordinary non-podded corn which had never been crossed with a podded variety. (See Plate XII.)

The $F_{1}$ generation was also crossed back with the recessive the non-podded variety - and in the next generation yielded 41 podded ears and 50 non-podded ears. In other words Hh $\mathrm{xh}$ gave $50 \% \mathrm{Hh}$ and $50 \%$ hh as was to be expected. The character was again strictly discontinuous. The extracted recessives proved absolutely true.

\section{Pericarp Color.}

There are various red sap colors appearing in the pericarp, the cob, the husks, the silks, the glumes and the anthers of maize. We have not been able to make a chemical study of them and 
so cannot say if they are due to the same compound, but the comparatively small amount of data regarding their inheritance that we have obtained is particularly interesting on account of the number of different organs in which color occurs. It has long been thought that such colors that manifest themselves in different parts of a plant, are single units as regards heredity, but are produced in visible quantities only when developmental conditions are favorable or when certain transmissible limiting factors or extension factors which effect their development, are present or absent. Our especial problem was to find out whether these red colors occurred and were transmitted separately or whether they were linked together in genetic or in chemical relationships. This work is therefore simply a report of progress.

The first red pericarp, which we will call $R_{1}$ was found in No. 27 , a rice pop maize. It was the ordinary dark red color of the varieties commonly known as red corns. It did not have a red cob or red silks, although the glumes of the male flowers were sometimes reddish. Crossed with number 28, a rice pop with white pericarp, white cob and silks, it gave 75 red and 22 white ears in $\mathrm{F}_{2}$. The color was inherited absolutely discontinuously, the reds being all dark and the whites showing no trace of color.

The only other cross with apparently this same dark pericarp color, was a peculiar ear found in a field of dent maize of unknown parentage. This ear, as shown in Plate XV, fig. a, had seeds with red pericarp on one side and seeds which were sometimes white and sometimes striped with red on the other side. The ear appeared in a field of white maize in which only white maize was planted. It must have been produced therefore by a hybrid seed $R_{1} r_{1}$. Furthermore since it was the only ear in the field showing red pericarp, it is likely that it was nearly all pollinated by white. One would expect its seeds therefore to be half $R_{1} r_{1}$ and half $r_{1} r_{1}$, and that they would give in the next generation $50 \%$ red ears, $50 \%$ white ears. In order to test any possible transmission of the variation which appeared in this ear however, both the red seeds and the seeds from the side which had white and striped kernels were planted. From the dark red seeds were obtained 22 dark red ears and 22 white ears; from the white and striped seeds were obtained 15 ears showing a few red striped seeds and 15 ears with only white 
seeds. No difference was observed between the progeny of white and of striped seeds. Both kinds of seeds from this side of the ear gave striped ears and white ears. A selfed red ear of this generation gave a simple mono-hybrid ratio in the next generation -75 red ears and 26 white ears. The explanation of this phenomenon evidently is the same as that of the bud variations that sometimes occur in perennials. They occur in annuals but are usually unnoticed. The plant due to produce a red ear varied somatically so that one-half of the ears was red and one-half striped. This variation was transmitted by seeds, but at the same time the hybrid character of its seeds was unchanged as shown by their segregation into reds and whites in the next generation and the normal segregation of the hybrid dark reds in a further generation. This strain had red cobs, and there was perfect coupling between the two characters in the next generation.

Two other red pericarp colors seemingly independent of red in other parts of the plant have been found, which may be called $R_{2}$ and $R_{3} . \quad R_{2}$ is a dark red that occurs as irregular red stripes radiating from the point where the silk was attached; $\mathrm{R}_{3}$ is a dirty red color more abundant at the base of the seed and almost wanting at the summit. The dye occurs in small amounts. The latter red, which occurs in Palmer's red-nosed yellow appears to be completely coupled * with red silks. It is almost certain that this red forms an allelomorphic pair with its absence that is entirely independent of $R_{1}, R_{2}$ and $R_{4}$, but our numbers are too small to make a full report on the matter. The mosaic red $\left(R_{2}\right)$ is also one that has not been subjected to sufficient genetic study. Thus far ( 2 generations) it has not bred true but has thrown a percentage of non-reds.

Two other red pericarps have occurred, however, which are interesting because they are the same in appearance but are not allelomorphic to each other. The first is a rose red $\left(\mathrm{R}_{4}\right)$ characteristic of No. 5. It develops only in presence of light, hence the ears with thick husks show the color but faintly. When the husks are stripped away and the ear matures in full sunlight, however, the color appears over the entire ear as a bright

* Coupling is proved by the fact that red silks occur without red pericarp in other combinations. 
rose red. In numbers 2,8 and 18 there appeared another red which we at first thought was the same as the above. It occurs in less amounts and on thick-husked ears can only be detected by careful examination. Since these two reds behave as separate allelomorphic pairs they are called $R_{4}$ and $R_{5}$.

The transmission of these two reds was shown by crossing No. $5\left(\mathrm{R}_{4}\right)$ with No. $18\left(\mathrm{R}_{5}\right)$. In $\mathrm{F}_{1}$ all of the ears were red. In $\mathrm{F}_{2}$ there were 131 red ears and 7 white ears. No. $5\left(\mathrm{R}_{4}\right)$ was also crossed with No. $2\left(\mathrm{R}_{5}\right)$ and gave similar results although the number of plants was small. In $\mathrm{F}_{2}$ there were 52 red ears and 2 white ears.

It may be asked whether the red in No. $5\left(\mathrm{R}_{4}\right)$ acts as a simple mono-hybrid in crosses with strains having no red in the pericarp. We have only one cross of this kind in which data for pericarp color were taken. No. 11-2 $\left(\mathrm{r}_{4}\right)$ was crossed with No. $5\left(\mathrm{R}_{4}\right)$ and yielded 251 red ears and 91 white ears in $\mathrm{F}_{2}$.

None of these varieties had the red color in other organs.

\section{Cob Color.}

Several crosses were made in which one parent had a red cob and one a white cob. None of the parents had dark red pericarps $\left(R_{1}\right)$ but in one case $R_{4}$ was present (the light red pericarp developing in presence of light). In a cross between No. 5 and No. 6, $\mathrm{F}_{2}$ yielded 277 ears, of which 212 had red cobs and 65 white cobs. It was strictly a mono-hybrid cross, and the character red-cob seemed not to be coupled with the pericarp color. This red we may call $R_{c}$.

The parents in this case were tested for purity although there are strains of No. 6 in our possession that do not have red cobs. The results of the other crosses were similar and space will not be taken to report them in full. It must be noted however, that although no di-hybrid reds were found, it is not beyond probability that such might be found in an extensive series of crosses.

\section{Silk Color.}

Varieties are also obtained which have red silks although the red color.is not manifested in other parts of the plant. In fact, No. 19 , which has the darkest red silks of any variety in our pos- 


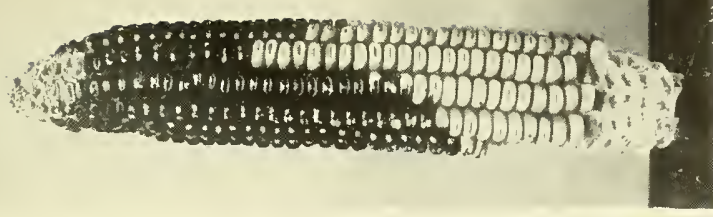

a. Somatic or bud variation from dark red seeds to slightly variegated seeds in ear whose seeds were supposed to be half $\mathrm{R}_{1}, \mathrm{r}_{1}$, and half $r_{1}, r_{1}$.

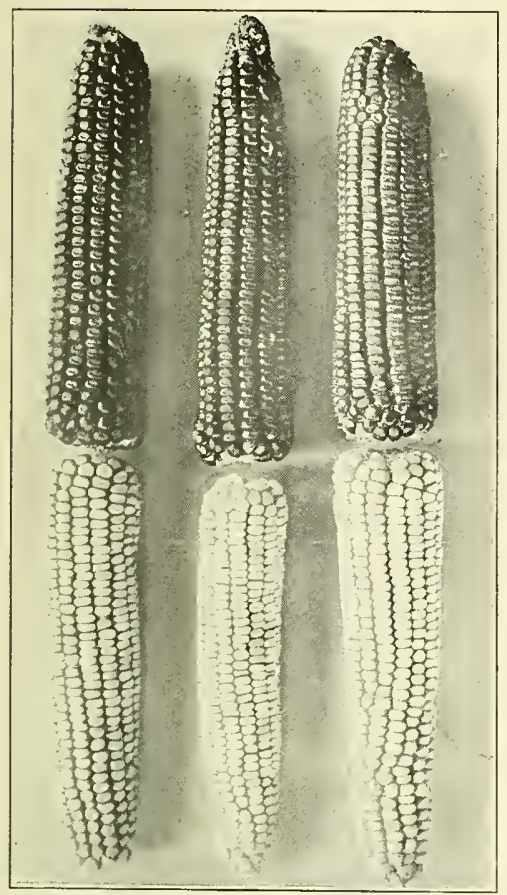

b. Progeny of red seeds of $a$. Half dark red, half white.

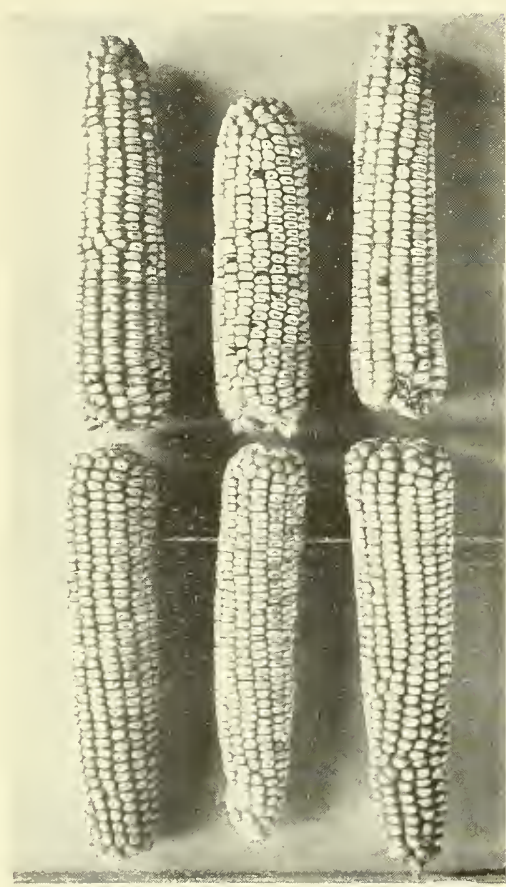

c. Progeny of slightly variegated seeds of $a$. Half slightly variegated, half white.

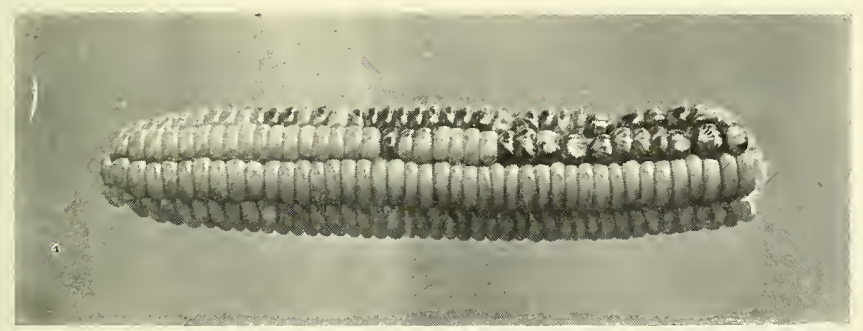

d. Sinilar bud variation in which $\mathrm{R}_{2}$ is concerned.

Pericarp Colors and Somatic Segregation. 

session, has white cob and pericarp. It is not quite clear, however, how this character is transmitted. The facts are obscured by the action of the bag over the ear to be hand-pollinated, which prevents the full development of the red color by shutting out the light. For this reason one cannot be certain whether the $\mathrm{F}_{1}$ plants which are selfed are full reds or only red-haired silks.

An illustration of what is obtained in a cross between red silk and non-red silk varieties is as follows. No. 12-2 which is pure for non-red silks was crossed with No. 9-2 which is pure for red silks. In $\mathrm{F}_{1}$ there were 110 plants with red silks and 27 with greenish-white silks with red hairs. In $F_{2}$ the progeny of $3 F_{1}$ plants were grown. The first ear gave 123 plants with red silks and 40 with white silks. The progeny of the other two ears were of three classes; reds, greenish-whites with red hairs and greenish-whites in the numbers $198: 29: 94$. We will not attempt to analyze this ratio. It is simply mentioned to show that the silk color does mendelize without the production of color in other parts of the plant.

\section{Glume Color.}

No plant has yet been obtained which has red glumes and yet shows no red color in other parts of the plant. One has been found however that is pure for red glumes and shows no red in other parts with the exception of the silks.

\section{General Consideration of Red Sap Color.}

It is difficult to put aside the thought that all of these red colors are localizations of the same general pigment. If this were true, there should be a series of varieties in which increasing extension of color is found, until red appears in all the organs in which it ever occurs. This is not true. Varieties exist, for example, with red pericarp and red cob, with red pericarp and white cob and with white pericarp and red cob. If these formed a series with increasing extension of red one might find the color localized in the cob and not found in the pericarp, but the theory could not account for the existence of varieties with red pericarp and white cob. It seems as if these facts would drive us to one of two conclusions. We are dealing. 
either with different color compounds each of which manifests itself in only one organ, or with identical genes held in the germ cells in such different combinations that they may be manifested differently. The latter interpretation is more probable, and the natural assumption is that identical genes held by different chromosomes in some way accounts for the different manifestations. Yet there is an obstacle to this assumption which though not necessarily insurmountable, is at least important. One cannot quite understand why a red color should be manifested in different organs simply because its gene is held by different chromosomes.

Since the first draft of this paper was written Emerson * has reported important data from many crosses where certain of these red colors of maize are sometimes absolutely coupled in their inheritance and sometimes show spurious allellomorphism. For example, if a plant with a red cob and a red pericarp is crossed with one in which these colors are absent, there is segregation in $\mathrm{F}_{2}$, but the colors remain together. On the other hand, if a cross is made between a plant having a red cob and a white pericarp and one having a white cob and a red pericarp, the colors show spurious allelomorphism. The spurious allelomorphism is shown by the $F_{2}$ generation, in which is produced 1 red pericarp-white cob : 2 red pericarp-red cob : 1 white pericarpred cob. His idea is that in the case first mentioned the colors are both carried in the same chromosome while in the second case they are carried in different but homologous chromosomes. As Emerson himself has stated, this theory assumes the inevitable pairing of the two chromosomes carrying the colors, which is probable but unproved. Our own data show no facts diametrically opposed to this hypothesis but the criticism regarding genes held by different chromosomes that was made above would also apply here.

\section{Physical Transformations of Starchiness.}

Although presence and absence of starchiness behaves as a Mendelian allelomorphic pair in heredity, the physical condition of the starch is a different matter. Starchiness acts as a filial or endosperm character and shows as Xenia in individual seeds.

\footnotetext{
* At meeting of Amer. Soc. Nat., Ithaca, N. Y., Dec. 29, 1910.
} 
The physical condition of the starch behaves as a plant character affecting the entire ear. One may have ears which show a tendency towards the dented character in some seeds and a tendency towards the flint character in other seeds. Such ears are probably always heterozygous dent-flint combinations, and simply show zygotic variations. The different kinds of seeds give the same results in the next generation and show no tendency toward a real segregation of dent and flint characters in the individual seeds.

The difference in the appearance of the starch in the different races of maize has been described earlier in this paper. The immediate cause of these differences is the amount and location of the soft starch formed in proportion to that of corneous or translucent starch. In the pop corns there is total absence of soft starch or at most only a small amount immediately surrounding the top and back of the embryo. As this amount of soft starch increases, the starch cells of the seeds lose their ability to hold the steam formed by the moisture they contain when heated, and can no longer evert their entire contents as cooked starch. They may pop slightly but they can no longer be considered commercial pop corns. They have passed into the flint corn class. This class includes varieties with varying amounts of soft starch up to those in which it covers the cap. The latter are dent corns, for the dent is simply formed by the greater percentage of contraction which the soft starch undergoes in drying. The amount of dentness is in direct proportion to the thickness of the soft starchy layer at the cap. A few varieties are known in which the soft starch has replaced almost all the corneous starch. They are known as semi-starchy corns. They are not so well known however, as the floury corns in which the corneous starch is absent.

As all of these varieties are known in $Z$. mays curagua, Z. mays hirta and $Z$. mays tunicata, it is obvious that the proportions these two kinds of starch (in appearance at least) plays a great part in the commercial classification of maize. Also, since so many varieties are known in which every possible ratio of corneous starch to soft starch occurs, it is evident that the transmissible characters which cause these differences are relatively numerous and their interactions complex. For these reasons, it is perhaps too much to expect that the inheritance of this 
complex of characters will be cleared up until all possible combinations of these varieties have been made and studied. Our data serve only to establish certain general facts.

The first bit of evidence in the matter comes from a consideration of the behavior of the only class of maize varieties that apparently are beyond the scope of the subject in hand - the sugar varieties. When the latter are crossed with starchy varieties it is perfectly clear that starchiness is a separate character independent of the physical form in which it exists. Sugar varieties are found that are simply dents and flints which lack starchiness. We have also produced by crossing, sugar varieties that are characteristic pop corns lacking starch. No sugar varieties are known which would be soft starch varieties ( $Z$. mays amylacea) if they contained the S factor, but it can hardly be doubted that such could be produced. The experimental evidence is as follows. When Black Mexican, Early Crosby and Golden Bantam are crossed with dent varieties, the Xenia starchy seeds, or $F_{1}$ generation are all flint-like in character. These when grown produce $F_{1}$ ears which have an appearance intermediate between dents and flints and give in $\mathrm{F}_{2}$ ears which are characteristically flint in character. In the case of the cross between Black Mexican sugar No. 54 and Illinois High Protein dent No. 8, these flint segregates of $\mathrm{F}_{2}$ were carried to the $F_{3}$ generation and bred true. Since pure dent varieties were the male parents of these crosses, the occurrence of flints in $\mathrm{F}_{2}$ can only be accounted for by supposing that the sugar varieties that were used as the female parents of the crosses were latent flints. In the same way Stowell's Evergreen sugar and Late Egyptian sugar were proved to be latent dents by crossing them with starchy flint varieties. The Xenia seeds were dented and pure dents appeared in the $\mathrm{F}_{2}$ generation. One peculiar thing occurred in the cross between Black Mexican sugar, No. 54 and Illinois High Protein dent, No. 8. In $F_{1}$ all of the ears were intermediate between dent and flint with a tendency toward dentness, except one. This ear was a pure flint in appearance. Only one of the intermediate ears was grown in the $\mathrm{F}_{2}$ generation and it produced 91 dents and intermediates and 6 flints. The pure dents could not be separated from the intermediates but flints occurred in the ratio of one out of sixteen. The ear which was apparently flint in $F_{1}$ proved 


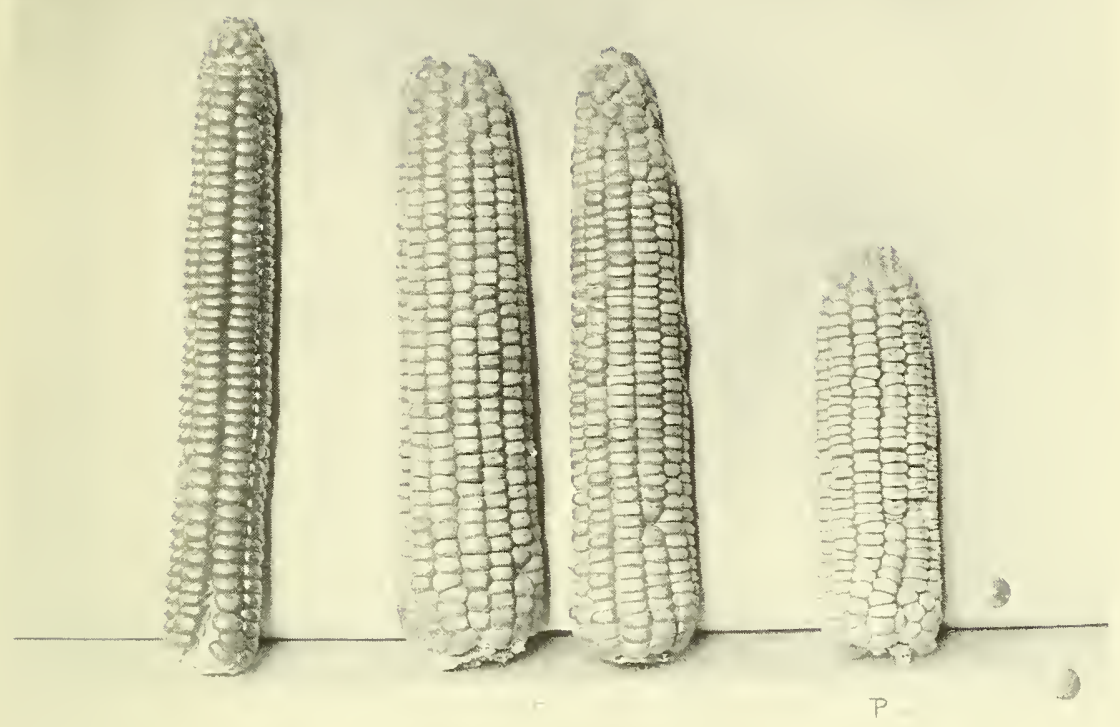

At left, No. 15, Longfellow flint. At right, No. 8 Illinois high protein dent. In center, F I ears of cross $\mathrm{I}_{5} \mathrm{x}$, showing intermediate character of physical condition in which the starch is stored.

\section{Dent-Flint Crosses.}



to be an intermediate in $\mathrm{F}_{2}$. Thirty-four ears were obtained, of which three were clearly dented, a number were intermediate, while from ten to twenty would ordinarily be classed as flints. Thirteen of the latter were grown in the $\mathrm{F}_{3}$ generation and produced from 50 to 175 ears apiece. Nine out of the thirteen gave only flint ears in a total of 947 individuals. The other four ears produced a total of 264 ears of which between 10 and 20 were flints (i. e. ten were certainly flints and ten others were questionable). Therefore, since 9 out of 13 of the 20 ears classified as "probable flints" in $\mathrm{F}_{2}$ proved to be true flints in $\mathrm{F}_{3}$, we have 14 ears pure flint to 20 dents and intermediates in $\mathrm{F}_{2}$. We do not know enough about this cross to say just what occurred here, but it is probable that one factor for dentness was missing in the pollen which produced the hybrid seed from which this lot $\mathrm{F}_{2}$ ears came. In the other case a di-hybrid ratio appears.

Several other crosses were made between true dent and true flint races, that is, races in which the parents both were starchy. No. 15 Longfellow flint was crossed with No. 8 Illinois High Protein dent. The $\mathrm{F}_{1}$ generation was intermediate in character. Through an unfortunate oversight data regarding the segregation in $\mathrm{F}_{2}$ were taken on the progeny of only one ear of the three $\mathrm{F}_{1}$ ears planted. This ear gave 33 dents and intermediates to 3 flints. About 200 ears were obtained from the other two $\mathrm{F}_{1}$ ears planted and from our general field notes we can say that not less than 15 dents and intermediates to each flint ear were obtained. One flint ear gave a crop of 94 ears in $\mathrm{F}_{3}$, all of which were flint. One dent ear grown in $\mathrm{F}_{3}$ also proved to be pure. A better idea of these results is given by the photographs on Plates XVI and XVII, however, than can be given by written description.

Two crosses were made between No. 11, Sturgis' flint and No. 8, Illinois High Protein dent. Both were intermediate in $F_{1}$. In $F_{2}$, progeny of one $F_{1}$ ear of the first cross gave 44 dents and intermediates to 3 flints. In $\mathrm{F}_{3}$, one ear from an intermediate of $\mathrm{F}_{2}$ gave 23 dents and intermediates and 2 flints. Five $F_{1}$ ears of the other cross were grown in $F_{2}$ resulting in 175 dent and intermediate ears, and 17 flint ears. The ratio here is about $10: 1$, but if any error was made in the classification it certainly occurred by placing intermediates in the flint class. 
Another cross of this kind was that of No. 5-5, Watson's flint with No. 2, Illinois Low Protein. The ears were intermediate in $F_{1}$. In $F_{2}$ there was segregation, for ears exactly like No. 2 were obtained. Out of the 101 ears obtained, however, no ears were produced that could be classed definitely as flints. One or two flint-like ears occurred which will be tested for purity this coming season. It is quite likely that we have here a tri-hybrid or ṕossibly a tetra-hybrid.

The female parent of this cross, No. 5, was also crossed with No. 6, Leaming dent. $F_{1}$ generation was intermediate as before. Five $F_{1}$ ears were grown with the following results:

\begin{tabular}{cc} 
Dents and Inter. & Flints \\
98 & 16 \\
71 & 17 \\
51 & 5 \\
42 & 7 \\
\hline Total, 262 & - \\
& 45
\end{tabular}

These ears gave different ratios. Probably more ears were classed as flints than would prove to be such in the $\mathrm{F}_{3}$ generation, yet they were classified similarly in each case and $\mathrm{F}_{3}$ tests would probably only reduce the proportion of flints from each ear. Paradoxical as it may seem, however, different ratios are to be expected in $F_{2}$ if the general hypothesis concerning the applicability of Mendelian principles to cases where variation is apparently continuous, is true (East:10). This is explained in the following paragraphs.

In the crosses described above three facts stand out definitely. The characters which give the flint or the dent appearance to maize are transmitted as plant characters to the entire ear and not as endosperm characters to the individual seed. They conform to the essential feature of Mendelism by showing segregation; and they, are due to the action of more than one transmissible character. The question remains, can any or all of these characters be named?

Our experience suggests that the proportion of corneous starch to soft starch depends partially upon size and shape of the pericarp and upon the number of rows per ear. All of the 
races (pop corns) in which soft starch is absent have small seeds, and the full corneous starch character cannot be transferred to large seeds by recombination through hybridization. On the other hand, by crossing a pop maize with a dent maize dent seeds may be obtained which are much smaller than many races with flint seeds. Further, dent races are known which have much larger seeds than some races in which the corneous starch is entirely absent (the flour corns). There is also some relation between the size of the plant and the amount of soft starch in their seeds. The floury or semi-floury corns are in general larger than the corneous starchy corns. Here again, however, there is an overlapping, for we have produced dent races by crossing with dwarf pop races, which are much smaller in size than the large pop and flint races.

Relationship between the physical character of the starch and shape of pericarp is much more intimate than it is between the former and size characters. In the rice pops the pericarp is drawn to a point at the place where the silk is attached. This makes the rice pop races have rather long slender seeds, but it is probably due to a separate character or characters. Leaving this complication out of consideration one may say that the pop corns have small seeds which are almost as broad as they are long. As the seeds become larger, if the ratio of length to breadth remains about unity or less, flint races are formed. If, instead, the ratio of length to breadth increases, dent races are formed. On the other hand, medium large to large seeded races may have almost any ratio of length to breadth and be either flint, dent or floury varieties.

Of course the shape of the pericarp depends somewhat on the number of rows, as the greater this number the more the seeds are crowded together and thus lengthened. Small-seeded pop and flint races exist with as high as 20 rows, but when the seeds are medium in size flint races are usually 8-rowed and 12-rowed, and never - in our experience - over 16 rowed. Dent races, on the other hand, seldom occur with less than 12 rows, but when large seeded they do exist with as few as eight rows. Floury races we have never seen with less than 10 rows, but they reach as high as 24 rows.

These relationships may simply be correlations and not direct causes of the proportion of corneous starch to soft starch 
that exists in various strains of corn. But even if they were directly concerned, they could not account for the large number of differences in varieties, for none of the correlations are sufficiently high. Many other characters, the exact nature of which is unknown, must be concerned in the matter. The simplest interpretation of the matter seems to be the interaction of independent allalomorphic pairs of the nature reported by Nillson-Ehle $(: 10)$ and East $(: 10)$ in earlier papers. If this interpretation be granted, one should expect that greatest difference in character pairs would exist in the case of pop and starchy races. Flint and dent races with about the same size seeds and small differences in number of rows should differ by fewer pairs of characters.

We have seen that in two of such crosses the evidence points to the existence of two allelomorphic pairs giving pure flints and pure dents in the $\mathrm{F}_{2}$ generation once in every sixteen individuals. In another cross (5-5 x 2) at least three character pairs are concerned. It happened that in two of these cases the male parents were Illinois High Protein and Illinois Low Protein dent races, which gives us some idea as to why there was a di-hybrid ratio in one case and a higher ratio in the other case. These two strains were both isolated by selection from a commercial variety known as Burr's White. This variety, as are most commercial varieties, is a mixture of complex hybrids. By continued selection of ears high in protein and of ears low in protein with close interbreeding of the progeny these two strains were isolated. The high proteid race is characterized by a high percentage of corneous starch, bringing it into closer relationship to the flint corns. The low proteid race is characterized by a high percentage of soft starch, bringing it into closer relationship with the flour corns. It was the high proteid strain, that is, the one nearer the flint varieties, that gave the di-hybrid ratio when crossed with a flint race; while the low proteid strain, - the one nearer the flour corns, - gave the higher ratio.

This result is what one should expect, but can the $6: 1$ ratio obtained in the cross between No. 5 and No. 6 be explained so easily? We believe it presents no difficulties if the complex gametic constitution of No. 6 is properly appreciated. The individual which furnished the No. 6 pollen came from a selfed 
daughter ear of the original No. 6. Its sister ears varied in number of rows from 12 to 20 with the mode at 16 . The individual furnishing the pollen in cross $5 \times 6$ was in all probability therefore a complex hybrid itself, and the cross instead of being simple was really a collection of crosses. There is no doubt that many intermediate ears were classed as flint in the table given above. If they could all be grown for another generation it is quite likely that a series of mono-di-tri and higher hybrids would be found. It may be asked why, if this is the case, were not the other crosses complex? The answer is that they undoubtedly were more complex than they seemed. For example, if a large number of $\mathrm{F}_{1}$ ears were grown it is likely that some would give ratios other than those found. It was simply chance that gave us fairly good di-hybrid ratios from a few $F_{1}$ ears in two instances. The most important reason why the cross with No. 6 was likely to be more variable than the others, however, lies in the fact that all of the other strains had been inbred for much longer periods.

\section{Size Characters.}

The remainder of Part IV will be devoted to a discussion of the inheritance of size characters, - variations that have been considered to be and to casual observation are, continuous. Our studies have been concerned with the number of rows per ear, height of plant, length of ear and size of seed.

It is perfectly obvious to one familiar with the maize plant that it is almost impossible to work out in detail the inheritance of the complex factors that interact to cause the transmissible differences in the size of its organs. That size characters are complex in themselves is shown by the numerous varieties grown commercially. They each vary from their own means, but different variety means in height are found all the way from two and one-half to fourteen feet with but little actual difference between the most similar strains. Further to complicate matters, all size characters respond to environmental stimuli, and these non-inherited fluctuations obscure the analysis of pedigree cultures in a still greater degree. For these reasons we do not attempt to analyze our results further 
than to say that they do show segregation in every case.* And segregation is held to be the important and essential feature of Mendelism. Therefore we believe that size characters mendelize.

Let us now consider the hypothesis by which segregation in characters apparently continuous in their variation, could come about. Nillson-Ehle (:09) has shown that black glumes in oats when crossed with their absence behave sometimes as monohybrids and sometimes as di-hybrids, and that presence and absence of red pericarp color in wheat sometimes behaves as a tri-hybrid. He further showed, although not quite so conclusively, that presence and absence of ligule in oats behaves as a tetra-hybrid. In this and in a former paper (East : 10) it has been shown that yellow endosperm, red pericarp and

TABLE 26.

INHERITANCE OF ROWS IN CROSS ( $5 \times 6$ ).

\begin{tabular}{|c|c|c|c|c|c|c|c|c|c|c|c|}
\hline \multirow{2}{*}{ No. } & \multirow{2}{*}{ Gen } & \multirow{2}{*}{$\begin{array}{c}\text { Rows } \\
\text { of } \\
\text { Parents }\end{array}$} & \multicolumn{9}{|c|}{ Row Classes } \\
\hline & & & 8 & 10 & 12 & 14 & 16 & 18 & 20 & 22 & 24 \\
\hline $\begin{array}{l}\text { No. } 5 \text { flint } \\
\quad(2 \text { yrs. })\end{array}$ & $\mathrm{P}$ & 8 & 289 & 2 & 2 & & & & & & \\
\hline No. 6 dent & $\mathrm{P}$ & 18 & & & 6 & 31 & 51 & 18 & 4 & & \\
\hline No. $5 \times 6$ & $\mathrm{~F}_{1}$ & 8 & 13 & 36 & 53 & 10 & & & & & \\
\hline$(5 \times 6)-1$ & $\mathrm{~F}_{2}$ & 12 & 12 & 48 & 35 & 9 & 1 & & & & \\
\hline$(5 \times 6)-2$ & $\mathrm{~F}_{2}$ & 10 & 7 & 22 & 15 & 2 & & & & & \\
\hline $\begin{array}{l}(5 \times 6)-22 \\
(5 \times 6)-23\end{array}$ & $\begin{array}{l}\mathrm{F}_{2} \\
\mathrm{~F}_{2}\end{array}$ & $\begin{array}{l}10 \\
12\end{array}$ & $\begin{array}{l}8 \\
4\end{array}$ & $\begin{array}{l}45 \\
25\end{array}$ & $\begin{array}{l}31 \\
60\end{array}$ & $\begin{array}{l}1 \\
18\end{array}$ & 4 & 2 & 1 & & \\
\hline
\end{tabular}

dented seeds (as opposed to flinty seeds) behave as di-hybrids, with so many data that the facts can hardly be questioned. We have also shown although less conclusively that other red pericarped varieties and other varieties which differ in their ratios of soft to corneous starch behave as higher hybrids.

It should be clearly understood what this means to Mendelian theory. Several genes for the same character may exist in the germ cells of one organism, the number being limited possibly by the number of chromosomes. The limited number of cases thus

* It is probable that the number of internodes per plant is one of the factors directly concerned in the inheritance of height of plant. 


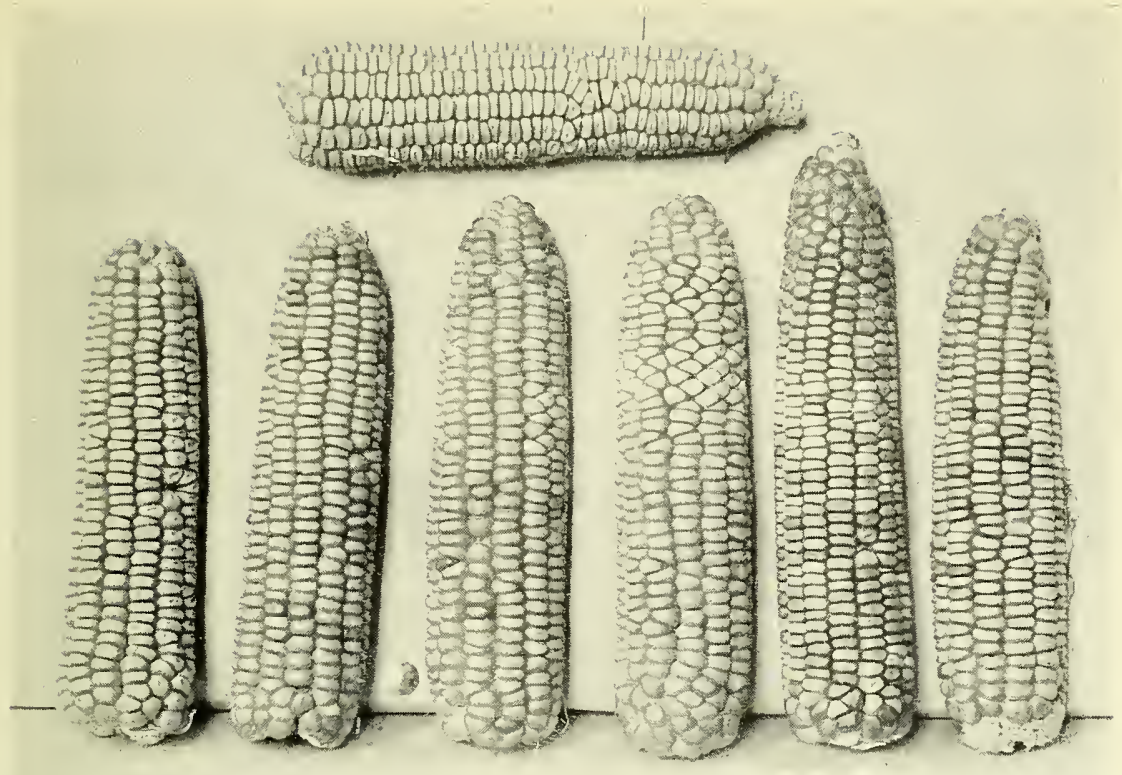

1.

a. F2 dent segregate above (frequency about $\mathrm{I}$ in Io). Random sample of its $\mathrm{F}_{3}$ progeny below.

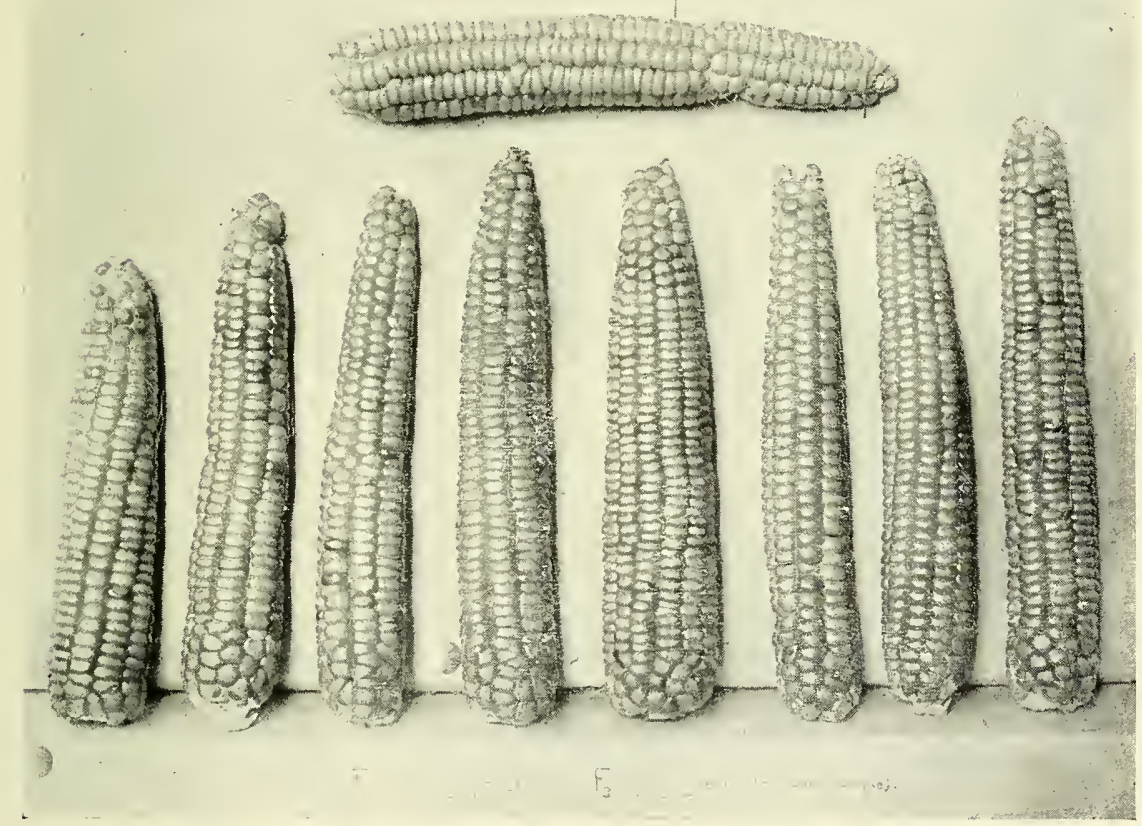

b. F2 flint segregate above (frequency about $I$ in I6). Random sample of its $\mathrm{F}_{3}$ progeny below.

Dent-Flint Crosses. 

far found presumably is due to the fact that few size characters have been investigated, for nowhere would these phenomena be so likely to occur as in quantitative characters.

It is fortunate for us that it has been possible to prove the presence of several independent allelomorphic pairs due to produce the same somatic character, for characters like color where dominance is relatively perfect. Beginning with this as a basis, one can extend the theoretical possibilities of such facts to other cases and thus be better prepared for the paradoxical complexities that occur in actual pedigree cultures. When in a cross there is simple presence dominant to absence of one gene for a certain character, the ratio in $\mathrm{F}_{2}$ is 3 dominant to 1 recessive; when two independent allelomorphic pairs producing the same character are concerned, the ratio in $\mathrm{F}_{2}$ is 15 dominants

TABLE 27.

INHERITANCE OF ROWS IN CROSS $(5 \times 2)$.

\begin{tabular}{|c|c|c|c|c|c|c|c|c|c|c|c|}
\hline \multirow{2}{*}{ No. } & \multirow{2}{*}{ Gen. } & \multirow{2}{*}{$\begin{array}{c}\text { Rows } \\
\text { of } \\
\text { Parents }\end{array}$} & \multicolumn{9}{|c|}{ Row Classes } \\
\hline & & & 8 & 10 & 12 & 14 & 16 & 18 & 20 & 22 & 24 \\
\hline $\begin{array}{l}\text { No. } 5 \text { flint } \\
\text { (2 yrs.) }\end{array}$ & $\mathrm{P}$ & 8 & 289 & 2 & 2 & & & & & & \\
\hline No. 2 dent & $\begin{array}{l}\mathrm{P} \\
\mathrm{F}_{1}\end{array}$ & $\begin{array}{r}16 \\
8\end{array}$ & 1 & 9 & $2 \frac{2}{20}$ & $\begin{array}{r}14 \\
4\end{array}$ & 56 & 42 & 20 & 1 & 1 \\
\hline$(5 \times 2)-6$ & $\mathrm{~F}_{2}$ & 10 & 4 & 18 & 61 & 14 & 3 & 1 & & & \\
\hline
\end{tabular}

to 1 recessive. In general then if $n$ allelomorphic pairs are concerned, in $F_{2}$ there will be a ratio of $4^{n}-1$ dominants to 1 recessive. It is not likely however that dominance is ever perfect in these complex hybrids. For example, in the case of the two yellow colors in the maize endosperm, the intensity of the yellow decreases in the following order $Y_{1} Y_{1} Y_{2} Y_{2}, Y_{1} y_{1}$ $\mathrm{Y}_{2} \mathrm{Y}_{2}$ or $\mathrm{Y}_{1} \mathrm{Y}_{1} \mathrm{Y}_{2} \mathrm{y}_{2}, \mathrm{Y}_{1} \mathrm{Y}_{1}$ or $\mathrm{Y}_{2} \mathrm{Y}_{2}, \mathrm{Y}_{1} \mathrm{y}_{1}$ or $\mathrm{Y}_{2} \mathrm{y}_{2}$ and $\mathrm{y}_{1} \mathrm{y}_{1} \mathrm{y}_{2} \mathrm{y}_{2}$. In size characters dominance is probably very incomplete or absent. A heterozygous combination presumably produces half the effect of a homozygous combination. Then as dominance becomes less and less evident the Mendelian classes vary more and more from the formula $(3+1)^{n}$ and approach the normal curve of error $(1 / 2+1 / 2) .^{n}$ When there is no dominance 
and open fertilization, a state is reached in which the curve of variation simulates the fluctuation curve, with the difference that the gradations are heritable. The heritable variations are always more or less obscured, however, by the ever present fluctuation.

The experimental results may now be considered-remembering only that fluctuations are present and that in maize many genotypes are often present in one parent. In Table 26 are shown the results from a cross between a race practically pure to the eight rowed type, No. 5, and a dent No. 6 , which varies from twelve to twenty rows with the mode at sixteen rows. The $F_{1}$ generation is intermediate and furnished four inbred ears that were grown in the $\mathrm{F}_{2}$ generation. Now three of these four $F_{2}$ families show no greater range of variation than $F_{1}$,

TABLE $2 S$.

INHERITANCE OF ROWS IN CROSS ( $11 \times 5)$.

\begin{tabular}{|c|c|c|c|c|c|c|c|c|c|c|c|}
\hline \multirow{2}{*}{ No. } & \multirow{2}{*}{ Gen. } & \multirow{2}{*}{$\begin{array}{c}\text { Rows } \\
\text { of } \\
\text { Parents }\end{array}$} & \multicolumn{9}{|c|}{ Row Classes } \\
\hline & & & 8 & 10 & 12 & 14 & 16 & 18 & 20 & 22 & 24 \\
\hline $\begin{array}{l}\text { No. } 11 \text { flint } \\
\text { No. } 5 \text { flint } \\
\text { No. } 11 \times 5 \\
(11 \times 5)-8 \\
(11 \times 5)-18\end{array}$ & $\begin{array}{l}\mathrm{P} \\
\mathrm{P} \\
\mathrm{F}_{1} \\
\mathrm{~F}_{2} \\
\mathrm{~F}_{2}\end{array}$ & $\begin{array}{r}12 \\
8 \\
12 \\
12 \\
10\end{array}$ & $\begin{array}{r}1 \\
289 \\
2 \\
10 \\
19\end{array}$ & $\begin{array}{r}4 \\
2 \\
11 \\
38 \\
33\end{array}$ & $\begin{array}{r}387 \\
2 \\
26 \\
107 \\
100\end{array}$ & $\begin{array}{r}2 \\
23 \\
5\end{array}$ & 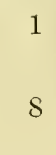 & & & & \\
\hline
\end{tabular}

yet it is a noticeable fact that they vary in different ways. Ear ( $5 \times 6)-1$ shows a modal condition at ten rows. It may be considered that the crossed seed from which the $F_{1}$ ear that produced this crop came, contained the genes for lower numbers of rows from the varying parent, No. 6 . Ear $(5 \times 6)-23$, on the other hand, evidently contains genes from No. 6 that were due to produce higher numbers of rows.

Table 27 shows a slightly higher variability in $\mathrm{F}_{2}$ than in $\mathrm{F}_{1}$.

Table 28 is interesting because it shows the results of a cross between two varieties that have been selected for many years until they are relatively true to the 12-rowed and 8-rowed 


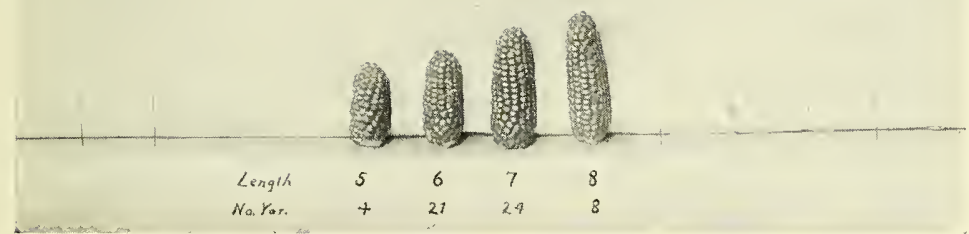

a. No. 6o, Tom Thumb maize, showing variation in length of ear. Class centers are even centimeters $\left({ }_{6}^{1}\right)$.

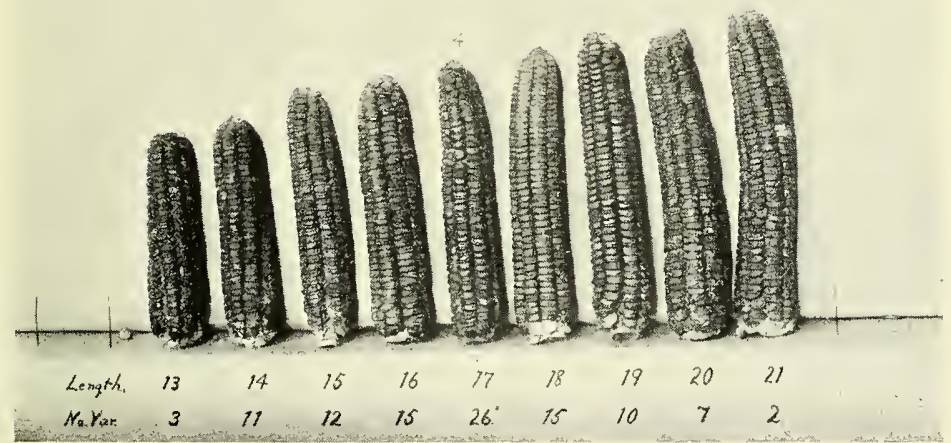

b. No. 54. Black Mexican sugar maize, showing variation in length of ear $\left(\begin{array}{l}1_{6 i} \\ f_{i}\end{array}\right)$. 



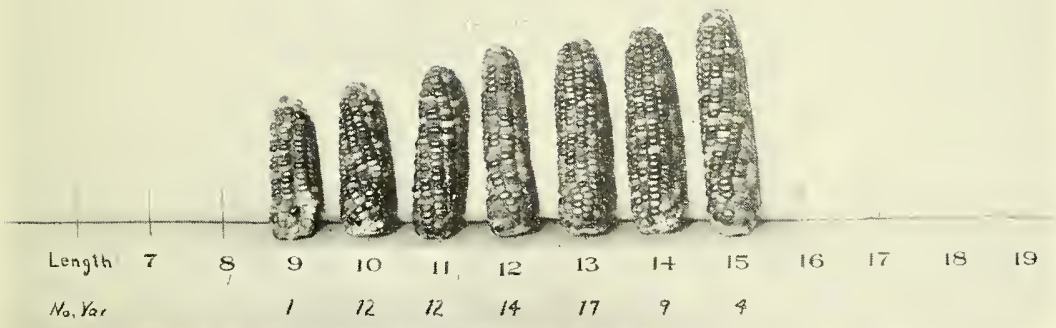

a. Variation in length of ear of FI, generation of cross between No. 60 and No. $54\left(\begin{array}{l}1 \\ 6\end{array}\right)$.

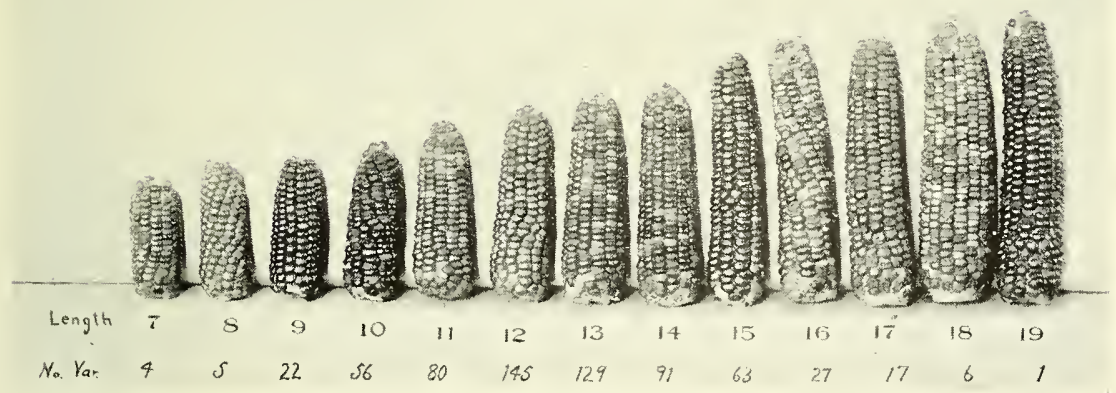

b. Variation in length of ear of F2 generation of cross between No. 60 and No. 54. Family $(60-5 \times 54)\left(\frac{1}{6}\right)$.

Inheritance of Length of Ears. 



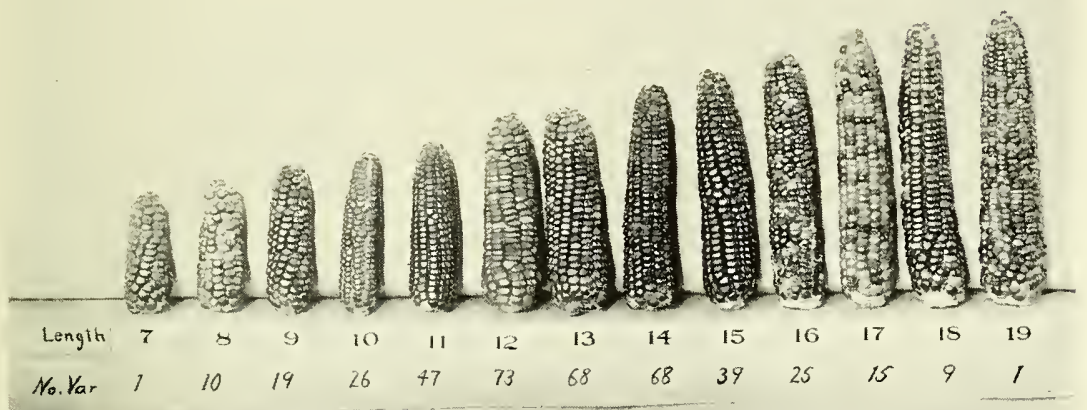

a. Variation in length of ear of $\mathrm{F}_{2}$ generation of cross between No. 60 and No. 54. Family $(60-3 \times 54)\left(\begin{array}{c}16 \\ 6\end{array}\right)$.

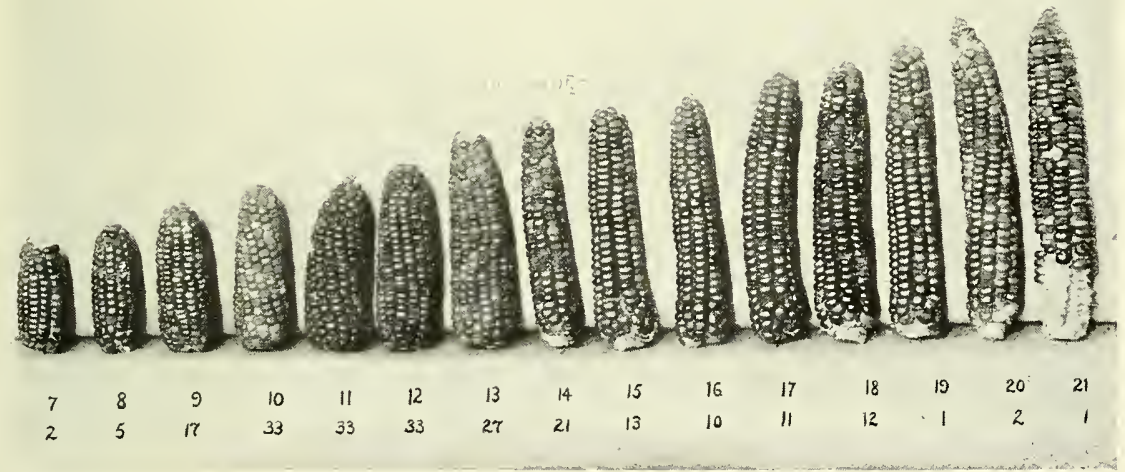

b. Variation in length of ear of $\mathrm{F}_{2}$ generation of cross between No. 60 and No. 54. Fanily $(60-8 \times 54)\left(\frac{1}{6}\right)$.

INHERITANCE OF LENGTH OF EARS. 



\section{की०CO \\ $P_{1}$ \\ की०तe?}

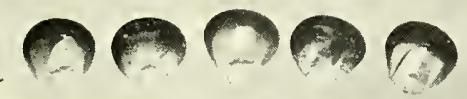

$\mathrm{F}_{2}$

asecos

Q

$F_{1}$

ADAm
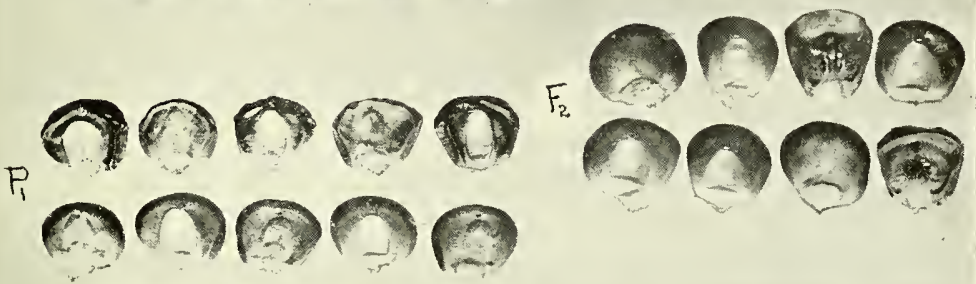

a. Average size of seeds of No.6o (upper left) and No. 5+ (lower left) and the Fi generation of the cross between them. Extremes of the $\mathrm{F}_{2}$ generation at right.

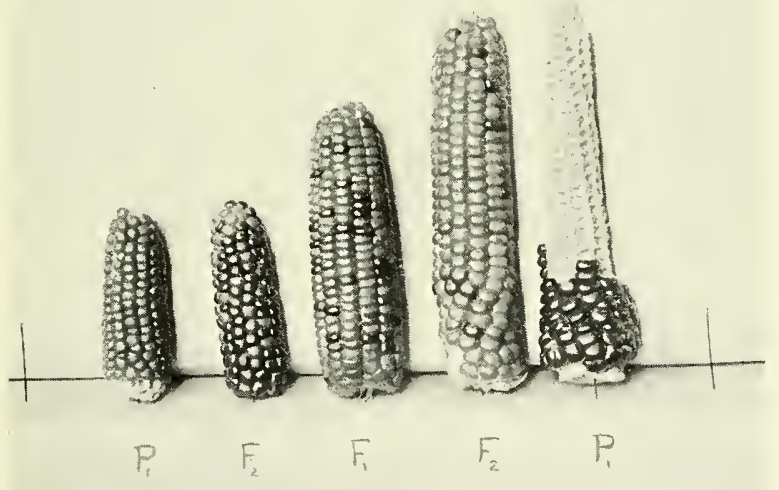

b. Average ears of No. 60 (left) and No. 58 (right) with average of Fi generation in center. Extremes of $F_{2}$ generation shown. 

TABLE 29.

INHERITANCE OF ROWS IN CROSS (11 x 18).

\begin{tabular}{|c|c|c|c|c|c|c|c|c|c|c|c|}
\hline \multirow{2}{*}{ No. } & \multirow{2}{*}{ Gen. } & \multirow{2}{*}{$\begin{array}{c}\text { Rows } \\
\text { of } \\
\text { Parents }\end{array}$} & \multicolumn{9}{|c|}{ Row Classes } \\
\hline & & & 8 & 10 & 12 & 14 & 16 & 18 & 20 & 22 & 24 \\
\hline No. 11 flint & $\mathrm{P}$ & 12 & 1 & 4 & 387 & 7 & 1 & & & & \\
\hline $\begin{array}{l}\text { No. } 18 \text { sugar } \\
\text { (2 yrs.) }\end{array}$ & $\mathrm{P}$ & 12 & 13 & 32 & 51 & 4 & & & & & \\
\hline No. $11 \times 18$ & $\mathrm{~F}_{1}$ & 12 & 2 & $\begin{array}{r}10 \\
9\end{array}$ & 24 & $\begin{array}{r}1 \\
10\end{array}$ & 1 & & & & \\
\hline $\begin{array}{l}(1 \times \times 18)-4 \\
(11 \times 18)-10\end{array}$ & $\begin{array}{l}\mathrm{F}_{2}^{2} \\
\mathrm{~F}_{2}\end{array}$ & $\begin{array}{l}12 \\
10\end{array}$ & $\begin{array}{l}1 \\
8\end{array}$ & $\begin{array}{r}9 \\
13\end{array}$ & 62 & $\begin{array}{l}10 \\
13\end{array}$ & & & & & \\
\hline
\end{tabular}

conditions, respectively. $\mathrm{F}_{2}$ shows a distinctly higher variability than $F_{1}$. It is expected that 8-rowed $F_{2}$ plants may breed relatively true.

Table 29 is given simply to show that a cross between two 12-rowed varieties does not show an extension of the row classes. Such a condition should sometimes be possible if our general hypothesis is true, yet it might not occur in more than one cross in hundreds.

Table 30 shows the results from a cross between another variety true to the eight rowed condition and a variety which varies from ten to eighteen rows with the modal condition at twelve. Unfortunately only a few plants matured in the $F_{1}$ generation and no conclusions can be drawn regarding its variability. The $\mathrm{F}_{2}$ generation apparently shows a marked segregation. The

TABLE 30.

INHERITANCE OF ROWS IN CROSS (15 X 8).

\begin{tabular}{|c|c|c|c|c|c|c|c|c|c|c|c|}
\hline \multirow{2}{*}{ No. } & \multirow{2}{*}{ Gen. } & \multirow{2}{*}{$\begin{array}{c}\text { Rows } \\
\text { of } \\
\text { Parents }\end{array}$} & \multicolumn{9}{|c|}{ Row Classes } \\
\hline & & & 8 & 10 & 12 & 14 & 16 & 18 & 20 & 22 & 24 \\
\hline $\begin{array}{l}\text { No. } 15 \text { flint } \\
\text { No. } 8 \text { dent } \\
\text { No. } 15 \times 18 \\
(15 \times 8)-2 \\
(15 \times 8)-3 \\
(15 \times 8)-2-10 \\
(15 \times 8)-2-1 \\
(15 \times 8)-2-5\end{array}$ & $\begin{array}{l}\mathrm{P} \\
\mathrm{P} \\
\mathrm{F}_{1} \\
\mathrm{~F}_{2} \\
\mathrm{~F}_{2} \\
\mathrm{~F}_{3} \\
\mathrm{~F}_{3} \\
\mathrm{~F}_{3}\end{array}$ & $\begin{array}{r}8 \\
14 \\
8 \\
10 \\
12 \\
14 \\
8 \\
12\end{array}$ & $\begin{array}{r}100 \\
\ldots \\
14 \\
4 \\
3 \dot{3} \\
4\end{array}$ & $\begin{array}{r}1 \\
3 \\
2 \\
15 \\
13 \\
1 \\
35 \\
41\end{array}$ & $\begin{array}{r}54 \\
5 \\
28 \\
25 \\
8 \\
23 \\
116\end{array}$ & $\begin{array}{r}36 \\
9 \\
6 \\
14 \\
4 \\
15\end{array}$ & $\begin{array}{r}12 \\
1 \\
3 \\
6 \\
3\end{array}$ & $\begin{array}{l}1 \\
1\end{array}$ & 1 & & \\
\hline
\end{tabular}


results in the $\mathrm{F}_{3}$ generation are the most interesting, however, for the progeny of an eight rowed $\mathrm{F}_{2}$ show a distinct tendency toward an 8-rowed condition, while progeny of $\mathrm{F}_{2}$ ears having twelve and fourteen rows respectively, though highly variable, show a transmission of their parental qualities.

Our largest pedigree series for number of rows is shown in Table 31. The male parent is the same as was used in the previous cross. The female parent is an eight-rowed type but is not so pure for this condition as the eight-rowed varieties previously used. The general crop in $\mathrm{F}_{1}$ was discarded before the

TABLE 31.

INHERITANCE OF ROWS IN CROSS ( $8 \times 54)$.

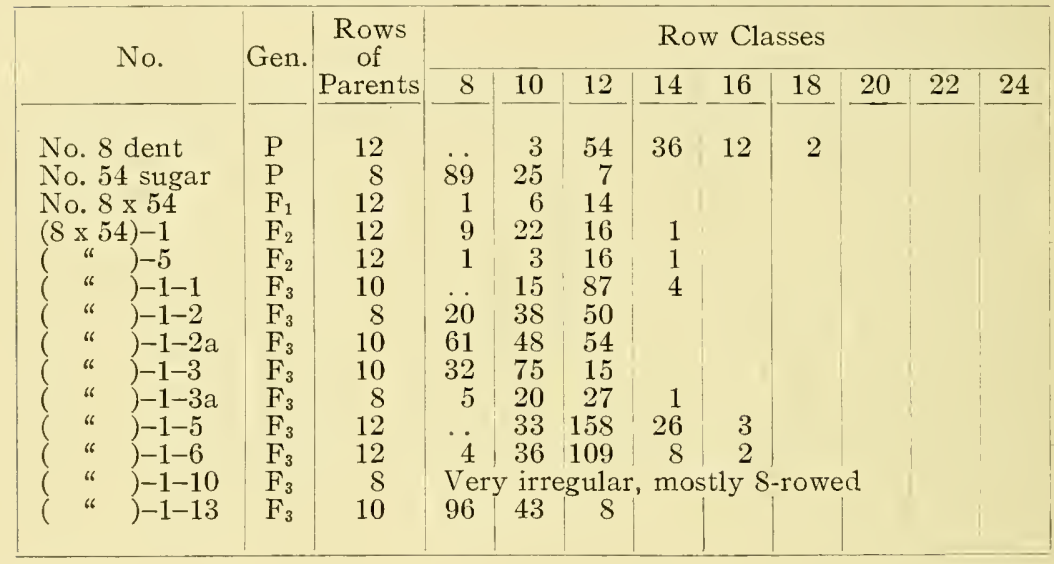

data was taken upon the number of rows. This oversight is partially rectified by the records from 21 hand-pollinated ears, but the true variability is presumably somewhat greater. Two $\mathrm{F}_{1}$ ears were grown in the $\mathrm{F}_{2}$ generation, one having the moda condition at ten rows and the other at twelve rows. Nine ears from the $F_{2}$ progeny from $(8 \times 54)-1$ produced $F_{3}$ crops. This table should be examined in order to appreciate the significance of the results of this generation. There is a marked tendency in different ears to segregate into twelve-row and eight-row types. Two of the ears have modal conditions at ten rows, 
but their variability is so great that the presumption is that this represents simply the continuance of the heterozygous condition. In our opinion there is no question about segregation of number of rows but we are perfectly aware that the believer in selection would be justified in the criticism that that is the cause of the results obtained.

Table 32 shows the frequency distribution of the heights of two varieties Nos. 5 and 6 , and the $F_{1}$ and $F_{2}$ generations of the resulting cross. A good idea of the possible segregation in the $\mathrm{F}_{2}$ generation of such crosses as this, is obtained by the comparative size of the coefficient of variation of the $F_{1}$ and the $F_{2}$ generations. In every case it is at least $50 \%$ higher in the $\mathrm{F}_{2}$ generation than in the $F_{1}$ generation. The $F_{1}$ generation is not intermediate between the two parents but is nearly as high as the taller parent. This fact is not to be regarded as in any way connected with dominance. It is due to the increased vigor which comes from crossing in maize as shown in a previous paper (East : 09). The total results of the $F_{2}$ generations show segregation from the lowest class range of the shorter parent to the highest class range of the taller parent. It must not be thought however that these segregates are regarded as pure types. Their behavior in further generations is still problematical. Continued selection of shorter or taller segregates presumably will give an approach toward the selected condition. The criticism that any such results would be due to selection and not segregation is not valid in this case, however, for segregates of extreme types that never appear in either of the parents alone have occurred here in the $\mathrm{F}_{2}$ generation.

Table 33 shows similar segregation in heights of plants in another cross, No. $(54 \times 60)$. The frequency distribution of the heights in No. 54 was obtained from plants grown during the season and on the same soil upon which the $\mathrm{F}_{2}$ generation was grown. The exact distribution of heights of No. 60 and of the $F_{1}$ ears was not taken because at that time another object was in view. The range of distribution as shown by the black lines, is correct. From notes recorded at the time we know that the $\mathrm{F}_{1}$ generation was quite uniform, the measurements being distributed around classes 67 to 73 . Here again the effect of crossing is observed in the relatively tall plants of this generation. The lowest plants in the $F_{2}$ generation reach 
the upper range of No. 60 while the highest plants are practically the height of the highest plants of No. 54. The reason that no plants were obtained in the lower range of No. 60 is due no doubt to their continued heterozygous condition in some of their characters and therefore an increased vigor.

Table 34 shows that the lengths of ears in the above cross segregate in a similar manner. The $F_{1}$ generation is not forced toward the long-eared parent as it is in the heights of the plants. In other words ear length does not show the increased vigor due to heterozygosis that is seen in the heights of plants. There can be scarcely a doubt that the greatly increased variability in $\mathrm{F}_{2}$ is the direct,result of segregation.

The segregations of weights of seeds in the above cross is shown in Table 35. The Black Mexican parent No. 54 shows somewhat distorted variation in this character as there are four classes of large sized seeds containing only six ears in all. No $F_{2}$ segregates occurred of this size. The reason is that the ears of No. 54 which produced this crop were commercial seed of which only three individuals were used in crossing. The $F_{1}$ generation in both Tables 34 and 35 were recorded from only one cross although three crosses were made. To be strictly fair, therefore, the $\mathrm{F}_{2}$ generation of cross No. $(60-5 \times 54)$ is the only one that can be directly compared with the $\mathrm{F}_{1}$ generation given. We have records, however, of a sufficient number of ears of the other two crosses to know that they differ but slightly if any from the one recorded in the tables. But even if we should be conservative and leave out of consideration the $F_{2}$ generations of crosses $(60-8 \times 54)$ and $(60-3 \times 54)$, there is still no question but that segregation has occurred. 


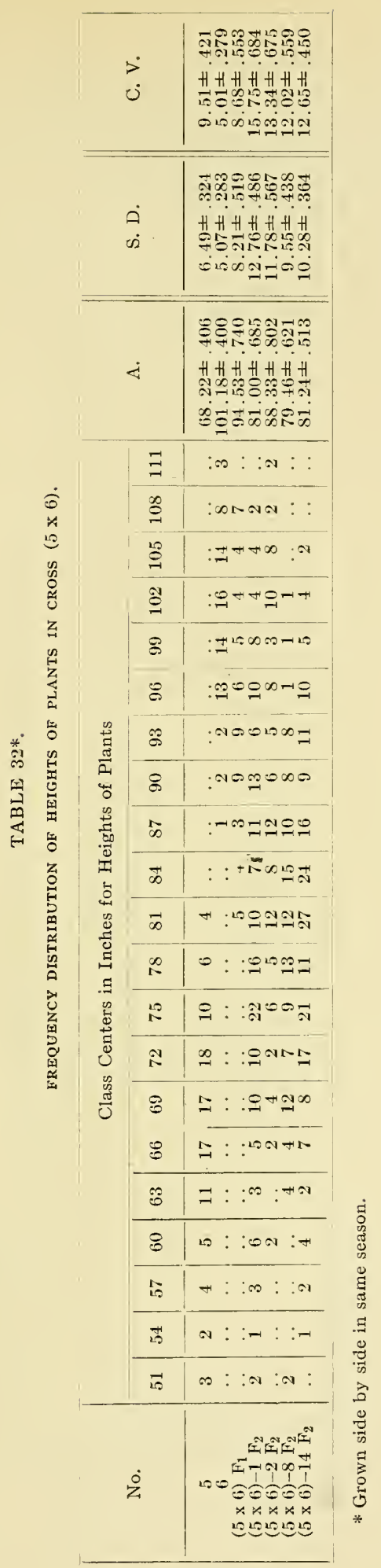




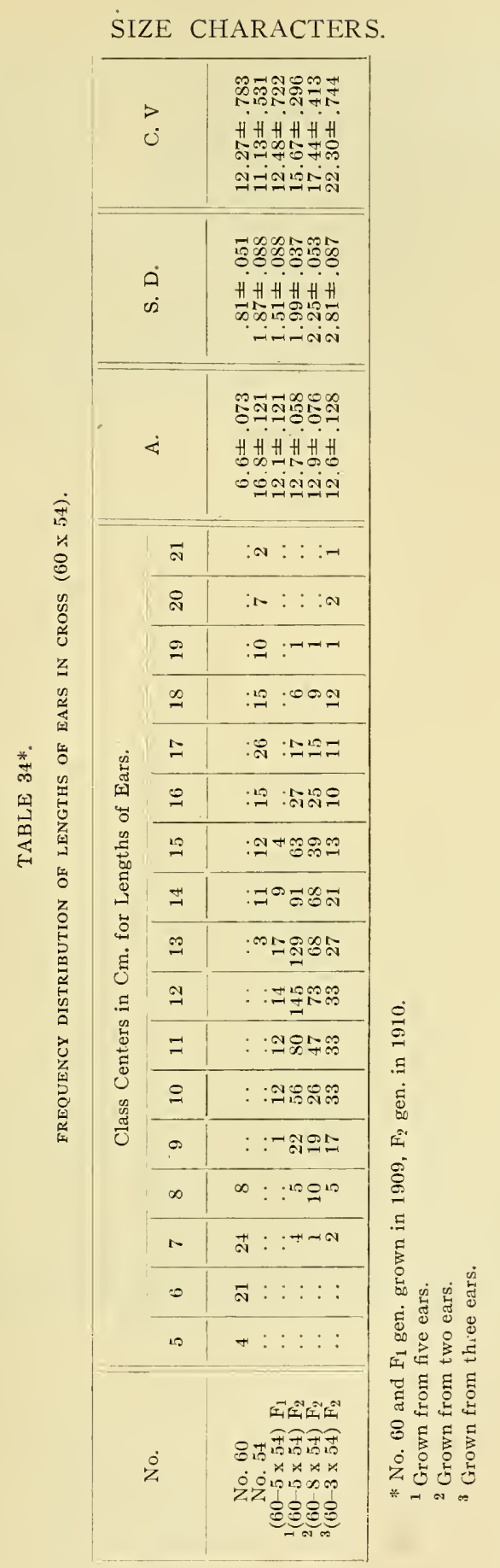




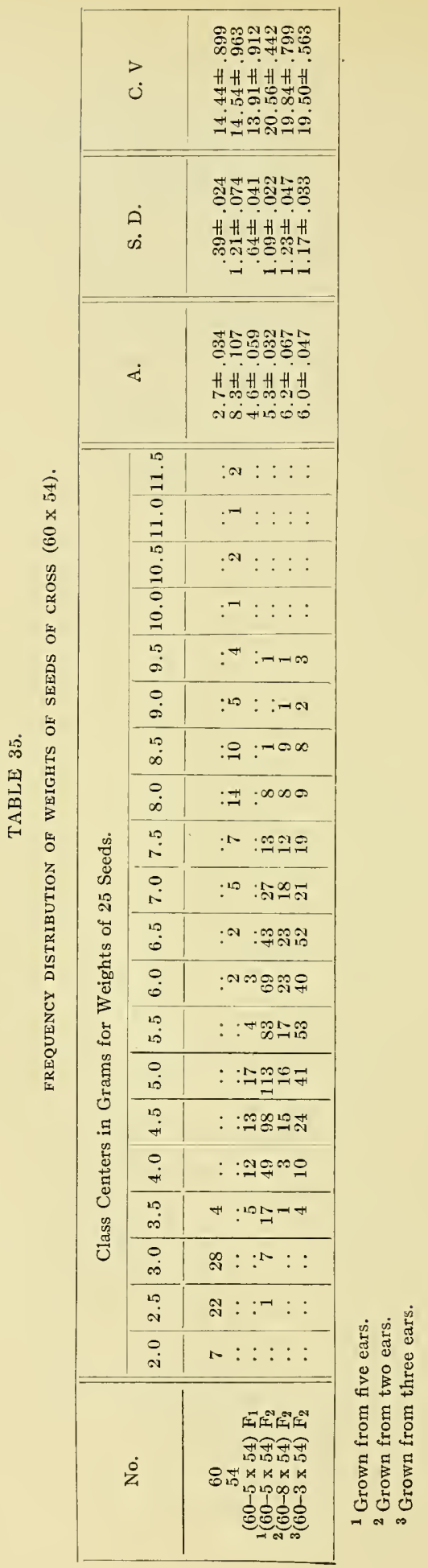




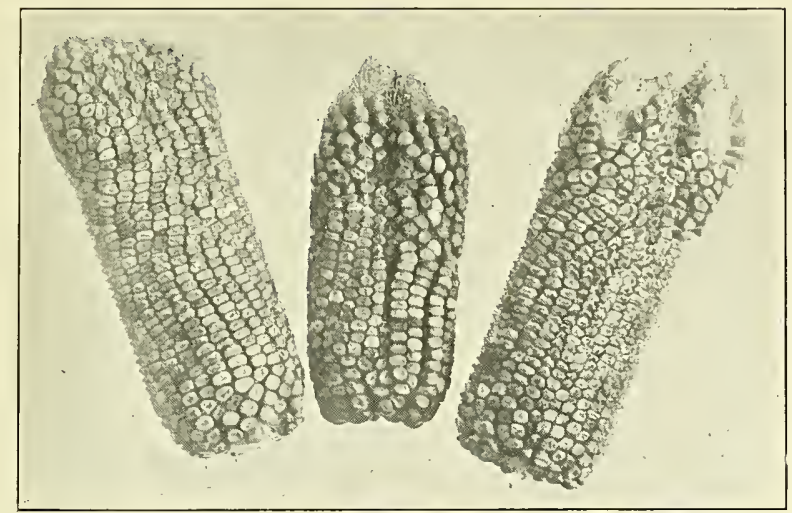

a. Fasciated ears. F2 generation of cross with normal showing dominants and heterozygotes.

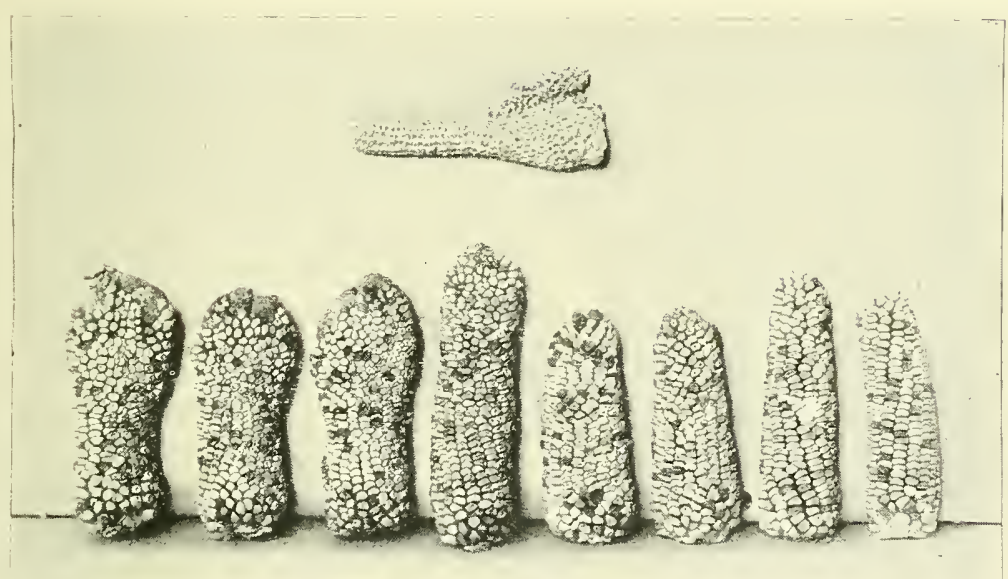

b. F2 cob of heterozygote above; sample of $\mathrm{F}_{3}$ progeny below. From left to right first six show the abnormality in different degrees. Last two ears are normal.

Inheritance of EAR Fasciations. 



\section{PART V. \\ PLANT ABNORMALITIES.}

A few abnormalities have appeared in the maize varieties under observation during the progress of these investigations. They have been studied with two objects in view. The first object was to see whether the manner of transmission of heritable monstrous characters gives any clue to the reason why monstrosities have seldom obtained a foothold in nature when in competition with normal types. The second object was commercial. If teratological specimens appear in commercial varieties of maize, it is desirable to know the easiest method to destroy them.

\section{Dwarf Forms.}

The first dwarf form appeared in the 1908 culture of No. 6 Leaming dent. This strain had been selfed for the two previous years without producing dwarfs. In the third generation, however, in a culture of 100 plants 5 dwarfs appeared. The plants were normal in appearance, having all parts correlated as in the full sized plants, as is shown in Plate XXV. They were from two to three feet in height and contrasted strangely with the other plants of the variety which were from nine to eleven feet in height. The female flowers seemed to be normal. At least cobs were formed and silks appeared. The pollen however was completely sterile. The dwarf plants were pollinated first with their own pollen and when no seeds formed were pollinated with pollen from normal-sized plants. A few seeds formed on two ears, which were planted the next season. From one ear which had been borne on a plant eighteen inches high only two plants resulted, one being a dwarf and the other of normal height. From the other ear which came from a plant three feet six inches high, seventeen individuals resulted, one of which was a dwarf. The dwarfs, as in the former year, had a normal correlation of parts. The leaves were opposite and the ear appeared in the axil of the sixth leaf from the top as in the 
normal plants. The pollen appeared to contain some normal grains this year and both of the plants were selfed. No seed set, however, and when pollinated with pollen from normal plants it was found that the silks had passed the receptive stage. This delay lost the strain. Seeds from the old ear of No. 6 had again been planted and had given two dwarfs out of sixty plants, but these had been lost in the same manner.

No. 69-5 a flint with a mosaic red pericarp also gave similar dwarfs with a ratio of 48 normal to 14 dwarf plants. The ear from which they came was a selfed ear from a commercial strain obtained the year before. The commercial strain had given no dwarfs but as only about 100 plants had been grown it is uncertain whether or not they had ever appeared before.

A different kind of dwarf plant appeared in a commercial strain of Stowell's Evergreen sugar corn in 1908. It was very short (18 inches) and had short leaves of the normal breadth. The joints were very close together and the whole appearance of the plant suggested a normal plant that had been pushed together like a telescope. An attempt to self this plant failed, but four days afterward it was pollinated with pollen from a normal strain of Stowell's Evergreen. A fairly good ear resulted which was planted in 1909. One dwarf like the maternal parent appeared out of thirty-seven plants. It was completely sterile, but a selfed normal plant from the same lot gave two dwarfs out of seventy-six plants in 1910. (See Plate XXIV.)

It is a matter of conjecture what occurred in these cases. In the first instance, at least, controlled cultures that had produced no dwarf plants, suddenly threw dwarfs. It was a much more definite occurrence than De Vries' Oenothera mutations for these were mutating when De Vries found them. If the normal type were completely dominant, one must conclude that one seed had been selfed in the case where the dwarf was pollinated with pollen from normal Stowell's Evergreen. In the other two cases the cross-pollination was made with pollen from plants of the same strain, and as only a small number of individuals were produced in the next generation, production of dwarfs was probably continued through the pollen gametes.

The variation was transmitted by plants normal in character, and whether one believes it to be a case of Mendelian dominance of normals or not, there was nevertheless definite segregation. 
The fact that segregates appeared in ratios of less than one abnormal to three normal, may have been due to any one of several causes. Abnormal zygotes may have been formed and not have been able to develop, for the germinating power of the seeds formed on the dwarf plants was very low. On the other hand, it may be that this result was due to the same fact that probably gives rise to higher ratios in crosses that have been studied thoroughly; namely, more than one chromosome possesses the necessary material for normal height. There is also the possibility that many abnormalities, particularly those which show great latitude in their development, are due not to regular Mendelian segregation, but to some abnormal chromosome reduction. If some reductions took place normally and some abnormally through some disturbance of the plant's normal physiology, abnormal and normal plants might be produced without definite and constant ratios.

\section{Regularity of Rows of Seeds on Cob.}

The great majority of maize ears have rows of seeds running in straight regular rows from butt to tip. Sometimes two rows or even four rows may be dropped in going from the butt to the tip but even then a sufficient amount of regularity exists to call them straight-rowed ears. A varying percentage of ears in each variety, however, have the rows quite irregular, - the seeds often being squeezed together in such a hit and miss manner that the number of rows can only be counted by making cross sections of the cob. Experience with maize cultures shows that there are two distinct kinds of irregularity, one a physiological fluctuation which is not inherited, and one a definitely inherited character or possibly a set of characters. The non-inherited fluctuations are always present while the inherited irregularity may be present or absent. The latter kind has been isolated in several varieties, the most conspicuous being the Country Gentleman sugar corn.

Since the inherited irregularity can only be distinguished from the fluctuation by breeding and then with difficulty owing to the obscuring effect of the latter, it is difficult to come to any conclusion regarding the method of its transmission when dealing with mixed strains. It could undoubtedly be determined by 
careful work with a cross of which Country Gentleman formed one of the parents. We have not made such a cross, but observations of large commercial cultures of Country Gentleman lead us to believe that irregularity is a Mendelian dominant, although it may not act as a simple mono-hybrid.

Ears with irregular rows appearing in our cultures have been planted several times, but have proved to have been due to physiological fluctuation in all but one instance. An ear of strain 29-2 produced some ears with irregular rows, one of which happened to have been inbred. This ear gave 33 normal progeny and 12 with irregular rows in the next generation. One of these irregular ears gave 33 normal and 15 irregular ears in a further generation, while one of the regular rowed ears gave 125 normal and 5 irregular ears. One of these 5 irregular ears was selfed and will be tested next year. This is about the percentage of irregular ears that the variety gives in the commercial field, however, so the idea suggests itself, that these five ears were fluctuations. If we regard this as the true interpretation of the regular ears giving irregular ears, and reduce the number of irregularities in the progeny of the irregular ears in the same proportion, a ratio of 66 normal to 23 irregular ears is obtained. This looks like a case of monohybridism with reversed dominance. It is suggested, however, if this is a case of twice planting a heterozygous mono-hybrid; that it is an example of fluctuating dominance in which some apparently normal ears are really heterozygotes. One cannot even say that only homozygotes show dominance, for it was an irregular ear in each case that threw normals. There is no a priori reason why this hypothesis should not be true, but it seems probable that a more complex set of conditions exists. The one fact that stands out clearly is that if the percentage of irregular ears increases much over four percent in a commercial progeny row culture, the whole culture must be discarded to eliminate the undesirable "blood."

\section{Bifurcated Ears.}

Occasionally there is found among the eight rowed flint corns ears which have only four rows. Their cobs are grooved so that they appear to be almost splitting. One of these individuals 
appeared in a culture of No. 17 (Palmer's Red-nosed yellow) that had been selfed for three generations. It was grown with the special object of finding out whether the four rowed condition is a final recessive condition as to number of rows. This proved not to be the case. The condition is a secondary effect of a heritable abnormality which causes the cob to show various conditions of splitting into two rowed sections at the base. The variations in this feature are shown in Plate XXIII, fig. a. From this ear, 34 ears abnormal in varying degrees and 12 normal ears were obtained. This ratio suggests the progeny of an ear heterozygous for presence and absence of the abnormality. It will be tested further.

A bifurcation of a different kind appeared in the progeny of No. 7 Leaming dent that had been selfed for four years. In its extreme form the tip of the growing ear becomes monstrously fasciate; but it may vary toward the normal to such a degree that the abnormality is shown only as a slight flattening of the ear when observed in cross-section. The ear in which this abnormality appeared was only slightly flattened; its progeny, however, showed 11 with divided tip and about 20 flattened ears out of 44 . (See Plate X XII.)

The normal-eared grand parent of No. 7 had been crossed with No. 19 , and from an extracted starchy ear of the $F_{2}$ generation there resulted the same abnormality. This ear, No. $(19 \times 7)-5-7$ had a divided fasciate tip. It produced 29 ears with divided tip, 33 ears abnormally flattened and 23 normal ears, - a ratio of 62: 23. The illustration of this sort of fasciation shown in Plate XXII, fig. b, gives an idea of how gradually the abnormal ears intergrade with the normal ears. Yet this is a dominant character alternatively inherited. It is difficult to tell the pure normal ears by inspection but they appear to breed true when isolated.

\section{Ears with Lateral Branches.}

An illustration of an ear with lateral branches which is probably nearer the ancestral type of maize appeared in the original culture of No. 17. It is figured in Plate X XIII, fig. b. The ear was not hand pollinated and of course no conclusion can be drawn from the ratio in which the abnormality appeared in 
the next generation. As a matter of fact 4 ears out of 25 progeny were so affected. One of these happened to have been selfed, but it produced only a few seeds. Ten plants resulted from this poor individual, two of which were abnormal.

The only valid conclusion from these data is that the character does segregate. Normals and abnormals are produced; which fact suggests - as stated earlier in the paper - that the loss of the lateral branching character of maize occurred as a retrogressive mutation.

\section{Plants with Striped Leaves.}

Zea mays japonica is a race which produces leaves with longitudinal stripes with and without chlorophyll formation. In other words, the leaves are green with white stripes. Several races of this kind exist where the striping is apparently homozygous and the race breeds true. What experience we have had with striped races has been with another type of striping. The phenomenon has appeared several times in our cultures, and is clearly the same thing that Baur (:09) obtained in pelargoniums. The full green type is dominant, the striped type is heterozygous, while the homozygous recessives are sometimes formed but cannot live because they lack assimilating organs. Crosses between the striped plants and normal green plants always gave all green progeny. Planting, in two cases, from plants that were striped when very young, 274 normal and 27 striped plants were obtained. This result might seem to indicate a more complex condition than Baur obtained. It is not necessarily so, however, for the plants were first examined for striping when about 18 inches high. This may have been too late to give them the proper classification, since it was found that many of the 27 striped plants became greener as they aged. Several plants without chlorophyll died when only a few inches high. These were probably homozygous recessives.

\section{Hermaphrodite Flowers.}

Perhaps it should be mentioned in passing that the immature sex organs, so called, of maize seem endowed with the power of becoming either stamens or carpels. One often finds a normal 
ear ending in stamens, and nearly every plant produces lateral branches which have carpels and stamens mixed together indiscriminately.

A number of cases have also been observed where a few of the ovules of an ear were surrounded by three stamens as in a perfect flower. The only instance we have seen where all of the ovules had three stamens within the glumes of the flower that is usually aborted, was that of the dwarfs with wide leaves mentioned under the heading "Dwarf forms." It might be supposed that this was an atavistic type representing some of the characters, at least, of the ancestral maize. We should prefer to believe, however, that this development of stamens is merely an accompaniment of the dwarfing due to an endeavor to retain physiologic balance. That is, this type is really a healthy luxuriant form producing very large ears for such a small plant. There may have been developmental energy present which when unable through inner limitations to produce a tall plant, manifested itself in producing stamens.

Considered together, these various abnormalities present several interesting features. It would be rash to make any dogmatic statements in regard to their inheritance, yet it is fair to say that if dominance shows progressive - and recessiveness retrogressive - variations, both types are present. Some of them are evidently simple in character - as far as inheritance goes - while others are complex. It may be that the same apparent type of variation will be found to be simple in some races and complex in others. By this it is meant that both $3: 1$ and higher ratios will be found affecting characters which to the eye are the same.

It does not seem probable that abnormal and degenerate types are always or even commonly extracted recessives in which absence of characters is concerned, as Davenport (:08) has suggested. This statement has little basis from the data presented here, but the senior author has worked out certain dominant abnormal types in the genus Nicotiana which adds to our experience. The presumption is that they are more often dominant like most of the abnormalities found in man.

Perhaps the fact of prime importance from these data is the variable dominance of characters and their obscuration by physiological fluctuation. As stated once before, this shows 
the extreme importance of pedigree cultures to the commercial breeder, for some of these complex abnormalities cannot be distinguished from normal plants by gross inspection. It is possible that histological study might show points of difference but these methods are not at the command of the commercial grower.

It will be noticed that several monstrous variations occurred in strains that had been selfed for several generations. The effects of inbreeding in maize will form the subject matter of another paper, but it might be well to suggest here a possible cause for their production. Inbreeding in maize gives the same effect as lack of nutrients, while cross-breeding gives the opposite effect. There is retardation or acceleration of cell division, respectively. Now such monstrosities as ears with divided tips, occur more frequently either in cross-bred plants that are over supplied with fertility, or in inbred plants. Perhaps the first case represents fluctuation only, and is uninherited; as to this point we have no data. But disregarding this possibility, might not abnormal distribution of chromatin produce these variations in both cases. The first kind could be caused by abnormally accelerated division and the second kind by abnormally retarded division.

\section{General Conclusions.}

The various points of genetic theory discussed in this paper are not sufficiently connected to make possible a short and at the same time intelligible recapitulation. We simply desire to mention our conclusions regarding the central problem of all genetic investigations, that of laws of heredity.

When Mendel's Law of Heredity was rediscovered in 1900, it was the general belief that it covered only a few isolated cases. Many apparent exceptions were cited. One by one, however, these exceptions have been found to yield to interpretation by simple extensions of the Mendelian notation when fully understood. In our experience as reported here, no exceptions to Mendelian interpretation have been found. Such exceptions may exist, yet it seems as unwise to say that Mendel's Law is not general as to conclude at once that it can be made to cover every possible case. One may say that Mendel's Law has 


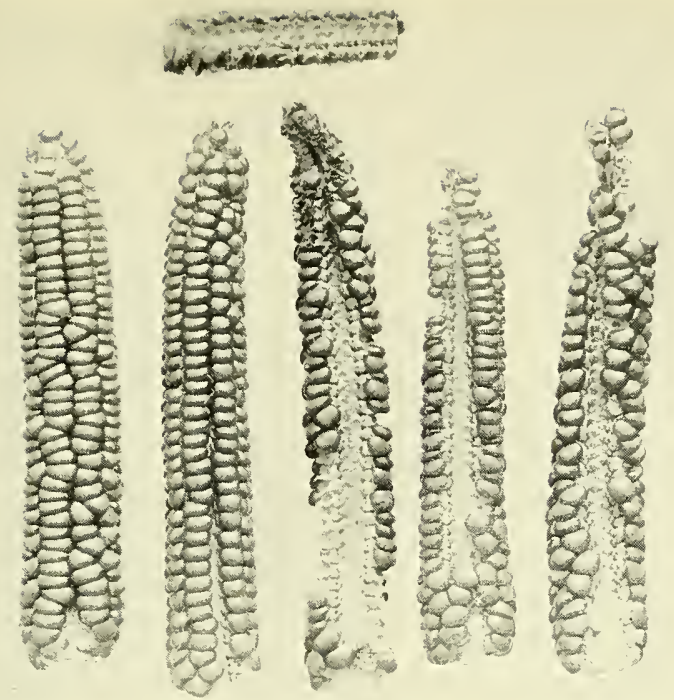

a. Heterozygous bifurcated cob above: dominant and heterozygous progeny below showing imperfect dominance.

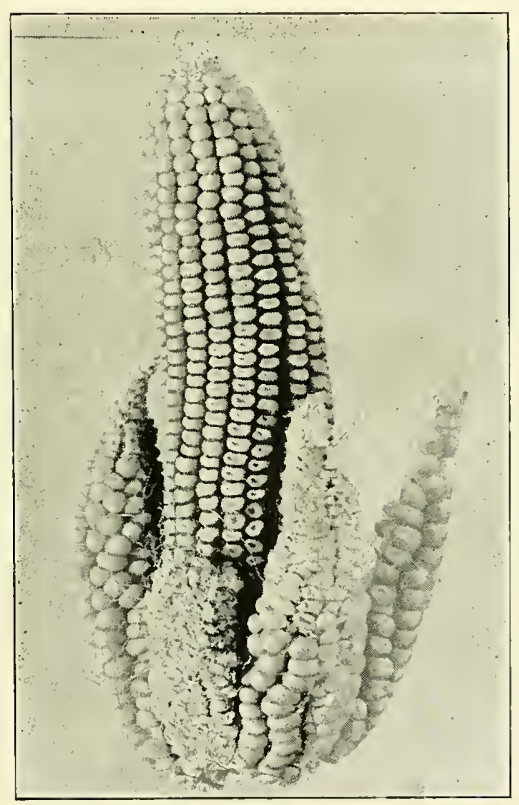

b. Multiple ear. An imperfectly dominant character. Aboriginal maize probably possessed a similar character.

AbNormaltiés. 



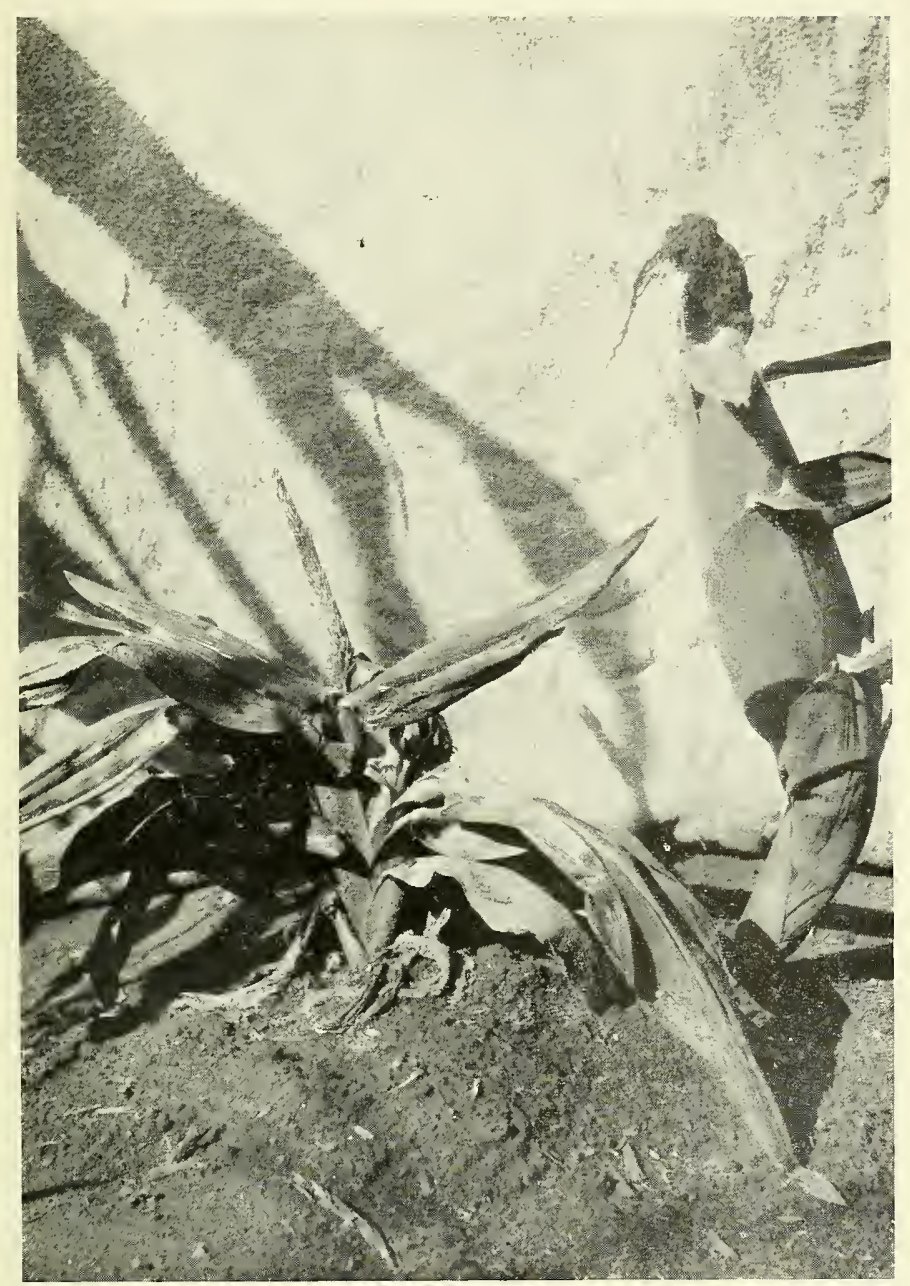

A plant of the dwarf mutation appearing in Stowell's evergreen sugar majze compared with a normal ear of the latter.

DWARF Forms. 



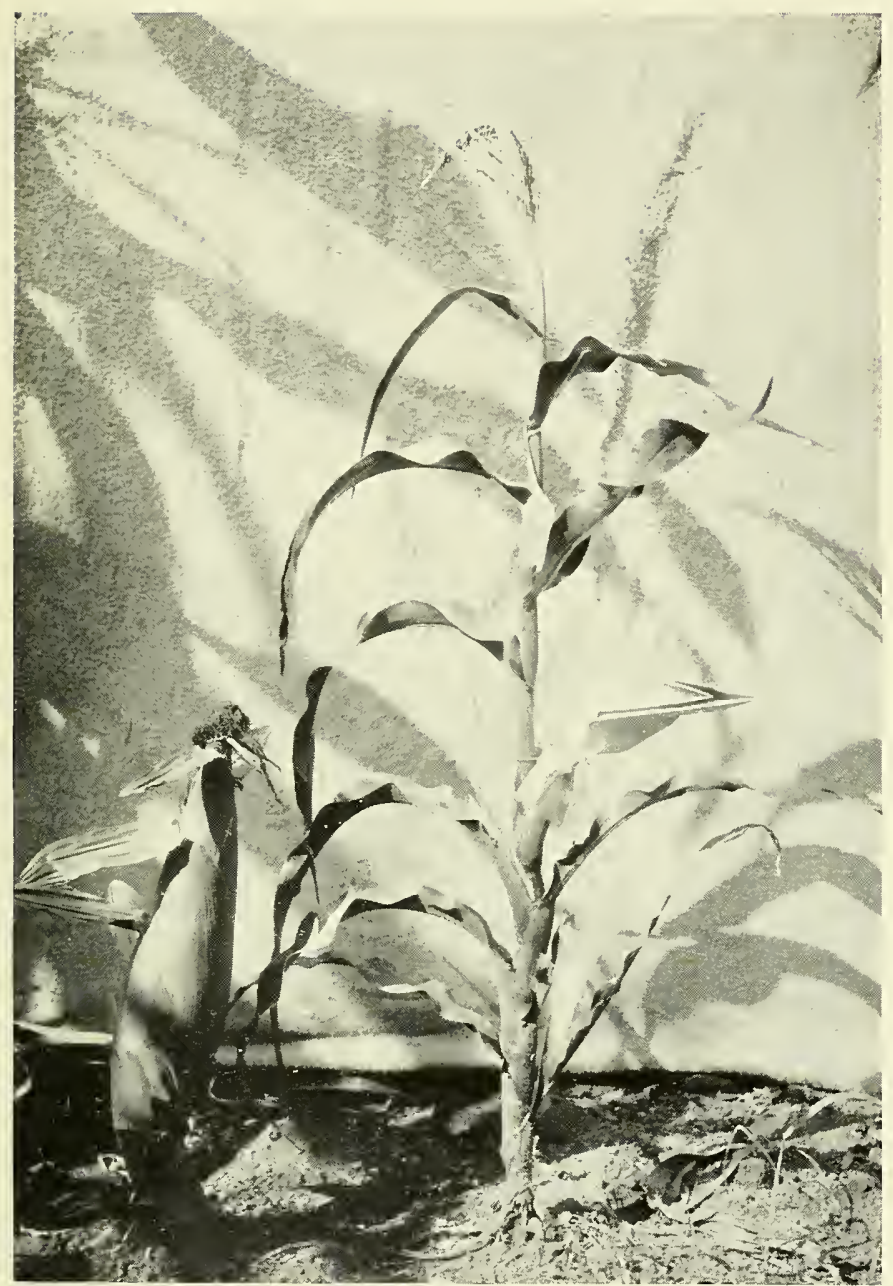

A dwarf type which appeared in Leaming dent maize compared with a normal ear of that variety.

DWARF FORMS. 

covered so many cases that its generality is rendered highly probable, although insufficient genetic investigation has been accomplished to place it on equal terms with any of the great laws of physics and chemistry. Yet some of the great laws of chemistry were accepted when surrounded by seeming exceptions. Some of these exceptions have been cleared up by such recent advances as the Ionic Theory and the Phase Rule; some still remain.

Is it not probable that other like generalities will be found in biology, which, although they may entirely change our general conception of the fundamental action of Mendêl's Laws, will nevertheless leave the facts upon which it was based as useful and practicable as have been left the facts of chemical recombination in definite and multiple proportions in the light of the Electron Theory? 


\section{LITERATURE CITED.}

Bateson, W. and Punnett, R. C.

:08 Reports to the Evolution Committee $4: 1-60$.

Bateson, W.

:09 Mendel's Principles of Heredity. Cambridge University Press. pp. 1-396.

BAUR, E.

:09 Das Wesen und die Erblichkeitsverhältnisse der "Varietates Albomarginatae Hort." von Pelargonium Zonale. Zeitschrift für induktive Abstammungsund Vererbungslehre $1: 330-351$.

Correns, C.

'99 Untersuchungen über die Xenien bei Zea Mays. Ber. d. Deutsch. Bot. Ges. 17 : 410-417.

:00 G. Mendel's Regel über das Verhalten der Nachkommenschaft der Rassenbastarde. Ber. d. Deutsch. Bot. Ges. $18: 158$.

:01 Bastarde zwischen Maisrassen mit besonderer Berücksichtigung der Xenien. Bibliotheca Botanica. $53: 1-161$.

:02 Scheinbare Ausnahmen von der Mendels'schen Spaltungsregel fur Bastarde. Ber. Deutsch. Bot. Ges. 20 : 159.

\section{COURCHET.}

'88 Recherches sur les chromoleucites. Ann. Sci. Nat. Bot. Ser. $8 . \quad 7: 263$. 
Davenport, C. B.

:08 Degeneration, albinism and inbreeding. Science N. S. $28: 454,455$.

:09 Inheritance of characteristics in domestic fowl. Carnegie Institution of Washington Publication $121: 1-100$.

: 10 Imperfections of dominance and some of its consequences. Amer. Nat. $44: 129-135$.

De Vries, H.

'99 Sur la fécondation hybride de l'albumen. Comptes rend. 1'Acad. Sci. 129 : 973-975.

:00 Das Spaltungsgesetz der Bastarde. (Vorläufige Mittheilung.) Ber. Deutsch. Bot. Ges. $18: 83$.

Dudley, P.

1724 An observation on Indian corn. Philosophical Transactions $6: 204-205$.

EAst, E. M.

:09 A note concerning inheritance in sweet corn. Science, N. S. $29: 465-467$.

:10 A Mendelian interpretation of variation that is apparently continuous. Amer. Nat. $44: 65-82$.

Focke. W. O.

'81 Die Pflanzenmischlinge. Borntraeger. Berlin. pp. 569.

GäRtNer, C. F.

'49 Versuche und Beobachtungen über die Bastarderzeugung im Pflanzenreich. Hering, Stuttgart. pp. 791 .

GuIgnaRd, L.

99 Sur les anthérozoides et la double copulation sexuelle chez les végétaux angiospermes. Rev. génér. d. Bot. 11 : 129-135. Also Comptes rend. l'Acad. Sci. 128 : 869. 
HARShberger, J. W.

'93 Maize : a botanical and economic study. Con. Bot. Lab. Uni. Pennsylvania 1 : 75-202.

'96 Fertile crosses of Teosinthe and Maize. Garden and Forest. $9: 522-523$.

Hildebrand, F.

'67 Unmittelbarer Einfluss der Pflanzenbastardirung auf die durch dieselbe erzeugte Frucht. Verh. des naturh. Ver. d. Rheinl. u. Westf. 24 : 101 et seq.

'68 Einige Experimente und Beobachtungen über . . . .

(2) den directen Einfluss des fremden Pollens auf die Beschaffenheit der durch ihn erzeugten Frucht. Botan. Zeitg. $26: 325$ et seq.

Johannsen, W.

:09 Elemente der exakten Erblichkeitslehre. Jena. Fischer pp. 1-515.

Kellerman, W. A. and Swingle, W. T.

'89 Experiments in cross-fertilization of corn. Ann. Rep. Kan. Exp. Station $1: 316-337$.

'90 Experiments in crossing varieties of corn. Ann. Rep. Kan. Exp. Station 2 : 288-334.

90a Crossed corn the second year. Ann. Rep. Kan. Exp. Station $2: 334-346$.

90b Bibliography of cross-fertilization of varieties of corn. Ann. Rep. Kan. Exp. Station $2: 346-353$.

'90c Preliminary study of the receptivity of corn silk. Ann. Rep. Kan. Exp. Station 2 : 353-355.

'91 Crossed varieties of corn the third year. Kan. Exp. Sta. Bull. 27 : 139-158.

LAMSON-SCRIBNER, E.

:00 American Grasses - III. U. S. Dept. Agr., Div. Agrostology Bull. 20 : 10-12. 
Lock, R. H.

:06 Studies in plant breeding in the tropics. III Annals of the Royal Botanic Gardens, Peradeniya. $3: 95-184$.

Mc Cluer, G. W.

'92 Corn crossing. Ill. Agr. Exp. Sta. Bull. 21 : 82-101.

Montgonery, E. G.

:06 What is an ear of corn? Pop. Sci. Mon. $68: 55-62$.

Morgan, T. H.

:10 The chromosomes in heredity. Amer. Nat. $44: 449$ 496.

Morrow, G. E. and Gardner, F. D.

'92 Field experiments with corn. I1l. Agr. Exp. Sta. Bull. 25 : 173-203.

NaUdin, Ch.

'63 Nouvelles recherches sur 1'hybridité dans les végétaux. Nouvelles Archives du Muséum. Tome 1.

NaWAschin, S.

'99 Resultate einer Revision des Befruchtungsvorgangs bei Lilium Martagon und Fritillaria tenelle. Bull. d. l'Acad. Imp. d. Sciences de St. Petersbourg, 9 : Nr. 4.

NiLlson-EHLE, H.

: 09 Kreuzungsuntersuchungen an Hafer und Weizen. Lunds Universitets Årsskrift, N. F. Afd. 2., Bd. 5, Nr. 2. 1-122.

Puvis, A.

'37 De la dégénération et de l'extinction des variétés de végétaux propagés par les greffes, boutures, tubercules, etc., et de la création des variétés nouvelles par les croisemens et les semis. Paris. 
SARGERET, E.

'26 Considérations sur la production des hybrides, des variantes et des variétés en général, et sur celles de la famille des Cucurbitacées en particulier. Ann. d. Sci. Nat. T. 8.

Sturtevant, E. L.

'99 Varieties of corn. U. S. Dept. Agr., Office Exp. Sta. Bull. 57 : 7-103.

DE Vilmorin, Henri.

'67 Sur la fecondation du Maïs. Bull. Soc. Botan. de France. Tome $14: 246$.

WATSON, S.

'91 Proc. Amer. Acad. Arts and Sci. 26 : 158.

WEBber, H. J.

:00 Xenia, or the immediate effect of pollen in Maize. U. S. Dept. Agr. Division of Vegetable Physiology and Pathology. Bull. $22: 1-44$.

Wheldale, M.

:09 The colors and pigments of flowers, with special reference to genetics. Proceedings Royal Society, B. $81: 44-60$.

:09 On the nature of anthocyan. Proceedings Cambridge Philosophical Society 15 : Pt. 2, 137-168.

: 10 Plant oxydases and the chemical inter-relationships of color-varieties. Progressus Rei Botanicae 3 : 457-494.

WINKLER, H.

:09 Uber die Nachkommenschaft der Solanum-Propfbastarde und die Chromosomenzahlen ihrer Keimzellen. Zeitschr. f. Botanik $2: 1-38$. 

538874 


\section{.}





\section{University of}

Connecticut

Libraries

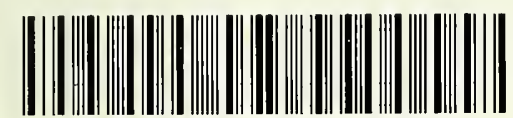

39153029221100 
